\title{
NF-KB mediated signaling mechanisms in epidermal homeostasis and carcinogenesis
}

\section{Doctoral Thesis}

In partial fulfillment of the requirements for the degree

"Doctor rerum naturalium (Dr. rer. nat.)"

in the Molecular Medicine Study Program

at the Georg August University Göttingen

\author{
submitted by \\ Verena Lorenz
}

born in Bremen, Germany

Göttingen, 2013 


\section{Members of the Thesis Committee:}

\section{Supervisor}

Univ. Prof. Dr. med. Michael P. Schön

Department of Dermatology, Venereology and Allergology

\section{Second member of the Thesis Committee}

Prof. Dr. Matthias Dobbelstein

Department of Molecular Oncology

Third member of the Thesis Committee

Prof. Dr. Heidi Hahn

Department of Human Genetics 
AFFIDAVIT

Here, I declare that my doctoral thesis entitled "NF-KB mediated signaling mechanisms in epidermal homeostasis and carcinogenesis" has been written independently with no other sources and aids than quoted.

Göttingen, April 2013

(Verena Lorenz) 


\section{Content}

I.

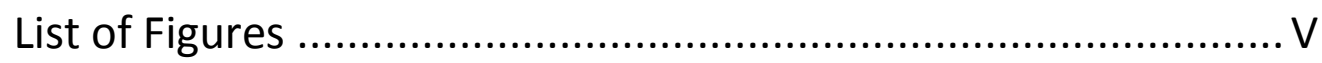

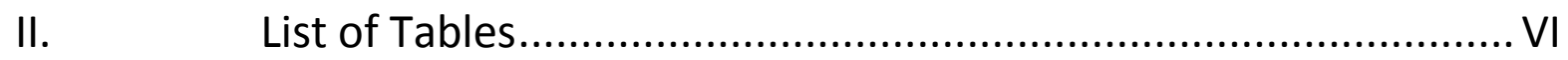

III. Abbreviations ....................................................................

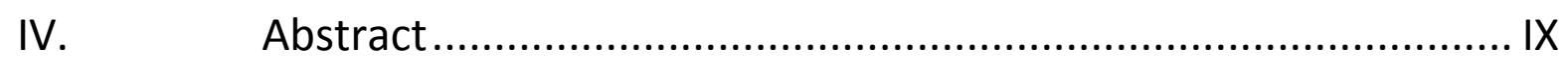

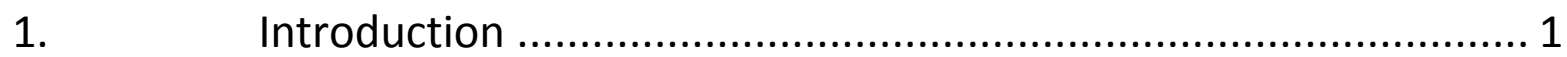

1.1 The human epidermis and terminal differentiation...................................... 1

$1.2 \quad$ Epidermal homeostasis and epidermal neoplasms........................................

$1.3 \quad$ The transcription factor NF-KB ........................................................ 4

1.3.1 Structure of the five NF-KB subunits........................................................

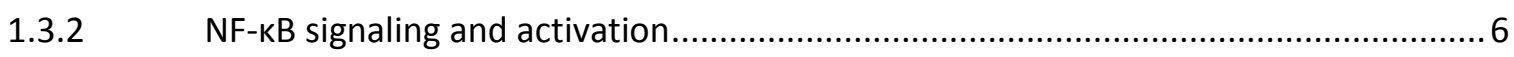

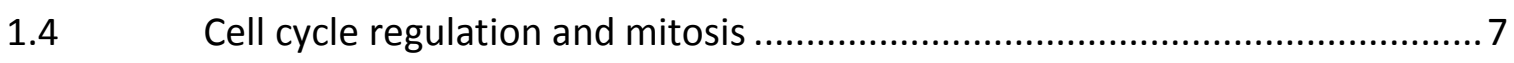

1.5 Molecular mechanisms of cellular migration and adhesion ....................... 11

1.6 NF-KB in epidermal homeostasis and SCC development ......................... 12

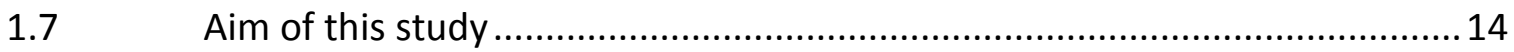

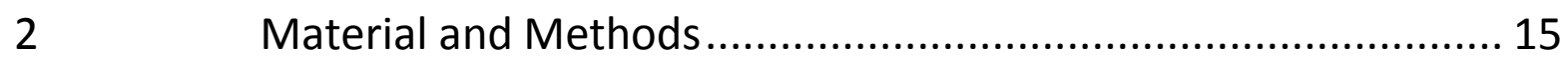

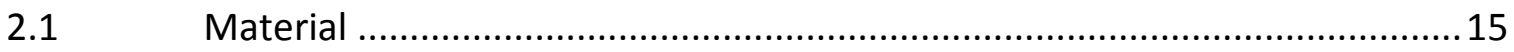

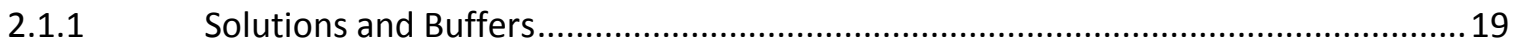

Cell Culture Reagents and Growth Media ....................................................... 22

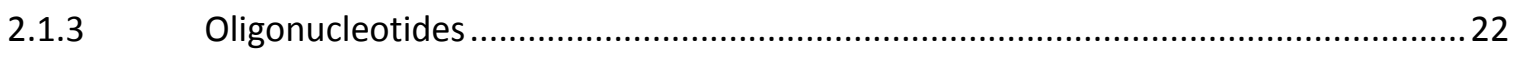

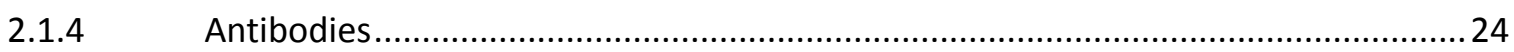

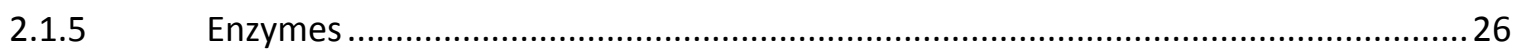




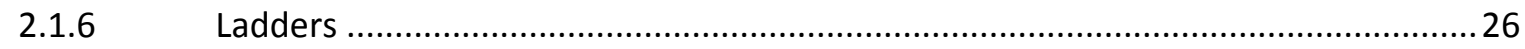

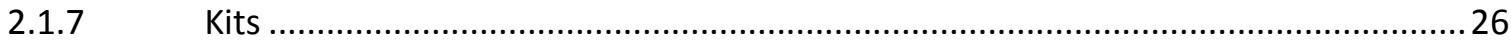

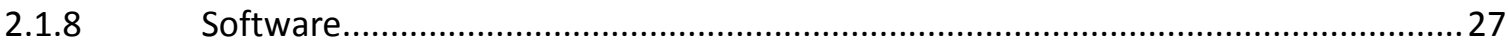

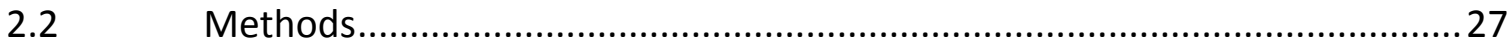

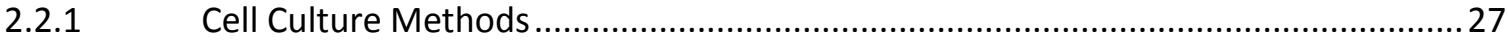

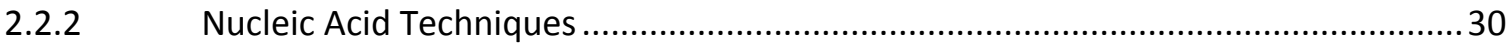

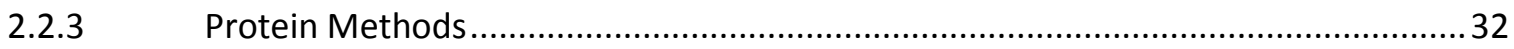

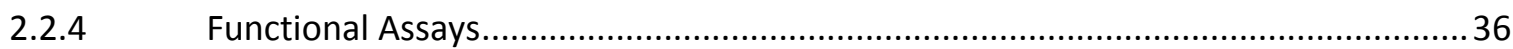

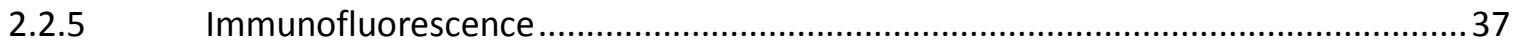

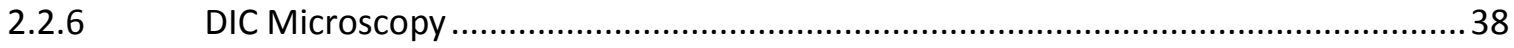

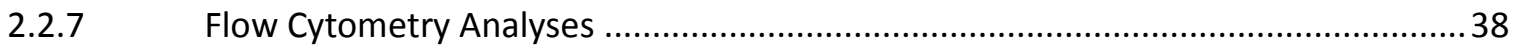

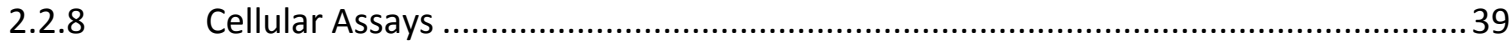

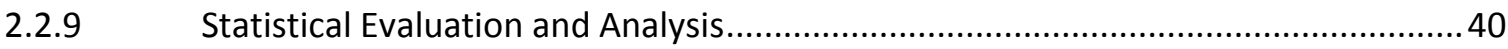

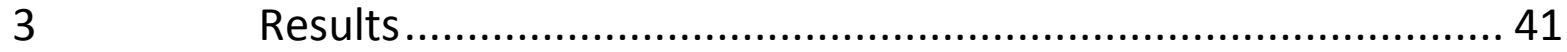

3.1 NF-kB expression and activity in HaCaT keratinocytes ................................ 41

3.2 Functional effects of NF-kB downregulation on HaCaT keratinocytes ..........46

3.3 c-Rel downregulation related effects in HaCaT keratinocytes ......................50

3.3.1 c-Rel downregulation induces growth reduction and cell cycle changes..................50

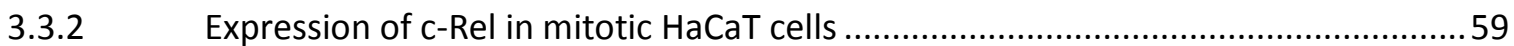

3.3.3 Phenotypic changes of c-Rel downregulated HaCaT cells .......................................60

3.4 Characterization of NF-kB expression in primary keratinocytes ................... 70

3.5 Impact of c-Rel downregulation on primary keratinocytes.......................... 72

4

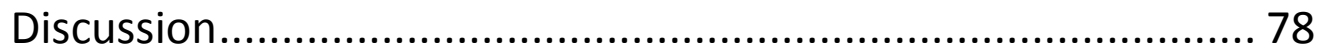

4.1 Pro-proliferative, anti-apoptotic implications for c-Rel in HaCaT cells .......... 78 
4.2 Putative role for c-Rel in cytoskeleton dynamics of HaCaT cells. .84

4.3 c-Rel downregulation in $\mathrm{HaCaT}$ and primary keratinocytes.

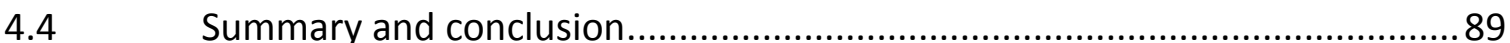

Literature

V. Curriculum Vitae. 101

VI.

Danksagung 


\section{List of Figures}

Figure 1: Schematic illustration of the human skin with enlarged epidermal layers (Neill, 2012).... 1 Figure 2: Schematic structure of the five NF-KB proteins (modified from Chen and Greene, 2004). 5 Figure 3: Major activation pathways of NF-KB (Sur et al., 2008).

Figure 4: Schematic illustration of cell cycle phases and associated regulatory proteins (modified from Peters, 2002).

Figure 5: Schematic illustration of major mitotic phases and associated processes (modified from Ruchaud et al., 2007).

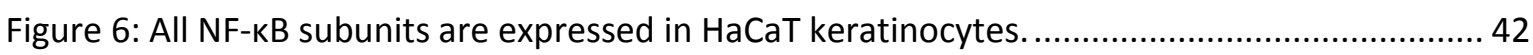

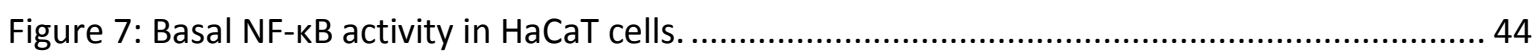

Figure 8: Confluence-dependent expression pattern of p50 and c-Rel in HaCaT keratinocytes..... 46 Figure 9: Efficient downregulation of all NF-KB proteins after siRNA transfection in $\mathrm{HaCaT}$ cells. . 47 Figure 10: c-Rel downregulation impairs cell viability and proliferation and induces apoptosis in HaCaT cells.

Figure 11: c-Rel downregulation is specific and does not affect any other NF-kB protein level in

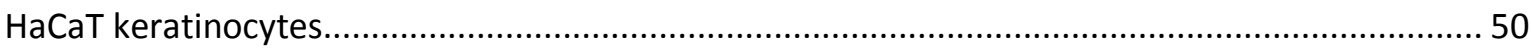

Figure 12: Time-related growth inhibition of c-Rel downregulated HaCaT cells........................... 51

Figure 13: Induction of G2/M phase cell portion in c-Rel downregulated HaCaT cells. .................. 52 Figure 14: c-Rel downregulation induces $\mathrm{p} 15^{\mathrm{INK} 4 \mathrm{~B}}$ expression but no subsequent $\mathrm{G} 1$ phase arrest in

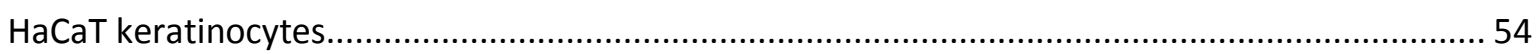

Figure 15: Induction of phospho-histone $\mathrm{H}^{\mathrm{Ser10}}$ in c-Rel downregulated HaCaT cells.................... 55

Figure 16: Stable survivin localization and expression in c-Rel downregulated HaCaT cells........... 56 Figure 17: Increased mitotic cell portion and aberrant mitotic spindle formation in c-Rel

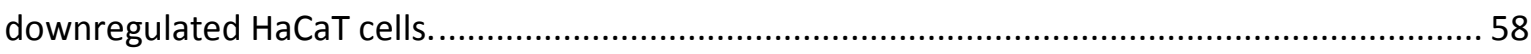

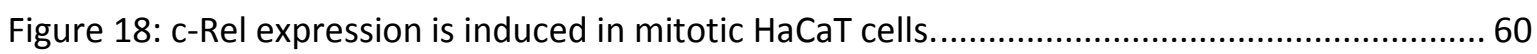

Figure 19: c-Rel downregulation alters $\mathrm{HaCaT}$ cell morphology to a more scattered, spindle-shaped phenotype.

Figure 20: c-Rel downregulation reveals no changes of $\mathrm{E}$-cadherin or $\mathrm{N}$-cadherin expression in

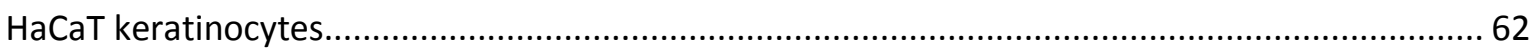

Figure 21: No changes in $B 1$ integrin surface expression on c-Rel downregulated HaCaT cells...... 64

Figure 22: Migration of c-Rel downregulated HaCaT cells is considerably impaired........................ 65

Figure 23: Reduced adhesion of c-Rel downregulated HaCaT keratinocytes. .................................67

Figure 24: Reduced stress fiber appearance in c-Rel downregulated HaCaT cells. ..........................69

Figure 25: Expression of NF-KB proteins in primary epidermal keratinocytes................................ 71

Figure 26: c-Rel downregulation leads to growth reduction in primary keratinocytes.................... 73

Figure 27: c-Rel downregulation reduces proliferation of primary keratinocytes. .......................... 74

Figure 28: Increased G2/M phase cell portion of c-Rel downregulated primary keratinocytes...... 75

Figure 29: c-Rel downregulation shows minor effects on primary keratinocyte phenotype and migration. 


\section{List of Tables}

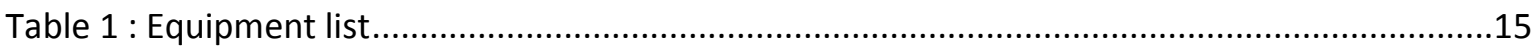

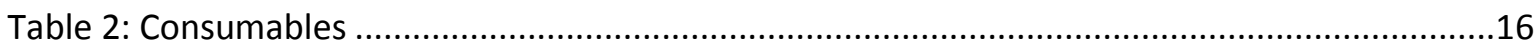

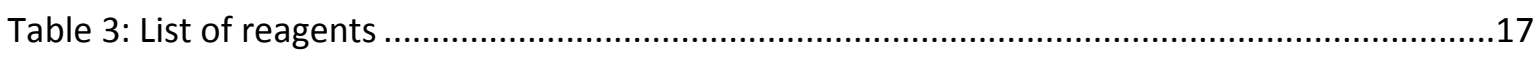

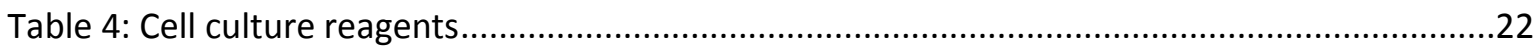

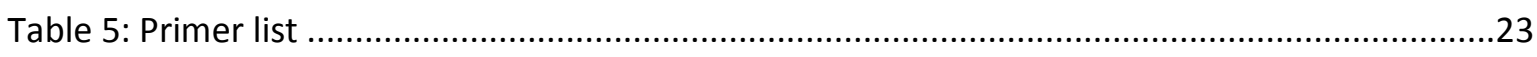

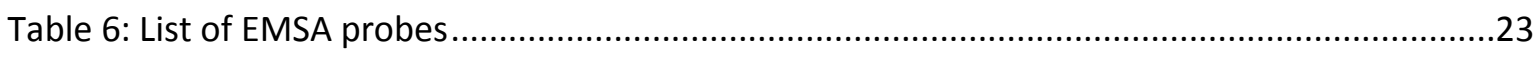

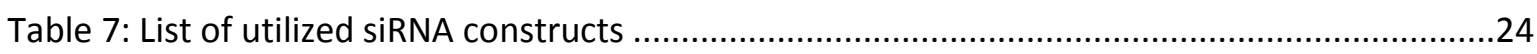

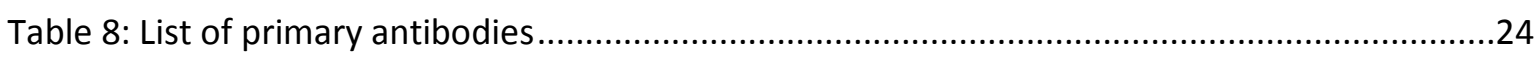

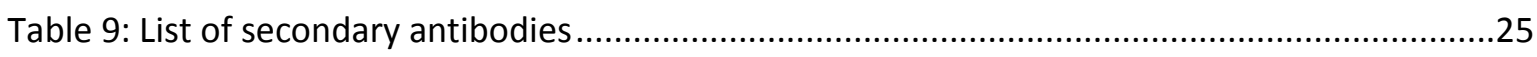

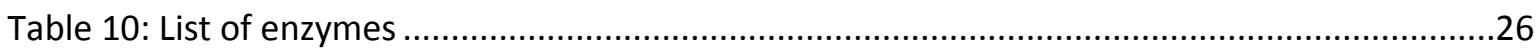

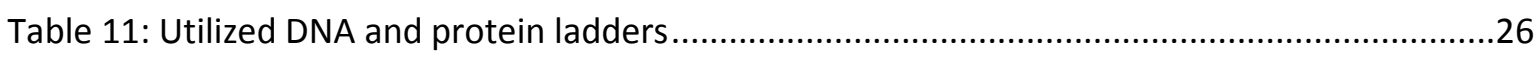

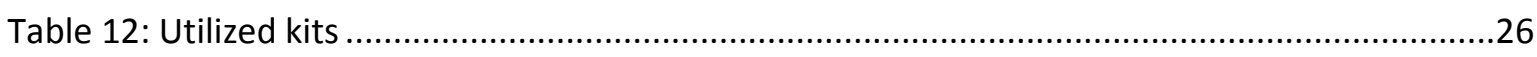

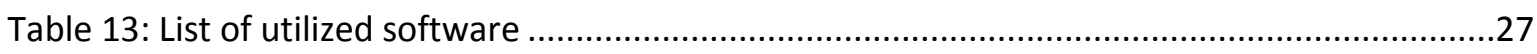

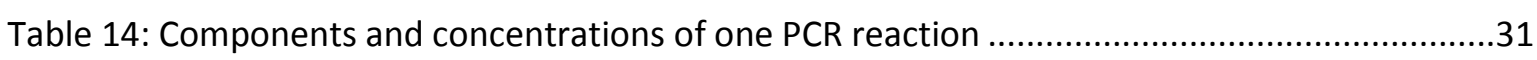

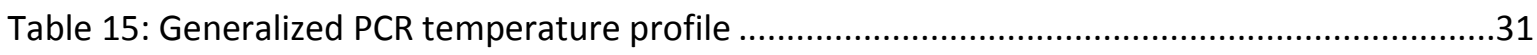

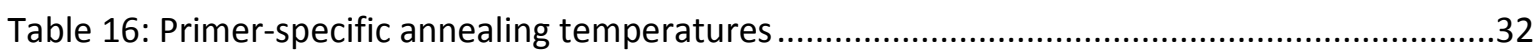

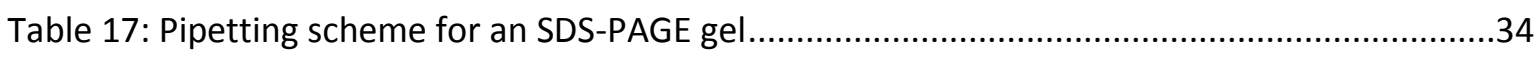

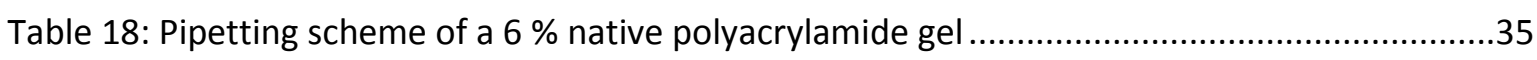

Table 19: Pipetting scheme for one EMSA shift or supershift reaction ............................................ 


\section{Abbreviations}

AK

BCC

BrdU

BSA

CDK

cDNA

CKI

$\mathrm{CP}$

CPC

DIC

DNA

dNTP

ECM

EMSA

FACS

F-actin

FCS

G

GTP

$\mathrm{HaCaT}$

HeLa
Actinic keratosis

Basal cell carcinoma

Bromodeoxyuridine

Bovine serum albumin

Cyclin dependent kinase

copy DNA

Cyclin dependent kinase inhibitor

Cold probe

Chromosomal passenger complex

Differential interference contrast

Deoxyribonucleic acid

Deoxynucleotide triphosphate

Extracellular matrix

Electrophoretic mobility shift assay

Fluorescence activated cell sorting

Filamentous actin

Fetal calf serum

Gravitation

Guanosine triphosphate

Human adult skin keratinocytes propagated under low $\mathrm{Ca}^{2+}$ conditions and elevated temperature, cell line

Henrietta Lacks, epithelial cell line 
HRP

IKK

IKB

LPS

MCC

MFI

MTOC

MTT

NEB

NF-KB

PCR

$\mathrm{p}-\mathrm{H} 3^{\operatorname{Ser} 10}$

RHD

RNA

RT

RT-PCR

SAC

SCC

SD

SiRNA

TA cells

TNF $\alpha$

UV
Horse radish peroxidase

Inhibitor of kappa B kinase

Inhibitor of kappa B

Lipopolysaccharide

Mitotic checkpoint complex

Mean fluorescence intensity

Microtubuli organization center

Dimethyl thiazolyl diphenyl tetrazolium salt

Nuclear envelop breakdown

Nuclear factor kappa-light-chain-enhancer of activated B-cells

Polymerase chain reaction

Phosphorylated histone H3 at Ser10

Rel homology domain

Ribonucleic acid

Room temperature

Reverse transcriptase-PCR

Spindle assembly checkpoint

Squamous cell carcinoma

Standard deviation

Small interfering RNA

Transient amplifying cells

Tumor necrosis factor alpha

Ultraviolet 


\section{Abstract}

The transcription factor NF-KB is a major player in a wide variety of crucial cellular functions such as proliferation, apoptosis, invasion as well as inflammation. However in the human epidermis, opposite, growth inhibitory effects have been associated with NF-KB activation. Epidermal homeostasis constitutes a prerequisite for maintaining a healthy skin barrier involving balanced proliferation and differentiation of epidermal keratinocytes. Various insults such as prolonged exposure to sunlight can induce deregulation of epidermal homeostasis leading to epidermal neoplasm development such as actinic keratosis or squamous cell carcinoma (SCC).

The major aim of this thesis was to elucidate the expression and function of NF-kB subunits in human keratinocytes in vitro. Transient downregulation revealed a novel role for c-Rel in several aspects of keratinocyte cell fate decisions. In contrast to former studies associating inhibition of the NF-KB proteins p50 and p65 with growth induction, downregulation of c-Rel led to keratinocyte growth inhibition. Concomitantly, cell cycle regulation was modified showing accumulation of mitotic cells with aberrant, predominantly monopolar mitotic spindle formation. Furthermore, increase in apoptosis resulting from c-Rel downregulation might be a consequence of prolonged mitotic arrest of those keratinocytes. Therefore, we suggest c-Rel being involved in regulation of mitotic entry or proceeding, however, specific target genes have not been identified yet. Furthermore, c-Rel downregulation yielded phenotypic modifications of immortalized HaCaT keratinocytes with a more spindled morphology and altered growth pattern. Adhesion and especially wound healing responses were abrogated in HaCaT cells, which could be attributed to diminished stress fiber appearance. However, this effect was not observed in c-Rel downregulated primary keratinocytes, possibly attributing to acquired mutations in the HaCaT keratinocyte cell line. 
In summary, this thesis elucidated the role of the single NF-KB proteins, especially of c-Rel in keratinocytes, thus contributing to a better understanding of the multi-facetted and complex regulation of NF-KB related functions and effects on epidermal homeostasis. 


\section{Introduction}

\subsection{The human epidermis and terminal differentiation}

The human epidermis constitutes the multilayered outer barrier of the skin protecting the organism against a wide range of external influences, e.g. against UV-radiation, bacterial and viral infection as well as dehydration. More than $90 \%$ of cells within the epidermis are keratinocytes; the remaining cells comprise melanocytes, Merkel cells and Langerhans cells. The innermost epidermal cell layer directly adjacent to the basement membrane is the basal layer followed by the spinous layer, granular layer and finally the outermost layer, the cornified layer or stratum corneum (Figure 1).

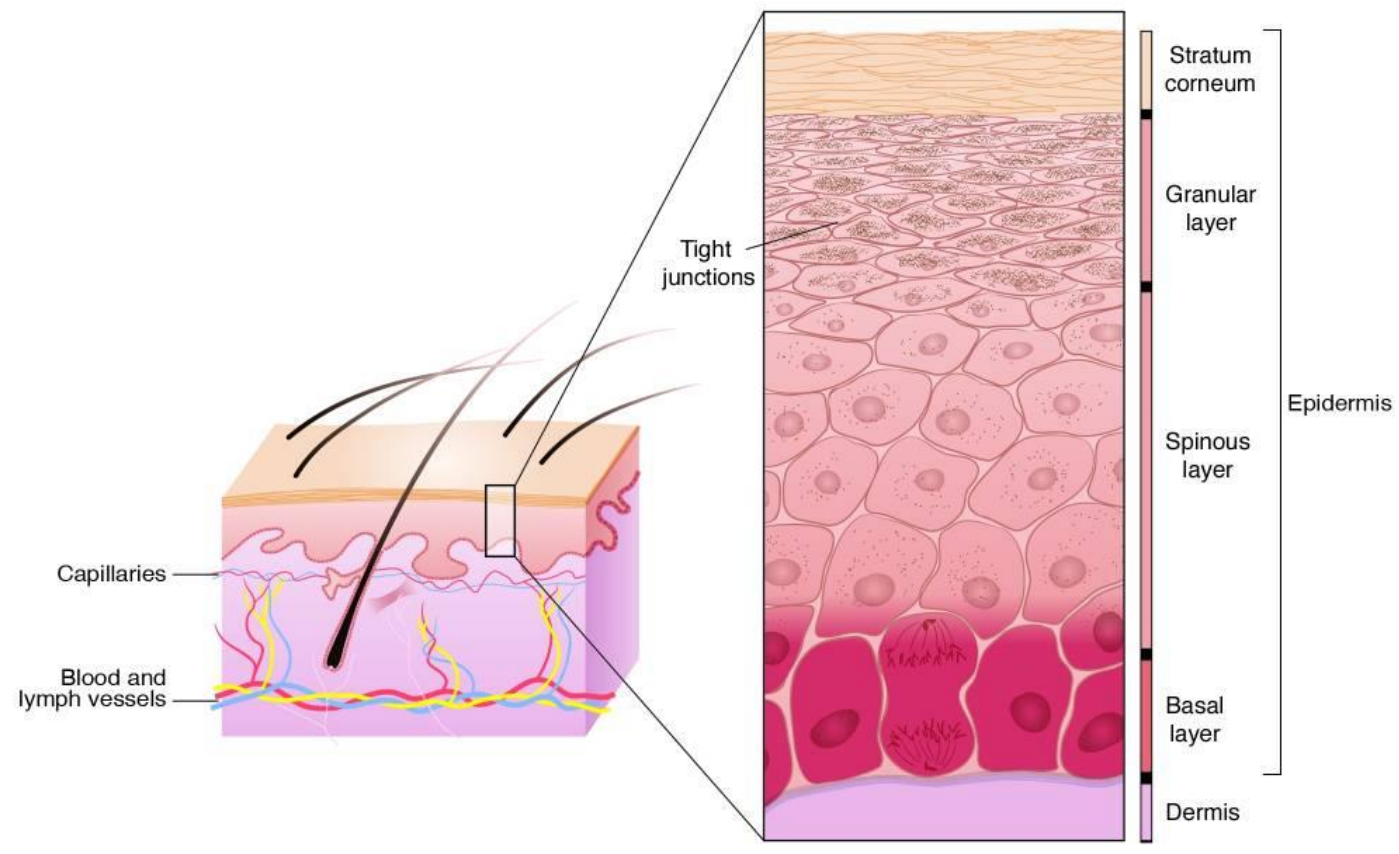

Figure 1: Schematic illustration of the human skin with enlarged epidermal layers (Neill, 2012). On the left side, a basic scheme of the human skin is depicted with blood and lymph vessel pervading dermis and adjacent epidermis. In the enlarged box, epidermal layers are shown with basement membrane (purple line) and underlying dermis. 
Under physiologic conditions, the ability of keratinocytes to proliferate is restricted to the basal layer of the epidermis. Basal keratinocytes show expression of keratins 5 and 14, are polarized and connected via hemi-desmosomes to the basement membrane. When a basal keratinocyte moves into suprabasal layers, terminal differentiation is initiated, a transitory and tightly regulated process: In the spinous layer, keratin expression switches to keratin 1 and 10 expression, respectively, leading to a more robust intermediary filament network further intensified by desmosomal interlinkage (Fuchs and Green, 1980). Concomitantly, lysine and glutamine-rich proteins such as involucrin are being expressed (Rice and Green, 1979). In the granular and cornified layer, keratinocytes flatten and de-nucleate while further structural proteins such as loricrin and filaggrin are synthesized as late differentiation markers, get enzymatically crosslinked and build up a proteinaceous sac. Finally, together with released lipid bilayers and the keratinocyte envelop, the water impermeable outermost skin barrier is formed. Typically, the life cycle of a keratinocyte starting in suprabasal layers until being shed of the skin surface takes about four weeks.

The molecular mechanism of initiation of terminal differentiation involves multiple regulatory levels (Blanpain and Fuchs, 2009). Implications for the transcription factor p63 belonging to the p53 tumor suppressor family have been made as well as for the canonical Notch signaling pathway (Blanpain et al., 2006; Koster et al., 2004; Koster and Roop, 2007; Mills et al., 1999; Rangarajan et al., 2001; Senoo et al., 2007; Truong et al., 2006; Watt et al., 2008; Yang et al., 1999). Further increasing its complexity, also timely expression of specific microRNAs (miR-203) as well as histone modifications seem to be required for accuracy of this process (Andl et al., 2006; Kouzarides, 2007; Yi et al., 2008). However, the exact interplay and orchestration is still topic of ongoing research. 


\subsection{Epidermal homeostasis and epidermal neoplasms}

Epidermal homeostasis describes the steady state between proliferating basal keratinocytes, differentiation of keratinocytes in suprabasal layers and final shedding of keratinocyte remnants from the cornified layer. To replenish the pool of basal keratinocytes, continually dividing cells are required. This task is mediated by epidermal stem cells residing in hair follicles, sebaceous glands and the basal layer. Distinctions are made between stem cells with unlimited proliferative capacity and transient amplifying (TA) cells with the ability to divide several times before undergoing differentiation (Alberts, 2002). In combination, stem cells and TA cells guarantee a continuous renewal of the epidermis thus sustaining epidermal homeostasis.

Environmental factors such as UV-radiation may dysregulate epidermal homeostasis and consecutively induce precancerous skin lesions such as actinic keratosis (AK). Histologic features of AK include atypical keratinocytes in the basal layer of the epidermis, interfering with terminal differentiation of keratinocytes resulting in a thickened hyperparakeratotic cornified layer. Furthermore, up to $60 \%$ of AK evolve into squamous cell carcinomas (SCC) of the skin (Marks, 1990). SCC constitute the second most common skin cancer type after basal cell carcinoma (BCC) with an estimated incidence of 34.000 in Germany in 2008 (Robert Koch-Institut, 2012). SCCs are also comprised of atypical keratinoytes additionally showing invasive growth into the dermis (Ratushny et al., 2012). Multiple signaling pathways are known to be involved in SCC development, however, the exact mechanisms have to date not to been fully elucidated. Nonetheless, p53 and Ha-ras mutations are frequently found in SCC (Brash and Ponten, 1998; Nelson et al., 1994). 


\subsection{The transcription factor NF-KB}

More than 25 years ago, the ubiquitously expressed transcription factor NF-KB was discovered by Baltimore and colleagues while studying the regulation of B-cell development (Singh et al., 1986). Since that time, NF-KB became one of the most intensively studied transcription factors due to its involvement in various crucial cellular processes. NF-KB activation has been associated with immune responses, anti-apoptotic and pro-proliferative characteristics as well as tumorigenesis (Karin, 2006). Furthermore, NF-KB dysregulation has been shown in various haematological malignancies, mesenchymal as well as epithelial malignant tumors like breast cancer (Sovak et al., 1997).

\subsubsection{Structure of the five NF-KB subunits}

NF-KB activates its target genes as a homo- or heterodimer composed of a combination of two of the five NF-kB subunits p50, p52, p65 (also known as RelA), RelB as well as c-Rel (Figure 2). Besides RelB homodimers, all dimer combinations have been previously described, the most abundant dimer form however constitutes the p50/p65 heterodimer (Chen and Greene, 2004). 


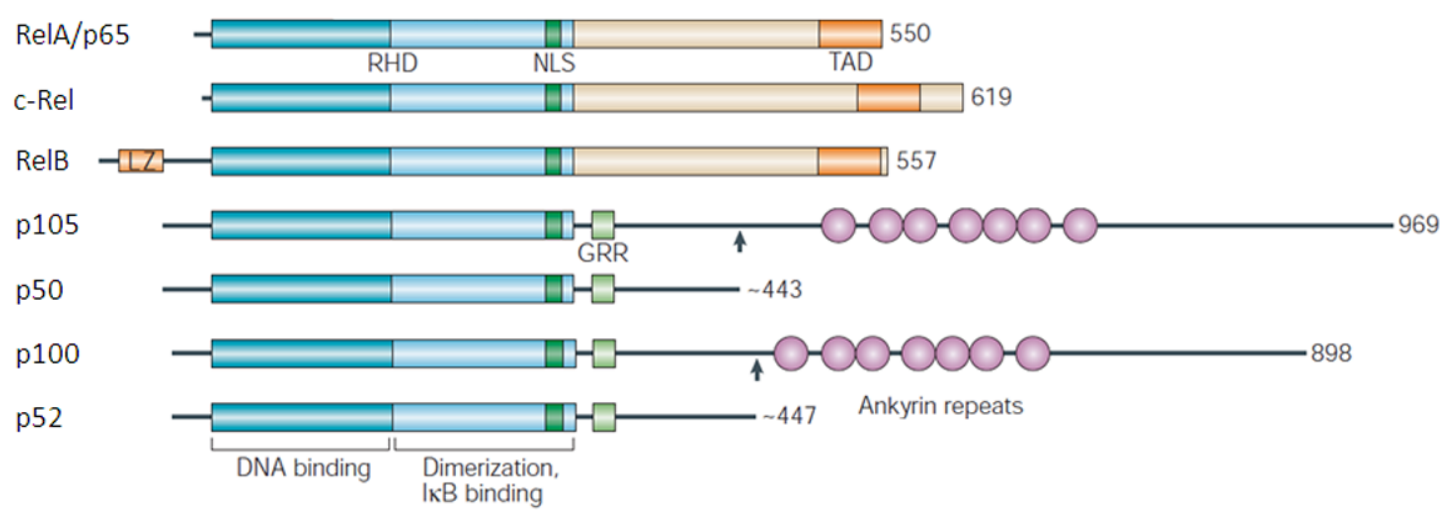

Figure 2: Schematic structure of the five NF-KB proteins (modified from Chen and Greene, 2004).

The five NF-KB proteins contain a Rel Homology Domain (RHD) mediating DNA binding, dimerization and binding to inhibitory proteins additionally carrying the Nuclear Localization Signal (NLS) mediating translocation into the nucleus. The subunits p50 and p52 are shown together with their precursor forms p105 and p100, respectively harboring large inhibitory ankyrin repeats. RHD $=$ Rel Homology Domain, $N L S=$ Nuclear Localization Signal, TAD= Transactivation Domain, GRR= Glycine Rich Region, LZ= Leucine Zipper.

All NF-KB proteins contain a conserved, N-terminal Rel Homology Domain (RHD) mediating dimerization and DNA-binding while also harboring the nuclear localization signal (NLS). Both p50 and p52 are synthesized as precursor forms p105 and p100, respectively, with large inhibitory ankyrin repeats at their C-terminus. When activated, the C-terminal part is removed via proteolytic processing resulting in the active protein (p50 or p52), which may then translocate - together with its dimer partner - into the nucleus. In contrast, the Rel proteins (p65, RelB and c-Rel) harbor C-terminal transactivation domains (TAD) further positively affecting target gene activation.

Although belonging to one transcription factor family, each NF-KB subunit seems to exert highly diverse functions. For example, knockout studies showed massive hepatocyte apoptosis and subsequent death for rela ${ }^{-/}$mice during early embryonic development (Beg et al., 1995). In contrast, relb $b^{-/}$mice are vital and develop a T-cell dependent inflammatory dermatitis (Barton et al., 2000). $n f k b 2^{-/}$and $n f k b 1^{-/}$mice develop normally with smaller defects in immune responses (Caamano et al., 1998; Sha et al., 1995). However, in c-rel/- mice, aberrant T-cell functions and alterations for B-cells were detected (Kontgen et al., 1995; Tumang et al., 1998). 


\subsubsection{NF-KB signaling and activation}

Under quiescent conditions, most NF-KB dimers are retained in the cytoplasm bound to a member of the inhibitor of NF-KB family (IKB). Upon activation, the respective stimuli determines which of the two major pathways is initiated, the classical (canonical) or the alternative (non-canonical) signaling pathway (Figure 3).

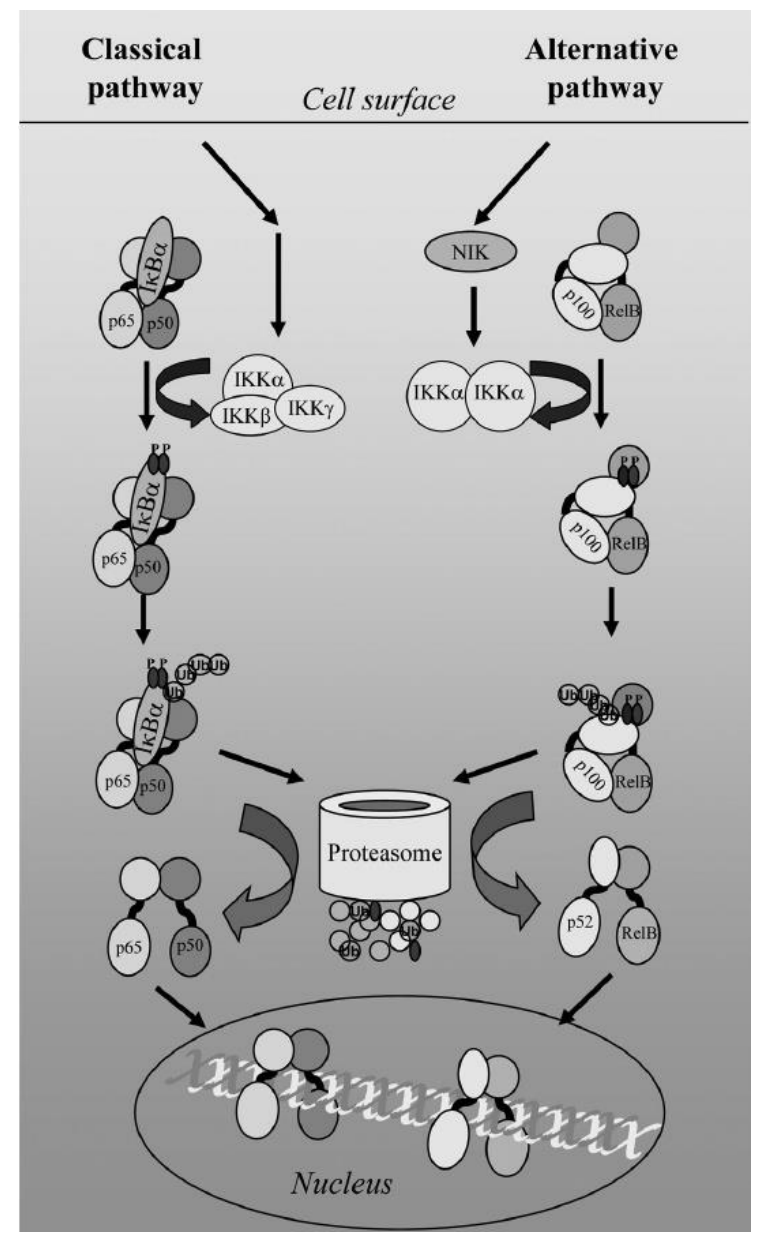

Figure 3: Major activation pathways of NF-KB (Sur et al., 2008).

Classical signaling (shown on the left side) involves activation of an IKK complex composed of IKK $\alpha$, IKKß and IKK $\psi$ phosphorylating IKB $\alpha$ leading to its proteasomal degradation and the freed translocation of the respective NF-KB dimer, here p50 together with p65 which is subsequently traveling into the nucleus activating its target genes. The alternative pathway (on the right side) involves activation of an IKK $\alpha$ homodimer by NF-KB inducing kinase (NIK) leading to phosphorylation of $\mathrm{p} 100$ bound to RelB and proteasomal processing to an active $\mathrm{p} 52 /$ RelB dimer travelling into the nucleus binding to promoters of specific target genes. 
The classical pathway is activated as a response to microbial or viral infections by pro-inflammatory stimuli such as tumor necrosis factor $\alpha$ (TNF $\alpha)$. This indirectly initiates activation of the IKB kinase (IKK) complex composed of IKK $\alpha$, IKK $\beta$ and IKKY (NEMO) further activating the inhibitory protein IKBa which is bound to the NF-kB dimer (mostly p50 and p65, sometimes involving c-Rel) normally retaining the dimer in the cytoplasm. Activation leads to ubiquitinylation and proteasomal degradation of $1 \mathrm{kB} \alpha$ resulting in release of the NF-KB dimer and translocation into the nucleus with subsequent target gene activation. The second major pathway, the alternative pathway, mainly involves p52/RelB heterodimers and is activated by lipopolysaccharides (LPS) or CD40 inducing IKK $\alpha$ homodimers, leading to proteasomal processing of p100 to p52 and p52/RelB dimer translocation into the nucleus (Senftleben et al., 2001). The alternative pathway is described as being crucial for secondary lymphoid organ development and B-cell survival and-maturation (Bonizzi et al., 2004).

Only little is known about dimer-specific modes of action since studies usually focus on $\mathrm{p} 65$, the most prominent NF-KB protein. The NF-KB nucleotide binding sequence is highly conserved, however, it is suggested that interaction of the respective NF-KB dimer with other transcription factors, chromatin and co-regulatory proteins or posttranslational modifications regulate different sets of target genes and thus different outcomes (Smale, 2012).

\subsection{Cell cycle regulation and mitosis}

Activity of NF-KB is associated with cell fate decisions such as cell proliferation thus involving cell cycle regulation. Generally, the cell cycle can be subdivided into four phases: Gap 1 (G0/G1) phase, Synthesis (S) phase, Gap 2 (G2) phase as well as Mitosis (M) phase (Figure 4). 


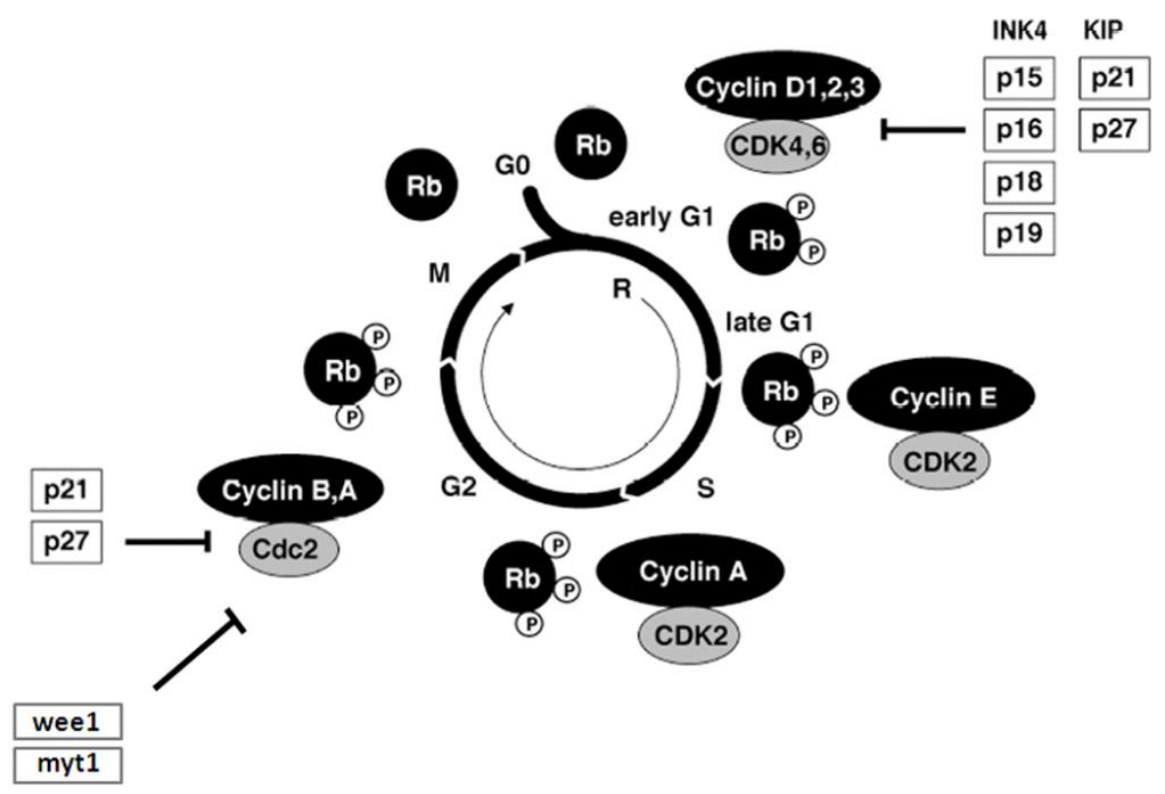

Figure 4: Schematic illustration of cell cycle phases and associated regulatory proteins (modified from Peters, 2002).

The four cell cycle phases G1 (early and late), S, G2, and M are depicted as parts of the black circle whereas G0 phase is shown on the outside indicating the ability of G0 phase cells to re-enter the cell cycle. The associated cyclin (black ellipse)/CDK (grey ellipse) complexes are depicted at the corresponding cell cycle phase together with the according phosphorylation status of the retinoblastoma tumor suppressor protein $(\mathrm{Rb})$ (black circle). Respective inhibitory proteins are shown at the corresponding cell cycle phase in grey boxes and indicate their target complexes with black inhibitory arrows.

To reassure all conditions are met for entering the next stage of the cell cycle, there are several cell cycle checkpoints serving as control mechanisms able to delay progression from one phase to the next, thereby ensuring cellular integrity. During G1 phase, a cell prepares for DNA replication and can be influenced by mitogenic or growth inhibitory signals resulting either in proceeding, pausing or exiting of the cell cycle regulated by the $\mathrm{G} 1 / \mathrm{S}$ phase cell cycle checkpoint. Transition from $\mathrm{G} 1$ to $\mathrm{S}$ phase is positively affected by complexes of cyclin D (D1, D2 or D3) along with the cyclin dependent kinases CDK4 or CDK6. These complexes and subsequently also cyclin E/CDK2 complexes activate the central retinoblastoma tumor suppressor protein $(\mathrm{Rb})$ which in turn induces expression of other proteins resulting in cell cycle progression and DNA synthesis. 
However, cell cycle progression from G1 to S-phase can be inhibited by cyclin dependent kinase inhibitors (CKIs), either Cip/Kip family members like $\mathrm{p} 21^{\mathrm{CIP} 1}$ or $\mathrm{p} 27^{\mathrm{KIP} 1}$ or INK4 family members such as $\mathrm{p} 15^{\mathrm{INK} 4 \mathrm{~B}}$ or p16 ${ }^{\text {INK4A }}$ (Figure 4).

Following DNA replication during S phase, cells proceed into G2 phase and prepare for mitosis, which is positively affected by cyclin A/CDK1 complexes. The G2/M checkpoint prevents premature entry into mitosis in case of DNA replication errors for instance. In late $\mathrm{G} 2$ phase and during mitosis, cyclin $\mathrm{A} / \mathrm{cdc} 2$ complexes and cyclin B/cdc2 complexes promote mitotic entry and proceeding. Several regulators of these complexes have been identified, e. g. protein kinase wee1 which is able to inactivate cdc2 at Tyr15 and/or Thr14 leading to cell cycle pausing whereas wee1 activity status is reversely dependent on cdc2 activity (Peters, 2002; Vermeulen et al., 2003). However, Cip/Kip family proteins such as $\mathrm{p} 21^{\mathrm{CIP} 1}$ or $\mathrm{p} 27^{\mathrm{KIP} 1}$ are also capable of inhibiting cyclin $\mathrm{B} / \mathrm{cdc} 2$ and cyclin $\mathrm{A} / \mathrm{cdc} 2$ complexes (Figure 4).

Mitosis comprises separation and equal distribution of condensed replicated chromosomes onto two daughter cells. The four major mitotic stages include prophase, metaphase, anaphase, and telophase (Figure 5). 

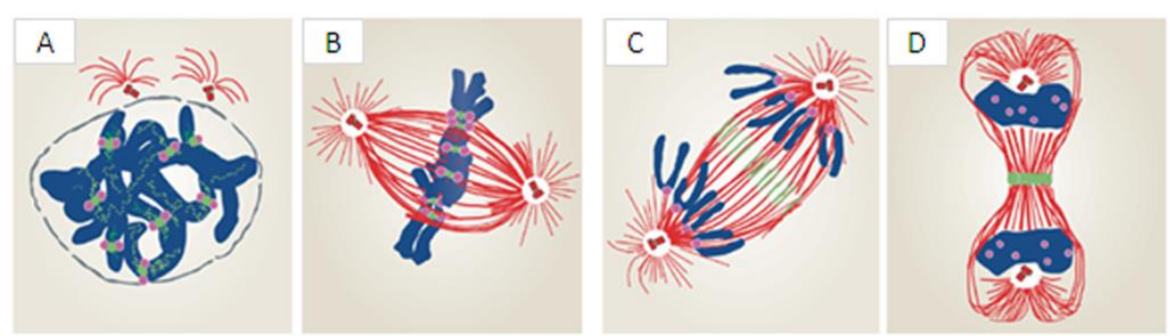

Figure 5: Schematic illustration of major mitotic phases and associated processes (modified from Ruchaud et al., 2007).

During prophase (A), chromosomes (blue) are condensating while centrosomes (red structures outside the nucleus) move to opposite cellular poles followed by nuclear envelop breakdown (indicated by interruptions in outer grey circle). The chromosomal passenger complex (CPC, green spots) is localized along the chromosome arms, mostly to the centromeres adjacent to both kinetochors (pink spots). In metaphase (B), the chromosomes are aligned and their kinetochores are attached to the evolved mitotic spindle (red filamentous structures) while the CPC is localized to the centromeres. During anaphase (C), sister chromatids are pulled towards each cellular pole by dynamic mitotic spindle disassembly whereas the CPC stays localized to the spindle midzone. In telophase (D), chromosomes are decondensating and cellular abscission occurs with CPC involvement.

During mitotic prophase and concomitant with chromosome condensation, the previously duplicated centrosomes separate, move to opposite cellular poles and establish microtubule organization centers (MTOCs) regulating mitotic spindle assembly. Then, nuclear envelope breakdown (NEB) occurs allowing the newly formed mitotic spindles to start interacting with the chromosomes kinetochors aligning them at the metaphase plate in metaphase. Correct attachments of spindle microtubules to the kinetochors of each sister chromatid are a prerequisite for pulling the chromatids apart during anaphase and for finally moving a complete set of chromosomes to each cellular pole. Microtubule attachments to kinetochors are monitored by the spindle assembly checkpoint (SAC) which prevents premature entry into anaphase thus guaranteeing proper chromosome segregation (Rieder et al., 1994). SAC activation is triggered by inappropriately attached kinetochores and involves amongst a variety of proteins the kinases budding uninhibited by benzimidazole 1 (Bub1), budding uninhibited by benzimidazole related 1 (BubR1) and monopolar spindle 1 (Mps1) (Musacchio and Salmon, 2007). Together, they form the mitotic checkpoint complex (MCC) protecting cyclin B from degradation thus preventing transition to anaphase (Musacchio, 2011). 
When meeting the conditions for transition to anaphase, sister chromatids are separated and pulled to opposite spindle poles. During telophase and cytokinesis, chromosomes de-condensate, a new nuclear envelop is formed and a contractile acto-myosin ring regulates abscission of the two daughter cells (Figure 5).

Concomitant with initiation of mitotic chromosome condensation, histone H3 phosphorylation at serine 10 occurs starting in late G2 phase reaching its maximum during metaphase and disappearing in late anaphase or early telophase (Hendzel et al., 1997). Aurora B kinase regulates as one part of the chromosomal passenger complex (CPC) this phosphorylation event, which is involved amongst others in correct microtubule attachments to the chromosomes kinetochores. Besides aurora $B$, the CPC comprises three functional components; survivin, borealin/Dasra-B as well as the inner centromere protein (INCENP). CPC localization changes with mitotic stages: In prophase, it persists on chromosome arms while during metaphase, the CPC is localized to centromeres correcting misattachments to kinetochores thereby supporting SAC functions. After metaphase, its localization is shifted to the spindle midzone, the equatorial cortex and finally to the midbody in telophase involved in abscission (Ruchaud et al., 2007; Vader et al., 2006, Figure 5).

\subsection{Molecular mechanisms of cellular migration and adhesion}

NF-KB activation is also associated with tumor invasion usually involving basic cellular processes such as cellular migration and motility. As a prerequisite, the adhesion process is deeply intertwined with migration but also showing some differences: Whereas adhesion involves the attachment of a cell to a substrate accompanied by clustering of adhesion receptors and bundled actin filaments, migration additionally involves alternating adherence and dis-adherence from the substrate leading to cellular motility (Kim et al., 1994). 
Integrins are classical adhesion receptors acting as variable heterodimers with high affinity for specific sequence motifs on extracellular matrix (ECM) proteins. Integrins own an extra- and an intracellular domain undergoing conformational changes upon binding. On the intracellular domain, adhesion induces linkage to the actin cytoskeleton via multi-protein complexes called adhesomes. Adhesomes are connected to filamentous actin (F-actin) which is generated out of monomeric globular actin (G-actin) involving actin nucleating proteins such as actin related proteins 2 and 3 (Arp2/3) (Pollard, 2007).

Based on the adhesion process, the migration cycle of one single cell involves the extension of actin-based lamellipodia at the cell front, which are broad and flat membrane protrusions as well as filopodia, smaller and finger-like actin protrusions. Anchoring of protrusions occurs as previously described. However during migration, thicker and bundled actin filaments are necessary for cellular movement; stress fibers. Stress fibers subsequently mediate movement of the cell body and retraction of the cell rear by generating traction forces together with myosin II finally completing one single migratory cycle (Vicente-Manzanares and Horwitz, 2011).

\subsection{NF-KB in epidermal homeostasis and SCC development}

In various cell types NF-KB activation is associated with tumor-promoting characteristics such as proliferation, anti-apoptosis and invasion (Karin, 2006). However, in human epidermis NF-KB exerts opposite effects: Immunohistochemical staining of NF-KB p50 in human epidermis showed cytoplasmic localization in basal, proliferating keratinocytes whereas in suprabasal keratinocytes, signals were localized to the nucleus (Seitz et al., 1998). Subsequent functional studies using an $1 \mathrm{~KB} \alpha$ mutant (IKB $\alpha \mathrm{M}$ ) to inactivate the classical NF-kB signaling pathway revealed a hyperplastic epidermis in vivo and increased proliferation of human primary keratinocytes in vitro. 
Concurrently, embryonic epidermis of rela ${ }^{-/-}$mice transplanted onto immune-deficient scid/scid mice resulted in hyperproliferation and showed similar effects in the human in vitro system (Zhang et al., 2004). Furthermore, overexpression of p50 and p65 induced the contrary effect, a hypoplastic epidermis in vivo as well as reduced cell growth of human keratinocytes in vitro (Seitz et al., 1998).

Besides phenotypic changes of transfected cells overexpressing p50 or p65, molecular analyses showed upregulation of cyclin dependent kinase inhibitor (CKI) p $21^{\text {Cip1/WAF1 }}$. In primary keratinocytes, p21 $1^{\text {Cip1/WAF1 }}$ induction led to $\mathrm{G} 1$ phase cell cycle arrest without affecting expression of early differentiation markers (Seitz et al., 2000a). Additionally, when studying apoptosis, a protective effect of both p50 and p65 by induction of anti-apoptotic factors TRAF1, TRAF2 and c-IAP1 and c-IAP2 was shown in primary keratinocytes (Seitz et al., 2000b).

Interestingly, generation of mice also using the $1 \kappa B \alpha$ mutant however under the control of a different promoter (keratin 5 instead of keratin 14 as used by Seitz and colleagues) resulted in development of dysplasia as well as spontaneous and rapid appearance of SCC (van Hogerlinden et al., 1999). Subsequent studies revealed SCC cells to be aneuploid and to arise without the involvement of known SCC-inducing $p 53$ or Ha-ras mutations. Furthermore, in mouse keratinocytes NF-KB inhibition could be associated with defective cell cycle checkpoint control in response to DNA damage (van Hogerlinden et al., 2002). However in the human system, NF-кB inhibition alone is not sufficient to induce SCC development. Expression of oncogenic active Ras in normal human keratinocytes induced cell cycle arrest, which could be bypassed by co-expression with IKB $\alpha \mathrm{M}$ leading to SCC-like tumor formation (Dajee et al., 2003). Up to now, only few studies focused on the expression of NF-KB proteins in SCC, however, one suggested NF-KB modulation of SCC associated gene expression in a murine model and showed dysregulation of NF-KB. Ambiguously, NF-KB inactivation seemed to reduce malignant phenotypic features here (Loercher et al., 2004). 


\subsection{Aim of this study}

Previous studies investigating the impact of NF-KB on epidermal keratinocytes focused on role of the classical NF-KB signaling pathway, i. e. the NF-KB proteins p50 and p65. These former studies most importantly revealed a negative growth control by NF-KB activation. While expression of the less frequently studied NF-KB subunits RelB, c-Rel and p52 has been shown in human epidermis as well as in primary keratinocytes (Takao et al., 2003), little is known on the functional contribution of these NF-KB subunits in the epidermis and primary keratinocytes, respectively. One functional approach revealed growth inhibition of primary human keratinocytes overexpressing p52, RelB and c-Rel, however pursuing experiments have not been performed (Hinata et al., 2003).

Therefore, this work aimed at unraveling the functional contribution of the five NF-KB subunits to epidermal homeostasis. Since the aforementioned studies showed pro-proliferative and thus tumor-promoting characteristics when both p50 and p65 where inhibited, effects of transient downregulation of each single NF-KB subunit were examined. Subsequently, typical NF-KB associated characteristics relevant during initiation and progression of epidermal carcinogenesis such as proliferation including cell cycle regulatory changes, apoptosis and migration, were analyzed. Initially, the spontaneously immortalized $\mathrm{HaCaT}$ cell line was used to characterize downregulation associated aspects and was later complemented by studies in primary epidermal keratinocytes. 


\section{Material and Methods}

\subsection{Material}

\begin{tabular}{|c|c|}
\hline Laboratory equipment & Company \\
\hline Appliskan Multimode Microplate Reader & Thermo Scientific \\
\hline Autoclave & Sanyo \\
\hline BD FACSCanto II & BD Biosciences \\
\hline Cary 50 Micro-Volume TrayCell Kit & Hellma \\
\hline Centrifuge Multifuge 15-R & Heraeus \\
\hline Centrifuge Pico 17 & Heraeus \\
\hline $\mathrm{CO}_{2}$ Incubator HeraCell $150 \mathrm{i}$ & Heraeus \\
\hline Cryo Freezing Container & Nalgene \\
\hline Double Distilled Water System Arium ${ }^{\circledR}$ 611VF & Sartorius \\
\hline Electrophoresis Power Supply-EPS 1001 & Amersham Biosciences \\
\hline Gel Imaging System U:Genius & Syngene \\
\hline Gradient Thermocycler Mastercycler & Eppendorf \\
\hline LAS-4000 Imaging System & Fujifilm \\
\hline Magnet Stirrer & VWR \\
\hline Micro Scale ALC & Acculab \\
\hline Microcentrifuge & Sprout \\
\hline Microscope Axiolmager M1 & Zeiss \\
\hline Microscope Axiovert 200 & Zeiss \\
\hline pH-Meter FE20-Five easy $^{\mathrm{TM}}$ & Mettler Toledo \\
\hline Pipette Set: 1,000, 100 and $10 \mu \mathrm{l}$ & Eppendorf \\
\hline PowerPac Basic & Bio-Rad \\
\hline PowerPack P25 & Biometra \\
\hline Refrigerated Centrifuge & Eppendorf \\
\hline Rocking Platform Polymax 1040 & Heidolph \\
\hline Scale Vicon & Acculab \\
\hline See-Saw Rocker SSL4 & Stuart \\
\hline Spectrometer Genesys 10Bio & Thermo Scientific \\
\hline
\end{tabular}




\begin{tabular}{|ll|}
\hline Sterile Bench & Heraeus \\
Thermal Mixer ThermoStat Plus & Eppendorf \\
Trans-Blot SD Semi-Dry Transfer Cell & Bio-Rad \\
Vertical Electrophoresis System Mini- & Bio-Rad \\
PROTEAN ${ }^{\circledR}$ TetraCell & \\
Vortex L46 & Labinco \\
Water Bath & Memmert \\
\hline
\end{tabular}

Table 2: Consumables

\begin{tabular}{|c|c|}
\hline Disposable/Material & Company \\
\hline 6-Well Plates & Greiner Bio One \\
\hline 8-Well CultureSlides & BD Biosciences \\
\hline 96-Well Plates, Flat Bottom & Greiner Bio One \\
\hline Cell Culture Flasks $25 \mathrm{~cm}^{3}, 75 \mathrm{~cm}^{3}$ & Greiner Bio One \\
\hline Cell Scrapers & Sarstedt \\
\hline Chromatography Paper Whatman ${ }^{\mathrm{TM}}$ & GE Healthcare \\
\hline Coverglasses, $24 \times 60 \mathrm{~mm}$ & Menzel-Gläser \\
\hline Cryo Vials Cryo.S & Greiner Bio One \\
\hline Culture-Inserts & Ibidi \\
\hline Falcon Tubes $15 \mathrm{ml}, 50 \mathrm{ml}$ & Greiner Bio One \\
\hline Filter Pipette Tips for PCR epT.I.P.S. ${ }^{\circledR}$ & Eppendorf \\
\hline Filter Pipette Tips for RNA TipOne & Starlab \\
\hline Freezing Tubes Cryo.S & Greiner Bio One \\
\hline Imaging Chamber 4CG & Zellkontakt \\
\hline Needle Microlance 3 & BD Biosciences \\
\hline Nitrocellulose Membrane & Bio-Rad \\
\hline Nylon Membrane, positively charged & Roche \\
\hline PCR Reaction Tubes, $0.2 \mathrm{ml}$ & Biozym \\
\hline Pipette Tips $10 \mu \mathrm{l}, 200 \mu \mathrm{l}, 1,000 \mu \mathrm{l}$ & Starlab \\
\hline Plastic Cuvettes & Sarstedt \\
\hline Plastic Pipettes $5 \mathrm{ml}, 10 \mathrm{ml}, 25 \mathrm{ml}$ & Sarstedt \\
\hline Polystyrene Round Bottom Tube, $5 \mathrm{ml}$ & BD Falcon \\
\hline
\end{tabular}




\begin{tabular}{|ll}
\hline Reaction Cups $2 \mathrm{ml}, 1.5 \mathrm{ml}$ and $0.5 \mathrm{ml}$ & Eppendorf \\
Syringe $1 \mathrm{ml}$ Omnifix 40 solo & B. Braun \\
TechnoCut Scalpel & HMD Healthcare
\end{tabular}

Table 3: List of reagents

\begin{tabular}{|c|c|}
\hline Reagent & Company \\
\hline 4',6-diamidino-2-phenylindole (DAPI) & Sigma-Aldrich \\
\hline 7x Protease inhibitor cocktail & Roche \\
\hline Acetic acid & Merck \\
\hline Aceton & Carl Roth \\
\hline Acrylamide/ Bis-acrylamide, $30 \%$ solution & Bio-Rad \\
\hline Ammonium persulfate (APS) & Gibco BRL \\
\hline Boric acid & Carl Roth \\
\hline Bovine serum albumin (BSA) & Carl Roth \\
\hline Bradford Reagent & Bio-Rad \\
\hline Bromophenol blue & Sigma-Aldrich \\
\hline BSA Standards, ready to use & Fermentas \\
\hline Dimethyl sulfoxide (DMSO) & Sigma-Aldrich \\
\hline Dithiothreitol (DTT) & Carl Roth \\
\hline dNTP mix, $10 \mathrm{mM}$ & Fermentas \\
\hline Ethanol & Carl Roth \\
\hline Ethylenediaminetetraacetic acid (EDTA) & Carl Roth \\
\hline Fluorescence Mounting Medium & Dako \\
\hline GelRed Nucleic Acid Gel stain, 10,000x & Biotium \\
\hline Glycerol & Sigma-Aldrich \\
\hline Glycine & Merck \\
\hline Hydrochloric acid (HCl) & Carl Roth \\
\hline Hydrogen peroxide $\left(\mathrm{H}_{2} \mathrm{O}_{2}\right)$ & Carl Roth \\
\hline Hydroxyethyl piperazineethanesulfonic acid (HEPES) & Carl Roth \\
\hline LE Agarose & Biozym \\
\hline Lipofectamine 2000 & Invitrogen \\
\hline Luminol & Sigma-Aldrich \\
\hline
\end{tabular}




\begin{tabular}{|c|c|}
\hline Magnesium chloride $\left(\mathrm{MgCl}_{2}\right)$ & Merck \\
\hline Methanol & Merck \\
\hline Nocodazole & Sigma \\
\hline Non-fat dry milk (NFDM) & Bio-Rad \\
\hline Nonidet P-40 (NP-40) & USB \\
\hline p-Coumaric acid & Sigma-Aldrich \\
\hline Phalloidin PromoFluor 555 & PromoCell \\
\hline Ponceau S & Sigma-Aldrich \\
\hline Potassium chloride $(\mathrm{KCl})$ & Carl Roth \\
\hline Potassium dihydrogen phosphate $\left(\mathrm{KH}_{2} \mathrm{PO}_{4}\right)$ & Merck \\
\hline Potassium hydroxide $(\mathrm{KOH})$ & Merck \\
\hline Propidium iodide & Carl Roth \\
\hline $\begin{array}{l}\text { Recombinant human tumor necrosis factor alpha } \\
\text { (rh-TNF } \alpha \text { ) }\end{array}$ & Immunotools \\
\hline Restore Western Blot Stripping Buffer & Thermo Scientific \\
\hline Sodium azide $\left(\mathrm{NaN}_{3}\right)$ & Merck \\
\hline Sodium chloride ( $\mathrm{NaCl})$ & Merck \\
\hline Sodium n-dodecyl sulfate (SDS) & Calbiochem \\
\hline Sulfuric acid $\left(\mathrm{H}_{2} \mathrm{SO}_{4}\right)$ & Carl Roth \\
\hline Tetramethylethylenediamine (TEMED) & Merck \\
\hline TRIS & Carl Roth \\
\hline TRIS-hydrochloride acid & Carl Roth \\
\hline Triton X-100 & Merck \\
\hline Trypan blue & Sigma-Aldrich \\
\hline Tween-20 & Carl Roth \\
\hline$\beta$-mercaptoethanol & Carl Roth \\
\hline
\end{tabular}




\subsubsection{Solutions and Buffers}

\section{ECL Solution}

Solution 1

- 100 mM TRIS-HCl, pH 8.5

- $\quad 0.4 \mathrm{mM} \mathrm{p-coumaric} \mathrm{acid}$

- $\quad 2.5$ mM luminol

Solution 2

- 100 mM TRIS-HCl, pH 8.5

- $\quad 0.018 \%$ hydrogen peroxide

Prior to usage, solution 1 and 2 were mixed 1:1

Nuclear Extraction Buffer A

- 10 mM HEPES-KOH, pH 7.9

- $\quad 1.5 \mathrm{mM} \mathrm{MgCl}_{2}$

- $10 \mathrm{mM} \mathrm{KCl}$

- $\quad 0.5 \mathrm{mM}$ DTT

\section{Nuclear Extraction Buffer C}

- 20 mM HEPES-KOH, pH 7.9

- $25 \%$ glycerol

- $420 \mathrm{mM} \mathrm{NaCl}$

- $\quad 1.5 \mathrm{mM} \mathrm{MgCl}_{2}$ 
- $\quad 0.2 \mathrm{mM}$ EDTA

- 0.5 mM DTT

\section{Ponceau S Staining Solution}

- $\quad 0.1 \%$ Ponceau S

- $\quad 5 \%$ Acetic acid

Running Buffer, 10x

- $\quad 1.92 \mathrm{M}$ glycine

- 250 mM TRIS

- $\quad 5 \%$ SDS

\section{$\underline{\text { SDS Lysis Buffer }}$}

- $\quad 10 \%$ SDS

- 50 mM TRIS, pH 7.0

- $1 \%$ SDS

- $\quad 5 \% \beta$-mercaptoethanol

- $\quad 1 x$ protease inhibitor cocktail

\section{SDS Sample Buffer, $5 x$}

- 200 mM TRIS, pH 6.8

- $\quad 4 \%$ SDS

- $\quad 40 \%$ glycerol 
- $\quad 0.07 \%$ bromophenol blue

$\underline{\text { TBE Buffer, } 10 x}$

- 890 mM TRIS

- 890 mM boric acid

- 20 mM EDTA, pH 8.0

$\underline{\text { TBS-T Buffer }}$

- $\quad 10$ mM TRIS

- 1 mM EDTA, pH 8.0

- $150 \mathrm{mM} \mathrm{NaCl}$

- $\quad 0.05 \%$ Tween 20

\section{Transfer Buffer}

- $\quad 48$ mM TRIS

- 39 mM glycine

- $\quad 0.0375 \%$ SDS

- $\quad 20 \%$ methanol 


\subsubsection{Cell Culture Reagents and Growth Media}

Table 4: Cell culture reagents
\begin{tabular}{|ll|}
\hline Product & Company \\
\hline DMEM high Glucose $(4.5 \mathrm{~g} / \mathrm{l})$ & PAA Laboratories \\
Keratinocyte Growth Medium 2 & PromoCell \\
Trypsin-EDTA $(1 \mathrm{x}) 0.05 \% / 0.02 \%$ in PBS & PAA Laboratories \\
Dulbecco's PBS $(1 \mathrm{x})$ without Ca and Mg & PAA Laboratories \\
Accutase & PAA Laboratories \\
Fetal Bovine Serum, Gold & PAA Laboratories \\
Penicillin/ Streptomycin (100x) & PAA Laboratories \\
L-Glutamine (200 mM) & PAA Laboratories \\
Cryo-SFM & PromoCell \\
\hline
\end{tabular}

\section{$\underline{\text { DMEM Growth Medium }}$}

- $\quad 10 \%$ FCS

- $100 \mathrm{U} / \mathrm{ml}$ penicillin

- $\quad 100 \mu \mathrm{g} / \mathrm{ml}$ streptomycin

- 2 mM L-glutamine

\section{Keratinocyte Growth Medium 2}

- $\quad 0.06 \mathrm{mM} \mathrm{CaCl}_{2}$

\subsubsection{Oligonucleotides}

\subsubsection{Primers}

Primer pairs for RELA u RELB were previously used (Takao et al., 2003), just like primers for NFKB1 and NFKB2 (Scian et al., 2005). 
REL primers were designed with the primer designing tool of PrimerBLAST (NCBI) and ordered from MWG Eurofins Operon (Table 5). Remaining primer pairs were designed by former members of the lab.

\begin{tabular}{|c|c|c|c|}
\hline Gene & Forward primer & Reverse primer & Size \\
\hline NFKB1 & 5'-CACTTAGCAATCATCCACCTT-3' & 5'-AGCCCTCAGCAAATCCT-3' & $171 \mathrm{bp}$ \\
\hline NFKB2 & 5'-GGGGCATCAAACCTGAAGATTTCT-3' & 5'-TCCGGAACACAATGGCATACTGT-3' & $202 \mathrm{bp}$ \\
\hline RELA & 5'-AGCGCATCCAGACCAACAACAACC-3' & 5'-CCGCCGCAGCTGCATGGAGACAC-3' & $433 \mathrm{bp}$ \\
\hline \multirow[t]{2}{*}{ RELB } & 5'-ACCGCCAGATTGCCATTGTGTTC-3' & 5'-AGTGTGGGGGCCGTAGGGTCGTAG-3' & $428 /$ \\
\hline & & & $419 \mathrm{bp}$ \\
\hline REL & 5'-GGCCTCCTGACTGACTGACTG-3' & 5'-ACGCATTCCCCTCTGCCTG-3' & $146 \mathrm{bp}$ \\
\hline GAPDH & 5'-CTTTGGTATCGTGGAAGGACTC-3' & 5'-TTCGTTGTCATACCAGGAAATG-3' & $451 \mathrm{bp}$ \\
\hline BIRC5 & 5'-GCATGGGTGCCCCGACGTTG-3' & 5'-GCTCCGGCCAGAGGCCTCAA-3' & $446 \mathrm{bp}$ \\
\hline
\end{tabular}

\subsubsection{EMSA probes}

The sequence was chosen in compliance with diverse publications performing NF-KB specific EMSA. The biotin-labeled probes were ordered from Thermo Scientific UIm and the non-modified cold probes from MWG Eurofins Operon (Table 6).

Table 6: List of EMSA probes
\begin{tabular}{|llll|}
\hline Probe & Sense & Antisense & Modification \\
\hline NF-KB & 5'-AGTTGAGGGGACTTTCCCAGGC-3' & 5'-GCCTGGGAAAGTCCCCTCAACT-3' $^{\prime}$ & 3'-biotin \\
labeled & & & \\
NF-kB & 5'-AGTTGAGGGGACTTTCCCAGGC-3' $^{\prime}$ & $5^{\prime}$-GCCTGGGAAAGTCCCCTCAACT-3' & - \\
unlabeled & & & \\
\hline
\end{tabular}

\subsubsection{SIRNA}

All respective siRNA constructs were obtained from Qiagen (Table 7). 
Table 7: List of utilized siRNA constructs

\begin{tabular}{|lll|}
\hline Name & Product name & Target sequence \\
\hline control siRNA & AllStars Neg. Control siRNA & Not announced \\
p50 siRNA & Hs_NFKB1_7 & $5^{\prime}$-TACCTGGTGCCTCTAGTGAAA-3' \\
p65 siRNA & Hs_NFKB2_1 & $5^{\prime}$-AACCCAGGTCTGGATGGTATT-3' \\
RelB siRNA & Hs_RELA_5 & 5'-AAGATCAATGGCTACACAGGA-3' $^{\prime}$ \\
c-Rel siRNA (I) & Hs_REL_1 & 5'-CACAGATGAATTGGAGATCAT-3' $^{\prime}$ \\
c-Rel siRNA (II) & Hs_REL_4 & 5'-CCGGTGCGTATAACCCGTATA-3' $^{\prime}$ \\
c-Rel siRNA (III) & Hs_REL_6 & 5'-CACAGAACCCGTAACAGTAAA-3' $^{\prime}$ \\
\hline
\end{tabular}

\subsubsection{Antibodies}

\subsubsection{Primary antibodies}

Table 8: List of primary antibodies

\begin{tabular}{|ll|}
\hline Primary human antibody & Company \\
\hline CDK4 & Cell Signaling Technology \\
C-Rel & Cell Signaling Technology \\
Cyclin A & Cell Signaling Technology \\
Cyclin B1 & Cell Signaling Technology \\
Cyclin D1 & Cell Signaling Technology \\
Cyclin D3 & Cell Signaling Technology \\
E-cadherin & Cell Signaling Technology \\
GAPDH & BD (Becton, Dickinson and Company) \\
Integrin alpha v beta 5 & Cell Signaling Technology \\
Integrin $\beta 1$ & Millipore \\
Integrin $\alpha 2$ & Abcam \\
Involucrin & Chemicon \\
Isotype control lgG2a K, PE-labeled & Abcam \\
Lamin A/C & Biolegend \\
N-cadherin & Cell Signaling Technology \\
\hline
\end{tabular}




\begin{tabular}{|ll|}
\hline NF-KB p100/p52 & Cell Signaling Technology \\
NF-KB p105/p50 & Epitomics \\
NF-KB p105/p50 & Santa Cruz Biotechnology \\
p15 INK4B & Cell Signaling Technology \\
p16 INK4A & Cell Signaling Technology \\
p21 Waf1/Cip1 & Cell Signaling Technology \\
p27 Kip1 & Cell Signaling Technology \\
p65 & Santa Cruz Biotechnology \\
Paxillin & Abcam \\
phospho-cdc2 (Tyr15) & Cell Signaling Technology \\
phospho-Histone H3 (Ser10) & Cell Signaling Technology \\
phospho-wee1 (Ser642) & Cell Signaling Technology \\
RelB & Cell Signaling Technology \\
$\beta$-actin & Millipore \\
$\beta$-tubulin & Sigma-Aldrich \\
Survivin & Santa Cruz Biotechnology \\
Vinculin & Sigma-Aldrich \\
\hline
\end{tabular}

\subsubsection{Secondary antibodies}

Table 9: List of secondary antibodies

\begin{tabular}{|ll|}
\hline Secondary antibody & Company \\
\hline Alexa Fluor $^{\circledR} 555$ Goat Anti-Rabbit IgG $(\mathrm{H}+\mathrm{L})$ & Invitrogen \\
Anti-mouse IgG $(\mathrm{H}+\mathrm{L}), \mathrm{F}\left(\mathrm{ab}^{\prime}\right)_{2}$ Fragment (Alexa & Cell Signaling Technology \\
Fluor $^{\circledR} 488$ Conjugate) & \\
Anti-Mouse IgG $(\mathrm{H}+\mathrm{L})$, HRP Conjugate & Promega \\
Anti-Rabbit IgG $(\mathrm{H}+\mathrm{L})$, HRP Conjugate & Promega \\
Polyclonal Goat Anti-Mouse Immunoglobulins/ & Dako \\
FITC Goat $\mathrm{F}\left(\mathrm{ab}{ }^{\prime}\right)_{2}$ & \\
\hline
\end{tabular}




\subsubsection{Enzymes}

Table 10: List of enzymes

\begin{tabular}{|ll|}
\hline Enzyme & Company \\
\hline Taq DNA polymerase & PEQLAB \\
DNase I & Omega BioTek \\
RNase A & Carl Roth \\
\hline
\end{tabular}

\subsubsection{Ladders}

Table 11: Utilized DNA and protein ladders

\begin{tabular}{|ll|}
\hline Ladder & Company \\
\hline PageRuler Prestained Protein Ladder & Thermo Scientific \\
GeneRuler 100 bp Plus DNA Ladder & Thermo Scientific \\
\hline
\end{tabular}

\subsubsection{Kits}

Table 12: Utilized kits

\begin{tabular}{|ll|}
\hline Kit Name & Company \\
\hline Cell Cycle Regulation Antibody Sampler Kit I & Cell Signaling Technology \\
Cell Cycle Regulation Antibody Sampler Kit II & Cell Signaling Technology \\
ECM Cell Culture Optimization Array & Fermentas/Thermo Scientific \\
E.Z.N.A. ${ }^{\circledR}$ Total RNA Kit I & Millipore \\
Nuclear Extraction Kit & Omega BioTek \\
Chemiluminescent Nucleic Acid Detection & Panomics/ Affymetrix \\
Module Kit & Pierce/Thermo Scientific \\
LightShift Chemiluminescent EMSA Kit & Pierce/Thermo Scientific \\
CellTiter 96 ${ }^{\circledR}$ Non-Radioactive Cell Proliferation & Promega \\
Assay (MTT) & \\
DetachKit & PromoCell \\
Cell Death Detection ELISA ${ }^{\text {PLus }}$ & Roche \\
Cell Proliferation ELISA, BrdU & Omega BioTek \\
RNase-free DNase Set & Roche \\
\hline
\end{tabular}




\subsubsection{Software}

Table 13: List of utilized software

\begin{tabular}{|ll|}
\hline Program & Company \\
\hline Axiovision Rel 4.7 & Zeiss \\
LAS2000 Imaging System & Fujifilm \\
Multi Gauge V3.2 & Fujifilm \\
Metamorph 6.3r2 & Molecular Devices \\
Microsoft Office 2007 & Microsoft \\
ImageJ & National Institute of Health \\
Primer BLAST/ Primer designing tool & NCBI \\
\hline
\end{tabular}

\subsection{Methods}

\subsubsection{Cell Culture Methods}

\subsubsection{Keratinocyte Cultivation, Cell Counting and Cryopreservation}

In the past, the cultivation of primary keratinocytes has been a challenge due to the frequent contamination with fibroblasts and other cells (Prose et al., 1967). In 1975, Rheinwald and Green established serum-based isolation of primary keratinocytes on a feeder layer of lethally irradiated 3T3 fibroblasts which provided keratinocyte essential growth requirements leading exclusively to keratinocyte colony growth (Rheinwald and Green, 1975). This finally led to development of serum-free cultivation media without the need of fibroblasts meeting the specific requirements of keratinocytes, containing essential supplements such as epidermal growth factor (EGF) and bovine pituitary extract (BPE) (Boyce and Ham, 1983; Maciag et al., 1981; Wille et al., 1984). Even though a lot of progress has been made, nowadays cultivation of primary keratinocytes is still not of greatest ease due to the cell's restrictive proliferative capacity on the one hand resulting in low passaging number and on the other hand due to easy induction of confluence-dependent growth inhibition. However, human keratinocytes isolated from foreskin retain higher proliferative capacity than keratinocytes isolated from adult skin. 
In 1988, Boukamp and colleagues established a spontaneously immortalized human keratinocyte cell line retaining typical primary keratinocyte characteristics (Boukamp et al., 1988). The cell line named HaCaT originates from a 62-year-old patient from excised, normal appearing skin in the periphery of a melanoma. The name refers to the human adult skin origin and cultivation in media with low $\mathrm{Ca}^{2+}$ concentrations and elevated temperature. $\mathrm{HaCaT}$ cells are an optimal model system with retained characteristics of primary keratinocytes as they still show the ability to differentiate and to generate a normal epidermis when transplanted onto nude mice (Boukamp et al., 1988).

Furthermore, they are non-tumorigenic but aneuploid with stable marker chromosome expression and show some molecular aberrations, i.e. loss of both p53 alleles, hypermethylation of the promotor region of $\mathrm{p} 16^{\mathrm{INK} 4 \mathrm{~B}}$ as well as a greater susceptibility to apoptosis (Chaturvedi et al., 1999). Due to their spontaneous immortalization and aforementioned retained typical characteristics, they constitute one of the best model systems to study primary keratinocyte characteristics.

For subsequent studies, HaCaT cells were provided by P. Boukamp (Boukamp et al., 1988) and cultivated in Dulbecco's Modified Eagle Medium (DMEM) growth medium at $37^{\circ} \mathrm{C}$ in a humidified atmosphere with $5 \% \mathrm{CO}_{2}$. Routinely, mycoplasma infestation was excluded by performing respective PCRs. The cells were sub-cultivated by two washing steps with PBS and incubation for 5-6 min with $1.5 \mathrm{ml}$ trypsin-EDTA until approximately $90 \%$ of the cells detached. By addition of $5.5 \mathrm{ml}$ growth medium the reaction was stopped, the cell suspension was transferred to a $15 \mathrm{ml}$ falcon tube and centrifuged at $400 \times \mathrm{g}$ for $4 \mathrm{~min}$. The supernatant was removed and the pellet refilled with fresh growth medium up to $10 \mathrm{ml}$. For further cultivation, cells were diluted 1:5 until 1:10 up to a total volume of $12 \mathrm{ml}$ with fresh growth medium in a new T75-cell culture flask.

For following experiments, cells were diluted 1:3 or 1:4 with trypan blue and counted in a Neubauer chamber. The portion of vital cells was determined and the respective cell number was utilized for subsequent experiments. 
Cryo-preserved primary human keratinocytes were thawn and cultivated in Keratinocyte Growth Media 2. Subcultivation occurred with the DetachKit. Cells were received at passage 2 from the distributor and used for transfection experiments exclusively from passage $3-4$ to guarantee basal keratinocyte characteristics.

For cryo-preservation, cells were harvested, resuspended in Cryo-SFM at a maximum concentration of $3 * 10^{6}$ cells $/ \mathrm{ml}$ and transferred to cryo vials. Subsequently, vials were put into a cell freezing container and stored at $-80^{\circ} \mathrm{C}$ overnight. The next day, vials were transferred to liquid nitrogen.

\subsubsection{Cell Stimulation}

In case of nocodazole treatment, cells were incubated with $50 \mathrm{ng} / \mathrm{ml}$ nocodazole for $16 \mathrm{~h}$ before harvesting. For TNF $\alpha$ stimulation, cells were incubated with $30 \mathrm{ng} / \mathrm{ml} \mathrm{rh}-\mathrm{TNF} \alpha$ in growth medium for 30 min prior to performing further experiments.

\subsubsection{Cell Synchronization}

For cell synchronization by medium depletion, $0.5 * 10^{5}$ cells $/ \mathrm{ml}$ were seeded and adhered in standard growth medium overnight. After washing steps with PBS, cells were starved in DMEM growth medium containing $0.5 \%$ FCS for $72 \mathrm{~h}$. Afterwards, DMEM complete growth medium was added. Cells were harvested $0 \mathrm{~h}, 2 \mathrm{~h}, 6 \mathrm{~h}, 8 \mathrm{~h}$ and $24 \mathrm{~h}$ after serum addition and subjected to western blotting and cell cycle analysis experiments by flow cytometry. 


\subsubsection{4 siRNA Transfection of Cells}

siRNA was transiently transfected at a concentration of 200 pmol using Lipofectamine 2000. Initially, siRNA and the transfection reagent were diluted in the respective amount of nullmedium depending on the experimental setup and incubated at RT for 15 min.

Exemplarily, $5 \mu$ l Lipofectamine 2000 and $12.5 \mu$ l siRNA $(20 \mu \mathrm{M})$ were added to $250 \mu \mathrm{l}$ nullmedium for one 6-well sample. Both suspensions were mixed and incubated at RT for another $15 \mathrm{~min}$. In the meantime, cells were detached and resuspended in media lacking antibiotics. Finally, $1.5 * 10^{5}$ cells were added per well to the siRNA-lipofectamine suspension and filled up with medium lacking antibiotics. After $24 \mathrm{~h}$, medium was replaced and after $72 \mathrm{~h}$, cells were used for future studies.

\subsubsection{Nucleic Acid Techniques}

\subsubsection{RNA Isolation and Concentration Determination}

Total RNA was isolated using the E.Z.N.A. RNA Isolation Kit according to the manual. Cells were detached with trypsin-EDTA and pelleted in PBS at $800 \times \mathrm{g}$ and $4^{\circ} \mathrm{C}$ for $10 \mathrm{~min}$. Depending on the pellet size, either $350 \mu$ or $700 \mu$ l TRK Buffer were added followed by the same amount of $70 \%$ ethanol. The sample was homogenized with a microlance 3 needle with further steps carried out as described. In cases of contamination with genomic DNA, DNase I digestion was performed according to the manufacturer's recommendations. Finally, RNA concentration and purity was determined by measuring the absorbance at $260 \mathrm{~nm}$ and $280 \mathrm{~nm}$ with the Genesys 10 Bio spectrophotometer. 


\subsubsection{2 cDNA Synthesis}

cDNA was generated using the First Strand cDNA Synthesis Kit. Equal amounts of total RNA (usually $1 \mu \mathrm{g}$ ) were mixed with $1 \mu \mathrm{l}$ of Oligo $\mathrm{d}(\mathrm{T})$ primers and Aqua bidest $a d$ $11 \mu \mathrm{l}$ and incubated at $65^{\circ} \mathrm{C}$ for $5 \mathrm{~min}$. Thereafter, $1 x$ Reaction buffer, $20 \mathrm{U}$ RiboLock RNase Inhibitor, $40 \mathrm{U}$ MMuLV reverse transcriptase and $1 \mathrm{mM}$ dNTP mix were added to a total volume of $20 \mu \mathrm{l}$ and cDNA was generated at $37^{\circ} \mathrm{C}$ for $1 \mathrm{~h}$. The reaction was stopped by incubation at $70^{\circ} \mathrm{C}$ for $5 \mathrm{~min}$. Samples were stored until further use at $-20^{\circ} \mathrm{C}$.

\subsubsection{Reverse Transcriptase-PCR}

RT-PCR reaction samples including Taq DNA polymerase were prepared as depicted in Table 14.

Table 14: Components and concentrations of one PCR reaction
\begin{tabular}{|lc|}
\hline Component & Final concentration \\
\hline $10 x$ Reaction buffer & $1 \mathrm{x}$ \\
Forward primer $(10 \mu \mathrm{M})$ & $0.4 \mu \mathrm{M}$ \\
Reverse primer $(10 \mu \mathrm{M})$ & $0.4 \mu \mathrm{M}$ \\
dNTPs $(10 \mathrm{mM})$ & $0.4 \mathrm{mM}$ \\
Taq DNA polymerase $(5 \mathrm{U} / \mu \mathrm{l})$ & $1 \mathrm{Unit}$ \\
Aqua bidest & ad $24 \mu \mathrm{l}$ \\
cDNA template & undetermined $(1 \mu \mathrm{l})$ \\
\hline
\end{tabular}

The PCR reaction was performed in a thermocycler as follows (Table 15).

Table 15: Generalized PCR temperature profile

\begin{tabular}{|lccc|}
\hline & Temperature & Time (min) & Cycles \\
\hline Initial denaturation & $95^{\circ} \mathrm{C}$ & $02: 00$ & 1 \\
Denaturation & $95^{\circ} \mathrm{C}$ & $00: 30$ & variable \\
Annealing & Variable & $00: 30$ & \\
Elongation & $72^{\circ} \mathrm{C}$ & $00: 45$ & $5: 00$ \\
Final elongation & $72^{\circ} \mathrm{C}$ & & 1 \\
\hline
\end{tabular}


Annealing temperatures and cycle numbers were primer-pair dependent (Table 16).

Table 16: Primer-specific annealing temperatures
\begin{tabular}{|lcc|}
\hline Primer & Annealing temperature & Cycles \\
\hline NFKB1 & $60^{\circ} \mathrm{C}$ & variable \\
NFKB2 & $62^{\circ} \mathrm{C}$ & variable \\
RELA & $62^{\circ} \mathrm{C}$ & variable \\
RELB & $60^{\circ} \mathrm{C}$ & variable \\
REL & $60^{\circ} \mathrm{C}$ & variable \\
GAPDH & $58^{\circ} \mathrm{C}$ & 26 \\
BIRC5 & $62^{\circ} \mathrm{C}$ & 30 \\
\hline
\end{tabular}

Subsequently, samples were loaded with 5x DNA loading dye and applied to a polymerized 1-1.5\% agarose gel and separated at $100 \mathrm{~V}$ until the loading dye front passed $2 / 3$ of the gel. Finally, separated fragments were documented with the gel imaging system U:Genius.

\subsubsection{Protein Methods}

\subsubsection{Generation of Whole Cell Lysates}

For generation of whole cell lysates, cells were scrape-harvested and pelleted at $800 \times \mathrm{g}$ for $10 \mathrm{~min}$ at $4^{\circ} \mathrm{C}$. The appropriate amount of SDS lysis buffer (according to pellet size $150-300 \mu \mathrm{l}$ ) was added and incubated at $95^{\circ} \mathrm{C}$ for $5 \mathrm{~min}$. After homogenization with a microlance 3 needle, the suspension was centrifuged at 25,000 $\mathrm{g} g$ for $5 \mathrm{~min}$. The supernatant was carefully transferred to a fresh tube and after concentration determination stored until further use at $-80^{\circ} \mathrm{C}$.

\subsubsection{Generation of Cytoplasmic and Nuclear Lysates}

The respective cell samples were scrape-harvested and pelleted with $800 \times \mathrm{g}$ at $4^{\circ} \mathrm{C}$ for $10 \mathrm{~min}$. 
For western blotting experiments, nuclear and cytoplasmic lysates were generated according to the instructions of the nuclear extraction kit. Their concentration was determined and samples were stored until further use at $-80^{\circ} \mathrm{C}$.

For EMSA experiments, cell pellets were resuspended in $50 \mu \mathrm{l}-100 \mu \mathrm{l}$ Buffer A and incubated on ice for $30 \mathrm{~min}$. After addition of $1.6 \mu \mathrm{l}-3.2 \mu \mathrm{l} 10 \% \mathrm{NP}-40$ (v/v) respectively, samples were mixed for $10 \mathrm{sec}$ and centrifuged at $25,000 \times \mathrm{g}$ at $4^{\circ} \mathrm{C}$ for $10 \mathrm{~min}$. The supernatant (cytoplasmic fraction) was removed and the pellet resuspended in $25 \mu \mathrm{l}$ Buffer C. After 20 min incubation on ice, samples were centrifuged at $25,000 \times \mathrm{g}$ at $4^{\circ} \mathrm{C}$ for $2 \mathrm{~min}$ and the supernatant (nuclear fraction) was transferred to a fresh tube. Concentrations were determined and samples were stored until further use at $-80^{\circ} \mathrm{C}$.

\subsubsection{Determination of Protein Concentration}

Protein concentration was determined by using Bradford Reagent. BSA standards with concentrations ranging from $0.125 \mu \mathrm{g} / \mathrm{ml}-20 \mu \mathrm{g} / \mathrm{ml}$ were used to generate a standard curve. This was performed by mixing $1 \mu \mathrm{l}$ of each BSA standard with $1 \mu \mathrm{l}$ of the respective sample buffer diluted in $800 \mu \mathrm{l}$ Aqua bidest and $200 \mu \mathrm{l}$ Bradford Reagent. For concentration determination, $1 \mu \mathrm{l}$ of the respective lysate was added to $800 \mu$ l Aqua bidest and $200 \mu \mathrm{l}$ Bradford and incubated at RT for $10 \mathrm{~min}$. The protein concentration was determined by measuring the absorbance with Genesys 10 Bio Spectrometer at $595 \mathrm{~nm}$.

\subsubsection{SDS-PAGE and Western Blotting}

Between $20 \mu \mathrm{g}$ and $50 \mu \mathrm{g}$ of protein lysate were filled up to an equal sample volume with Aqua bidest and loaded with 1x SDS sample buffer. After 5 min incubation at $95^{\circ} \mathrm{C}$, respective samples were separated by SDS-polyacrylamide gel electrophoresis (SDS-PAGE). Depending on the protein size desired for detection, 8\%-15\% polyacrylamide gels were used. Exemplarily, the pipetting scheme of one $10 \%$ SDS-PAGE gel is depicted (Table 17). 
Table 17: Pipetting scheme for one SDS-PAGE gel

\begin{tabular}{|lclc|}
\hline Stacking gel & $\mathbf{1 x}$ & Separation gel (10 \%) & $\mathbf{1 x}$ \\
\hline Aqua bidest & $1.05 \mathrm{ml}$ & Aqua bidest & $2 \mathrm{ml}$ \\
$30 \%$ acrylamide/bisacrylamide & $0.25 \mathrm{ml}$ & $30 \%$ acrylamide/bisacrylamide & $1.65 \mathrm{ml}$ \\
$1 \mathrm{M}$ TRIS-HCl (pH 6.8) & $0.19 \mathrm{ml}$ & $1.5 \mathrm{M} \mathrm{TRIS}-\mathrm{HCl}(\mathrm{pH} 8.8)$ & $1.25 \mathrm{ml}$ \\
$10 \%$ SDS & $15 \mu \mathrm{l}$ & $10 \% \mathrm{SDS}$ & $50 \mu \mathrm{l}$ \\
$10 \%$ APS & $15 \mu \mathrm{l}$ & $10 \%$ APS & $50 \mu \mathrm{l}$ \\
TEMED & $3 \mu \mathrm{l}$ & TEMED & $15 \mu \mathrm{l}$ \\
\hline
\end{tabular}

Samples were separated at $150 \mathrm{~V}-200 \mathrm{~V}$ until the respective dye reached the lower front of the gel. Then, proteins were transferred onto a nitrocellulose membrane by semi-dry blotting at $150 \mathrm{~mA}$ for $50 \mathrm{~min}$. Therefore, filter and membrane were pre-equilibrated with ice-cold transfer buffer. Successful protein transfer was confirmed by staining with Ponceau $S$ staining solution and de-staining with Aqua dest. The membrane was blocked with $5 \%$ NFDM/TBS-T for $1 \mathrm{~h}$ and primary antibody incubation occurred in $1 \% \mathrm{NFDM} / \mathrm{TBS}-\mathrm{T}$ at $4^{\circ} \mathrm{C}$ overnight. Following three washing steps with TBS-T, HRP-labeled secondary anti-mouse or anti-rabbit antibodies were incubated in $1 \%$ NFDM/ TBS-T for $1 \mathrm{~h}$. After three additional washing steps, ECL solution was added equally covering the membrane and $5 \mathrm{~min}$ after incubation, chemiluminescent signals were recorded via LAS 2000 imaging system.

\subsubsection{Electrophoretic Mobility Shift Assay (EMSA)}

\section{Probe Annealing}

Biotin labeled or unlabeled complementary oligonucleotides were mixed at a 1:1 molar ratio with a starting concentration of $100 \mathrm{nmol} / \mu \mathrm{l}$ and diluted to a final concentration of $1 \mathrm{pmol} / \mu \mathrm{l}$ in $10 \mathrm{mM}$ TRIS with $1 \mathrm{mM}$ EDTA and $50 \mathrm{mM} \mathrm{NaCl}$ (pH 8.0). 
The samples were incubated at $95^{\circ} \mathrm{C}$ for $5 \mathrm{~min}$ and slowly cooled down for annealing of both oligonucleotides. Finally, samples were stored at $-20^{\circ} \mathrm{C}$ until further use and directly prior to use, further diluted for EMSA experiments.

\section{EMSA Shift und Supershift}

To determine NF-KB activity and dimer composition, EMSA shifts and supershifts were performed. Native conditions are of highest priority to guarantee transcription factor binding, thus potential SDS residuals had to be carefully removed. Initially, non-denaturing $6 \%$ polyacrylamide gels were casted according to the following scheme (Table 18).

Table 18: Pipetting scheme of a $6 \%$ native polyacrylamide gel

\begin{tabular}{|lc|}
\hline Component & Amount \\
\hline $10 x$ TBE & $0.5 \mathrm{ml}$ \\
$80 \%$ glycerol & $2 \mathrm{ml}$ \\
$10 \%$ APS & $312.5 \mu \mathrm{l}$ \\
Aqua bidest & $150 \mu \mathrm{l}$ \\
TEMED & $7.19 \mathrm{ml}$ \\
\hline
\end{tabular}

After polymerization, the gel was transferred to a native electrophoresis chamber filled with $0.5 \times \mathrm{TBE}$ and set at $100 \mathrm{~V}$ for $30-60 \mathrm{~min}$ at $4^{\circ} \mathrm{C}$ without any samples. In the meantime, samples were prepared as given in Table 19. 
Table 19: Pipetting scheme for one EMSA shift or supershift reaction

\begin{tabular}{|lc|}
\hline Component & Final concentration \\
\hline $10 x$ Binding buffer & $1 \mathrm{x}$ \\
Poly $(\mathrm{d} l \bullet \mathrm{dC})$ & $50 \mathrm{ng} / \mu \mathrm{l}$ \\
Unlabeled probe (for cold probe) & $4 \mathrm{pmol}$ \\
Labeled probe & $20 \mathrm{fmol}$ \\
Nuclear lysate & $6-15 \mu \mathrm{g}$ \\
Antibody & depending on concentration \\
Aqua bidest & ad $20 \mu \mathrm{l}$ \\
\hline
\end{tabular}

Samples were incubated at RT for 20 min for the shift or in case of supershift reactions for $30 \mathrm{~min}$. Native gelelectrophoresis was started with $0.5 \mathrm{x}$ TBE as running buffer at $4^{\circ} \mathrm{C}$ and $100 \mathrm{~V}$ until the loading dye reached the lower front of the gel. Proteins were transferred to a positively charged nylon membrane equilibrated in ice-cold $0.5 \times \mathrm{XTB}$ by semidry blotting at $380 \mathrm{~mA}$ for $30 \mathrm{~min}$. For fixation, the membrane was finally cross-linked at $312 \mathrm{~nm}$ on an UV transilluminator for $15 \mathrm{~min}$. Further steps were performed as described in the distributer's manual whereas chemiluminescence was finally detected by LAS 2000 imaging system.

\subsubsection{Functional Assays}

\subsubsection{MTT Assay and Growth Curve Generation}

The assay was performed according to the instructions of the CellTiter $96{ }^{\circledR}$ Non-Radioactive Cell Proliferation manual $72 \mathrm{~h}$ after siRNA transfection. The respective 96 well plate was finally incubated overnight in a humidified atmosphere at $37^{\circ} \mathrm{C}$. The next day, absorbance was measured at $570 \mathrm{~nm}$ with the Appliskan Plate Reader.

Cell growth was documented by photographing at least six microscopic fields (x160) each $24 \mathrm{~h}$ after transfection using an Axiovert 200 microscope and MetaMorph 6.3r2 software. Cell numbers were evaluated using ImageJ. 


\subsubsection{BrdU Proliferation Assay}

$60 \mathrm{~h}$ after transfection, $10 \mu \mathrm{M}$ BrdU was added to the transfected samples and incubated for $12 \mathrm{~h} .72 \mathrm{~h}$ after transfection, the experiment was performed according to the instructions of the BrdU Cell Proliferation ELISA manual. The reaction was stopped by adding $25 \mu \mathrm{l} 1 \mathrm{M} \mathrm{H}_{2} \mathrm{SO}_{4}$ and the absorbance was measured at $405 \mathrm{~nm}$ with the Appliskan Plate Reader.

\subsubsection{Apoptosis Assay}

To determine the apoptosis rate, samples were treated $72 \mathrm{~h}$ after transfection according to the specifications of the Cell Death Detection ELISA ${ }^{\text {PLUS }}$ manual. This system is based on determination of the amount of cytoplasmic histone-bound fragments as apoptotic marker. Finally, the absorbance was measured at $405 \mathrm{~nm}$ with the Appliskan Plate Reader.

\subsubsection{Immunofluorescence}

For immunofluorescence studies, cells were either directly seeded onto 8-Well Culture Slides or initially transfected, seeded and fixed $72 \mathrm{~h}$ after transfection with ice-cold $100 \%$ methanol or in case of phalloidin staining with $100 \%$ acetone for 5 min. Blocking and permeabilization occurred with $5 \%$ FCS/0.5 \% Triton X-100/PBS for $1 \mathrm{~h}$ followed by addition of primary antibody in $2.5 \% \mathrm{FCS} / \mathrm{PBS}$ overnight at $4^{\circ} \mathrm{C}$. After three washing steps with PBS the following day, the conjugated secondary antibody was added for $1 \mathrm{~h}$ at RT in $2.5 \%$ FCS/PBS. The cells were washed five times with PBS, chambers were removed with the provided tools and air-dried. Wells were covered with Fluorescence Mounting Medium supplemented with $0.5 \mu \mathrm{g} / \mathrm{ml}$ DAPI. Photographs were taken with Axiolmager M1 and Axiovision software Rel 4.7.

vf 


\subsubsection{DIC Microscopy}

Cells were transfected and seeded onto 4-Well Imaging Chambers and were documented $72 \mathrm{~h}$ after transfection by DIC microscopy with the Axiovert 200 microscope.

\subsubsection{Flow Cytometry Analyses}

\subsubsection{Flow Cytometry Surface Staining}

After cell harvesting with accutase, the pellet was resuspended in ice-cold $10 \%$ $\mathrm{FCS} / 1 \% \mathrm{NaN}_{3} / \mathrm{PBS}$ together with $1 \mu \mathrm{g}$ antibody and incubated in the dark at $4^{\circ} \mathrm{C}$ for 30 min. Cells were washed three times with ice-cold PBS, resuspended in $3 \%$ BSA/PBS with the secondary antibody and incubated at RT for $20 \mathrm{~min}$. After three additional washing steps with ice-cold PBS, cells were resuspended in $100 \mu \mathrm{l}$ ice-cold $3 \% \mathrm{BSA} / 1 \%$ $\mathrm{NaN}_{3} /$ PBS. Surface staining intensity was determined with BD FACSCanto II.

\subsubsection{Flow Cytometry Cell Cycle Analysis}

$72 \mathrm{~h}$ after transfection, cells were trypsinized and resuspended in $0.5 \mathrm{ml}$ PBS. Fixation occurred by dropwise addition of $3 \mathrm{ml}$ ice-cold $100 \%$ ethanol to each sample and repeated mixing. After at least $2 \mathrm{~h}$ at $-20^{\circ} \mathrm{C}$, fixed cells were centrifuged at $4^{\circ} \mathrm{C}$ and $400 \times \mathrm{g}$ for $5 \mathrm{~min}$ to remove residual ethanol. The resulting pellet was resuspended in PBS containing $100 \mu \mathrm{g} / \mathrm{ml}$ RNase $\mathrm{A}$ and $50 \mu \mathrm{g} / \mathrm{ml}$ propidium iodide up to a final volume of $0.5 \mathrm{ml}$, and incubated in the dark for $30 \mathrm{~min}$. Cell cycle phase distribution was determined with BD FACSCanto II. 


\subsubsection{Cellular Assays}

\subsubsection{Migration Assay}

Cells were transfected and seeded onto a migration insert consisting of two adjacent wells separated by a $50 \mu \mathrm{m}$ thick gap. $48 \mathrm{~h}$ after transfection, $\mathrm{HaCaT}$ cells were irradiated with 55 Gray for growth inhibition. $72 \mathrm{~h}$ after transfection, the migration insert was carefully removed with sterile forceps. By phase contrast microscopy, appropriate gaps were chosen and marked for further documentation.

Photographs were taken with MetaMorph software and Axioskop 200 microscope, evaluation of wound closure rate occurred via ImageJ.

\subsubsection{Adhesion Assay}

\section{General Adhesion Assay}

Samples were trypsinized $72 \mathrm{~h}$ after transfection, reseeded in equal cell number $\left(1 * 10^{5}\right.$ cells $\left./ \mathrm{ml}\right)$ and allowed to attach for $3 \mathrm{~h}$ and $6 \mathrm{~h}$, respectively. Non-attached cells were washed off by careful rinsing with DMEM growth medium. Evaluation was performed by documenting 10 microscopic fields (x160) in a total of 3 wells ( 30 fields) for each sample and counting the number of attached cells at the respective time point.

\section{ECM Adhesion Assay}

$72 \mathrm{~h}$ after transfection, cells were harvested with accutase, resuspended in DMEM without supplements and reseeded at a cell number of $1 * 10^{6}$ cells $/ \mathrm{ml}$. Cells were allowed to attach to $0.125 \mu \mathrm{g} / \mathrm{ml}-20 \mu \mathrm{g} / \mathrm{ml}$ of collagen I, fibronectin, laminin and vitronectin for $2 \mathrm{~h}$. The adhesion rate was determined according to instructions of the ECM Cell Culture Optimization Assay. The absorbance was measured at $544 \mathrm{~nm}$ with the Appliskan Plate Reader. 


\subsubsection{Statistical Evaluation and Analysis}

To determine $\mathrm{p}-\mathrm{H}^{\mathrm{Ser} 10}$ positive cell portion of $\mathrm{HaCaT}$ cells, at least ten immunofluorescence photographs $(x 100)$ were evaluated using ImageJ. For primary keratinocytes, 20 immunofluorescence photographs $(x 200)$ were evaluated similarly. Determination of the mitotic cell portion based on $\beta$-tubulin immunofluorescence stainings evaluating at least 19 photographs (x200) by using ImageJ.

Normal and aberrant mitotic spindle classification based on immunofluorescence findings of at least 19 photographs (x200). Generally, $p$ values were determined by performing two-sided unpaired student's t-test. 


\section{Results}

\subsection{NF-kB expression and activity in HaCaT keratinocytes}

Previous studies showed the importance of NF-KB signaling in regulating epidermal homeostasis. To date, predominantly the role of $p 50$ and $p 65$ has been examined in primary epidermal keratinocytes by overexpression of the single subunits and by downstream inactivity of the canonical pathway using constitutively active inhibitory mutants of IKBa (Seitz et al., 1998; van Hogerlinden et al., 1999). Since various NF-KB subunits exert distinct functions as shown by knockout mice targeting single NF-KB subunits, this thesis aimed at elucidating the impact and contribution of the single NF-KB subunit in respect to cell fate decisions of keratinocytes.

As starting experiments, mRNA and protein expression was confirmed for all NF-KB subunits along with determining subcellular protein distribution patterns using the spontaneously immortalized keratinocyte cell line HaCaT (Boukamp et al., 1988).

Analysis of NF-KB gene expression by semi-quantitative RT-PCR with varying cycle counts revealed a relative stronger expression of $N F K B 1$ (encoding for $\mathrm{p} 105 / \mathrm{p} 50$ ) and REL (encoding for c-Rel) compared to RELA, NFKB2 (encoding for $\mathrm{p} 100 / \mathrm{p} 52$ ) and RELB (Figure $6 A)$. On the protein level, expression of all five subunits could be already shown with total protein load of $20 \mu \mathrm{g}$ (Figure 6B). In immunofluorescence studies, subcellular expression patterns were analyzed and a consistent, predominantly cytoplasmic staining of all five subunits could be observed (Figure 6C). Additionally, RelB immunofluorescence staining revealed small perinuclear speckles and staining for c-Rel showed small intranuclear speckles. However, downregulation of RelB and c-Rel resulted in persistence of the speckles suggesting an unspecific staining pattern. 
A

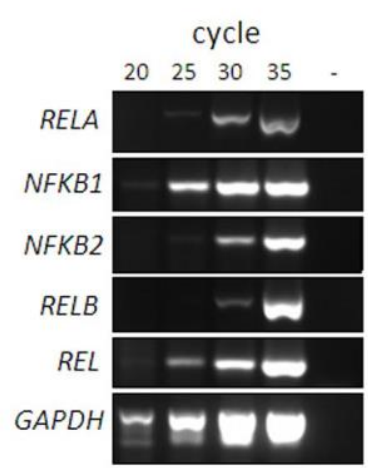

C
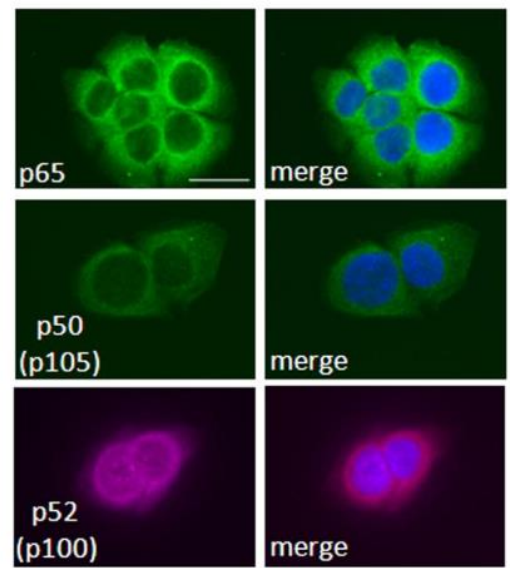

B
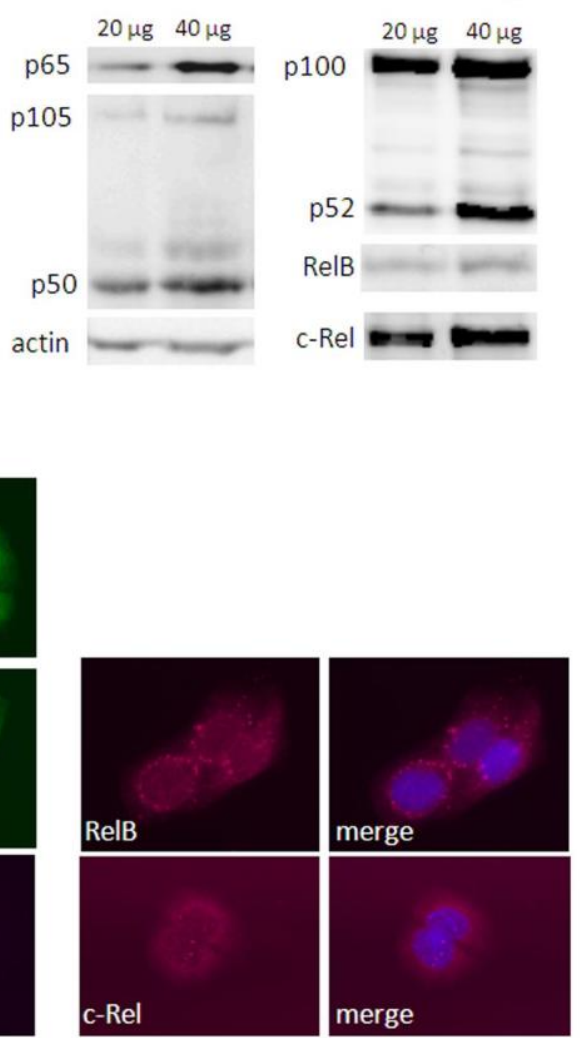

Figure 6: All NF-KB subunits are expressed in HaCaT keratinocytes.

(A) Semi-quantitative RT-PCR of unstimulated $\mathrm{HaCaT}$ cells for the NF-KB subunits with different cycle counts $(20-35)$. GAPDH served as positive control, $(-)=$ negative control. (B) Western blotting of $20 \mu \mathrm{g}$ and $40 \mu \mathrm{g}$ whole cell lysate of unstimulated HaCaT cells with antibodies directed against all NF-KB proteins. Actin served as loading control. (C) Immunofluorescence stainings of all NF-KB subunits in HaCaT keratinocytes. Samples stained for p65 and p50 were incubated with anti-mouse secondary antibody conjugated with AlexaFluor 488, whereas samples stained for p52, RelB and c-Rel were incubated with anti-rabbit secondary antibody conjugated with AlexaFluor 555. On the right side, photographs were merged with DAPI stained nuclei. One of two resembling experiments is shown representatively. Bar $=20 \mu \mathrm{m}$.

To further examine the functional activity of NF-KB in HaCaT keratinocytes, electrophoretic mobility shift assays (EMSAs) were performed with unstimulated and TNF $\alpha$-stimulated nuclear HaCaT lysates as positive control (Figure 7A). After exclusion of unspecific bands detected by the cold probe (CP), two specific bands could be shown (two arrows). Both bands indicate activity of NF-KB dimers composed of different NF-KB proteins. Therefore, EMSA supershifts were used to uncover these dimer complexes (Figure 7B). For positive control, a shifted signal (lower arrow) and a supershifted signal were detected for p65 (upper arrow). 
For the unstimulated sample, a shifted but no supershifted signal became obvious for p65, p52, RelB or c-Rel respectively. On the right, a single p50 EMSA supershift is depicted with unstimulated and TNF $\alpha$-stimulated lysate revealing a shift but no supershift (Figure 7B). However, the shifted signal was consequently reduced by the addition of antibody and for p65, p52 and c-Rel supershift samples, some brighter bands appeared at a higher molecular weight. Since supershifted bands should resemble the additional band in the positive control, the fainter signals were interpreted as unspecific bands.

Conclusively, moderate NF-KB activity in unstimulated HaCaT cells could be shown even though no discrimination in single subunit composition could be made. 
A

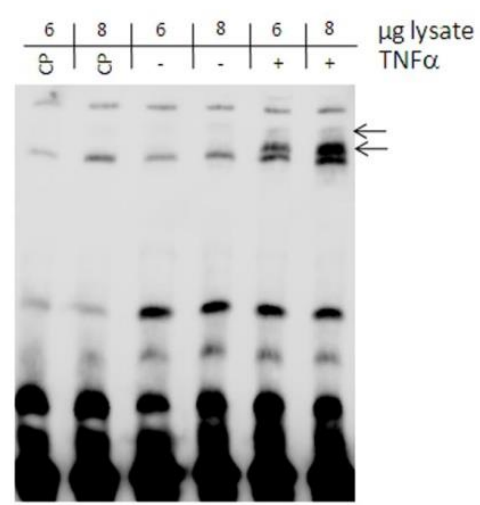

B

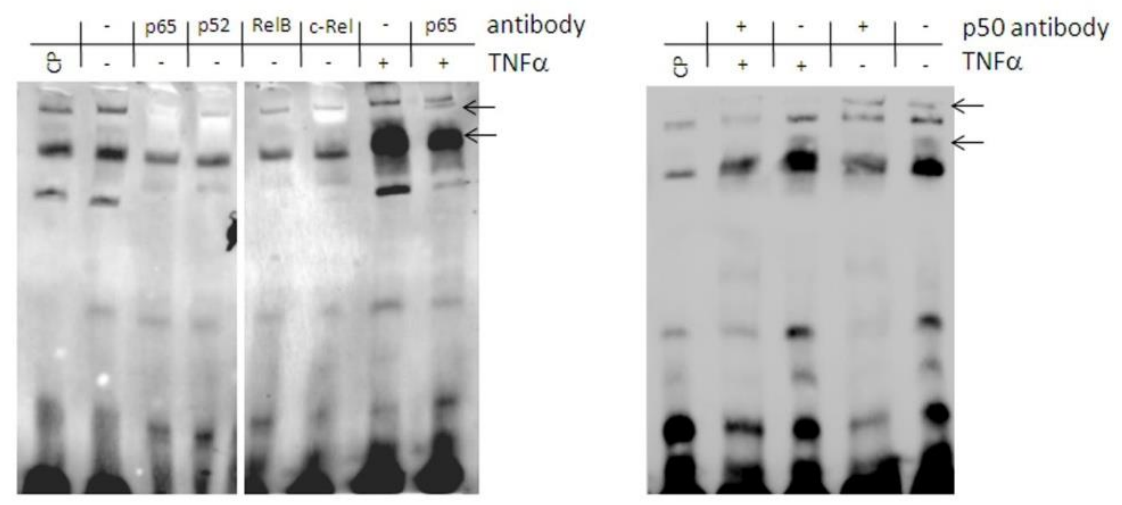

Figure 7: Basal NF-KB activity in HaCaT cells.

(A) Electrophoretic mobility shift assay (EMSA) of $6 \mu \mathrm{g}$ and $8 \mu \mathrm{g}$ unstimulated HaCaT nuclear lysate either as a cold probe (CP) showing unspecific bands, unstimulated (-TNF $\alpha$ ) or stimulated with $30 \mathrm{ng} / \mathrm{ml} \mathrm{TNF} \alpha$ for $30 \mathrm{~min}$ as positive control (+TNFa). Arrows on the right indicate specific NF-KB signals. (B) EMSA supershift of $15 \mu \mathrm{g} \mathrm{HaCaT}$ nuclear lysate applied as a cold probe (CP), without incubated antibody (-/-) or incubated with the respective antibody as indicated above. As positive control served $15 \mu \mathrm{g}$ of $30 \mathrm{ng} / \mathrm{ml} 30 \mathrm{~min}$ TNF $\alpha$ stimulated HaCaT nuclear lysate incubated without or with $2 \mu \mathrm{g}$ p65 antibody. A supershift band is indicated by superior arrow, shift band by the arrow below. On the right, a supershift for $p 50$ is shown, containing cold probe, unstimulated and TNF $\alpha$ stimulated sample with or without addition of p50 antibody. One of two representative experiments is shown here.

The proliferative potential of keratinocytes depends, amongst other factors, on its confluency. When keratinocytes become confluent, they usually stop proliferating and start the program of cellular differentiation. To include this aspect into our studies, we investigated the dependency of keratinocyte confluency on distribution and expression of NF-KB subunits. For this purpose, HaCaT keratinocytes were harvested at a low (30\%) and high ( $80 \%$ ) density (Figure $8 \mathrm{~A}$ ). Subcellular protein distribution was analyzed by generation of cytoplasmic and nuclear lysates (Figure 8B); cytoplasmic p50 increased twofold at higher cell density whereas c-Rel was about $40 \%$ induced in the cytoplasm. 
Nuclear localization however remained stable for both proteins. Even though RelB and p52 seem to be localized confluence-dependent as well, this could not be shown repeatedly.

Furthermore, whole protein content was analyzed by western blotting showing about twofold induction of p50 and about $50 \%$ induction of c-Rel at higher density (Figure $8 C$ ). However, examining mRNA expression via semi-quantitative PCR with varying cycle counts, no confluency-specific changes were obvious for NFKB1 or REL (Figure 8D) indicating for post-transcriptional regulatory mechanism.

Conclusively, induction of p50 and c-Rel at higher confluency indicates involvement in processes like growth inhibition or differentiation. Since up-regulation was predominantly cytoplasmic, we can only speculate about the exact mode of action at this time. However, subsequent functional studies aimed at elucidating this issue. 
A

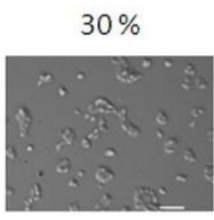

$80 \%$

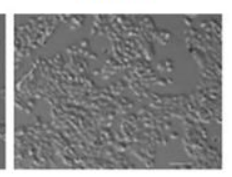

B

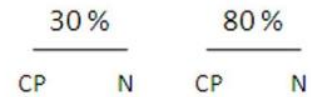

$\mathrm{p} 50$

p52

RelB

c-Rel

lamin
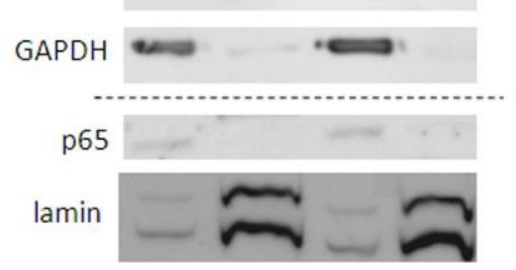

GAPDH
C

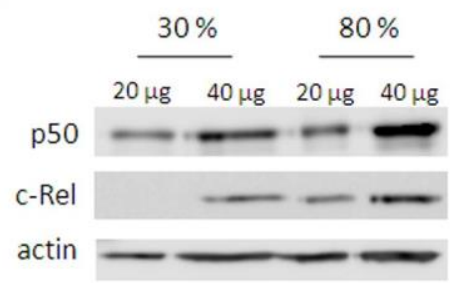

D

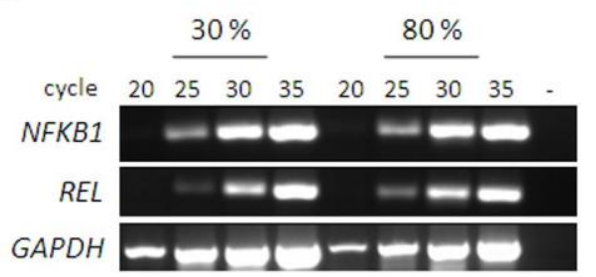

Figure 8: Confluence-dependent expression pattern of p50 and c-Rel in HaCaT keratinocytes.

(A) Representative phase contrast photographs of $30 \%$ and $80 \%$ confluent HaCaT cells. Bar= $100 \mu \mathrm{m}$. (B) Western blotting of $40 \mu \mathrm{g}$ cytoplasmic (CP) and nuclear (N) lysates of $30 \%$ as well as of $80 \%$ confluent HaCaT cells, respectively. Lamin and GAPDH served as loading and quality controls of the lysates. (C) Western blotting of p50 and c-Rel of $20 \mu \mathrm{g}$ and $40 \mu \mathrm{g}$ whole cell lysate of $30 \%$ and $80 \%$ confluent $\mathrm{HaCaT}$ cells, respectively. Actin served as loading control. (D) Semi-quantitative PCR of NFKB1 and REL of $30 \%$ as well as of $80 \%$ confluent HaCaT keratinocytes with varying cell cycle counts (20 - 35). GAPDH served as positive control. Generally, one of at least two representative experiments is shown.

\subsection{Functional effects of NF-kB downregulation on $\mathrm{HaCaT}$ keratinocytes}

As aforementioned, our studies targeted at unraveling the function of the single NF-KB subunits with special regard to cell fate decisions and epidermal homeostasis. In previous studies, inhibition of both p50 and p65 by forced expression of an IkBa mutant led to increased proliferation of human keratinocytes in vitro (Seitz et al., 1998; van Hogerlinden et al., 1999) whereas data for p52, RelB or c-Rel are scant. 
We therefore yielded to downregulate the abovementioned subunits by transient transfection of NF-KB specific siRNA constructs. Transfection with control siRNA proven to have no effect on any eukaryotic transcript served as control.

Successful downregulation via siRNA transfection of the respective NF-KB subunit was confirmed by western blotting. Each remaining protein level accounted between $20-30 \%$ of control siRNA level as determined by densitometry (Figure 9).

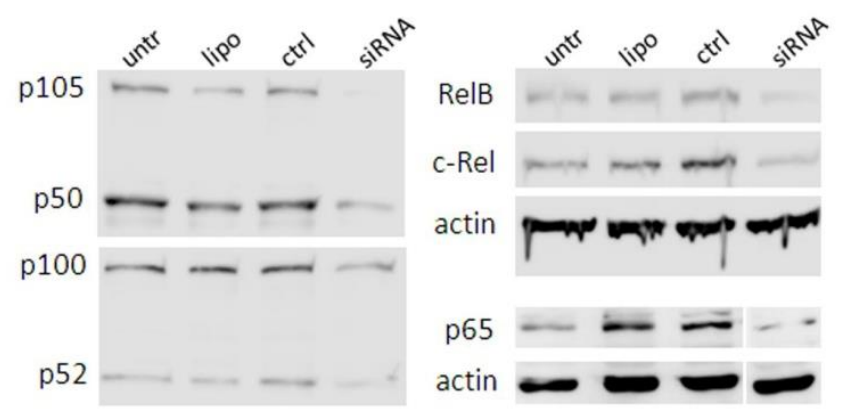

Figure 9: Efficient downregulation of all NF-KB proteins after siRNA transfection in HaCaT cells. Western blotting of $50 \mu \mathrm{g}$ whole cell lysate of untreated (untr), lipofectamine treated (lipo), control siRNA (ctrl) and the respective NF-KB siRNA (siRNA) treated HaCaT cells $72 \mathrm{~h}$ after treatment. Actin served as loading control.

Subsequent studies aimed at unraveling functional consequences of downregulation of each of the five NF-KB subunits in HaCaT cells. Initially, cell viability was studied, both $48 \mathrm{~h}$ and $72 \mathrm{~h}$ after transfection (Figure 10A). A clear and consistent effect was obvious $72 \mathrm{~h}$ after transfection for c-Rel siRNA transfected HaCaT cells. Compared to control, viability was about $55 \%$ reduced $(p<0.05)$ whereas downregulation of other NF-KB subunits did not induce a consistent effect regarding cell viability.

MTT cell viability assays are used to determine the number of living cells by conversion of a tetrazolium salt into a formazan product, however they do not discriminate between resting and proliferating cells. 
Therefore, proliferation of NF-KB downregulated HaCaT cells was determined by measuring incorporation of the thymidine analogue BrdU into the genome of replicating cells (Figure 10B). Respective experiments revealed a decreased proliferation of about $20 \%(p<0.05)$ for c-Rel siRNA treated cells.

In a next step, we examined whether any NF-KB knockdown has an effect on apoptosis of HaCaT cells by determining the amount of histone-bound DNA fragments. c-Rel downregulated HaCaT cells showed an increased apoptosis of about $25 \%(p<0.05$, Figure 10C). 
A
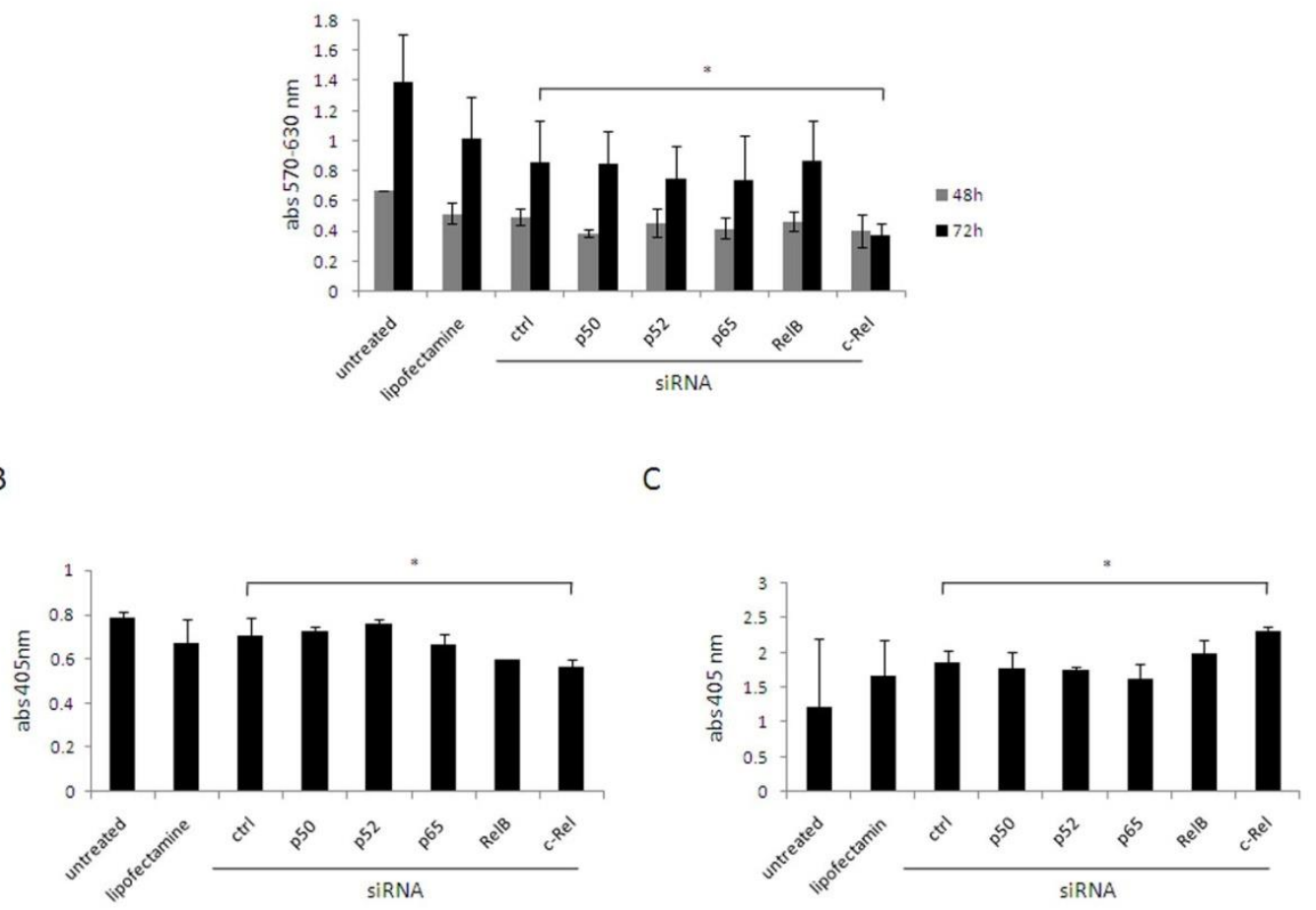

Figure 10: c-Rel downregulation impairs cell viability and proliferation and induces apoptosis in HaCaT cells.

(A) MTT viability assay of untreated, lipofectamine treated, control (ctrl) siRNA treated and NF-KB subunits siRNA treated HaCaT cells $48 \mathrm{~h}$ (grey bars) and $72 \mathrm{~h}$ (black bars) after transfection. Mean absorption values of two $(48 \mathrm{~h})$ and three $(72 \mathrm{~h})$ experiments are depicted here, every experiment was performed in triplicates, error bars are $\pm S D,{ }^{*}$ indicates $p \leq 0.05$. (B) BrdU incorporation assay of untreated, lipofectamine treated, control (ctrl) siRNA treated and NF-KB siRNA treated HaCaT cells $72 \mathrm{~h}$ after transfection. Three independent experiments revealed similar results, one is representatively shown here, error bars are $\pm S D, * p \leq 0.05$. (C) Apoptosis assay of untreated, lipofectamine treated, control (ctrl) siRNA treated and NF-KB siRNA treated HaCaT cells $72 \mathrm{~h}$ after transfection. Mean absorbance values of three independent experiments are depicted, every experiment was performed in triplicates, error bars are $\pm S D, *$ indicates $p \leq 0.05$.

In summary, c-Rel knockdown significantly affected cell growth by reducing proliferation and increasing apoptosis of $\mathrm{HaCaT}$ cells in contrast to p50, p65, RelB or p52 knockdown. Therefore, we focused our subsequent studies on c-Rel downregulation to unravel its impact on epidermal homeostasis and cell fate decisions in keratinocytes. 


\section{3 c-Rel downregulation related effects in $\mathrm{HaCaT}$ keratinocytes}

\subsection{1 c-Rel downregulation induces growth reduction and cell cycle changes}

Before studying c-Rel siRNA related effects in more detail, specificity of the chosen siRNA was tested regarding two aspects. First, two other c-Rel siRNAs (c-Rel siRNA II and III) besides the initially used (c-Rel siRNA I) were transfected to test specificity of the siRNA construct. Again, cell viability was examined $72 \mathrm{~h}$ after transfection (Figure 11A). Both constructs yielded similar effects with $42 \%$ reduced viability for c-Rel siRNA II $(p<0.001)$ and $46 \%$ reduced viability for $c-$ Rel siRNA III $(p<0.01)$, thereby confirming c-Rel specific effect with c-Rel siRNA I-related reduction being slightly more pronounced (66\% reduced, $\mathrm{p}<0.001)$.

Second, because c-Rel downregulation might influence other NF-KB protein expression levels due to the high homology among the NF-kB subunits or other compensatory mechanisms, western blotting was performed for all five subunits but no influence on any other NF-KB protein level except c-Rel was observed (Figure 11B).

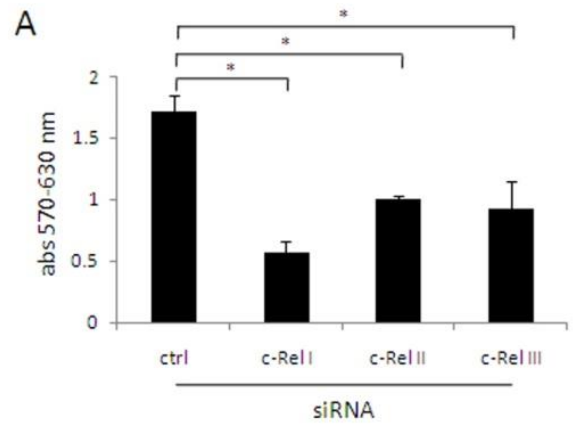

B

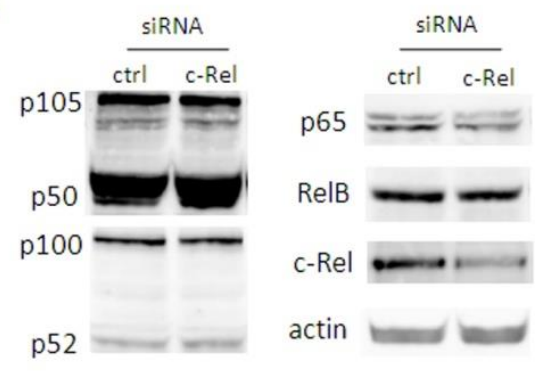

Figure 11: c-Rel downregulation is specific and does not affect any other NF-kB protein level in HaCaT keratinocytes.

(A) MTT viability assay of control (ctrl) siRNA transfected HaCaT cells as well as HaCaT cells transfected with three different c-Rel siRNAs (I, II and III) $72 \mathrm{~h}$ after transfection. Error bars are $\pm S D, *$ indicates $p \leq 0.05$. (B) Western blotting of $50 \mu \mathrm{g}$ whole cell lysate of control (ctrl) and c-Rel siRNA treated $\mathrm{HaCaT}$ cells $72 \mathrm{~h}$ after transfection. Actin served as loading control. The experiment was performed twice with similar results. 
To study growth characteristics of c-Rel downregulated HaCaT cells over a period of time, the number of adherent cells was documented and counted at $24 \mathrm{~h}$ intervals up to $96 \mathrm{~h}$ after transfection (Figure $12 \mathrm{~A}$ and $\mathrm{B}$ ). Both control and c-Rel siRNA cell growth remained similar until $48 \mathrm{~h}$ after transfection. Thereafter, control cells grew faster and reached confluency $96 \mathrm{~h}$ after transfection whereas growth of c-Rel downregulated cells remained static and was significantly reduced compared to control cells, about $70 \%$ $(p<0.001) 72 \mathrm{~h}$ after transfection and even more than $85 \%(p<0.001) 96 \mathrm{~h}$ after transfection. HaCaT cells still retain the ability to differentiate. Because differentiation is a confluency-dependent process, cell confluency impedes comparability of the samples. Therefore, $72 \mathrm{~h}$ after transfection proved to be an optimal measurement point: On the one hand, decreased proliferation of c-Rel downregulated HaCaT cells was obvious while on the other hand, control cells were still sub-confluent excluding differentiationassociated changes of the cells.

A

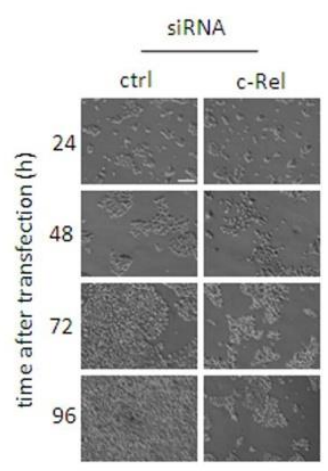

B

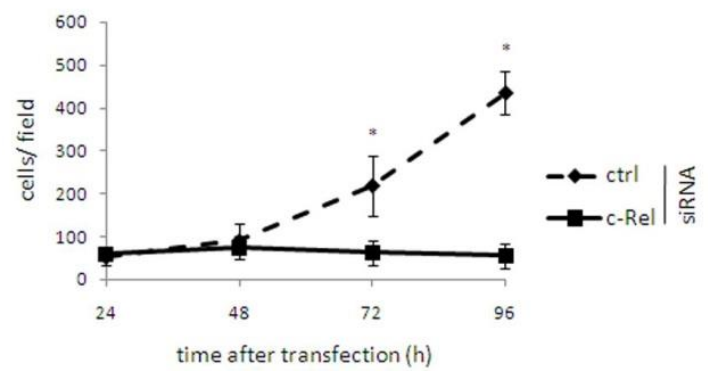

Figure 12: Time-related growth inhibition of c-Rel downregulated HaCaT cells.

(A) Exemplary photographs of control (ctrl) and c-Rel siRNA cells from 24 to $96 \mathrm{~h}$ after transfection (bar= $100 \mu \mathrm{m}$ ). (B) Growth curve of control (ctrl) and c-Rel siRNA cells on tissue-culture treated wells from 24 to $96 \mathrm{~h}$ after transfection. Curve represents mean cell numbers of least six microscopic fields $(x 160)$ evaluated using ImageJ. One of three experiments with similar results is representatively shown, error bars are $\pm S D, *$ indicates $p \leq 0.05$.

Subsequently, to further examine the observed growth reduction of c-Rel downregulated cells, cell cycle phase distribution of vital control and c-Rel knockdown cells was determined $72 \mathrm{~h}$ after transfection (Figure 13). 
Using flow cytometry to analyse the cell cycle, cells can be classified based on their DNA content into G0/G1 phase cells with a single set of chromosomes (first peak), S-phase cells duplicating their genome (elevated region between both peaks) and G2/M phase cells with a double set of chromosomes which either reside in G2 phase preparing for mitosis or which are mitotic (second peak) (Momoi et al., 1979). An overlay of one representative histogram of control and c-Rel knockdown cells points to an increased portion of c-Rel knockdown cells in G2/M phase as shown by the elevated second peak (Figure 13A). Overall, mean distribution values revealed an increase of c-Rel knockdown cells in G2/M cell portion of about $40 \%$ compared to control cells ( $28.78 \%$ vs. $20.65 \%$ of vital cells, $p<0.05$, Figure 13B).

A

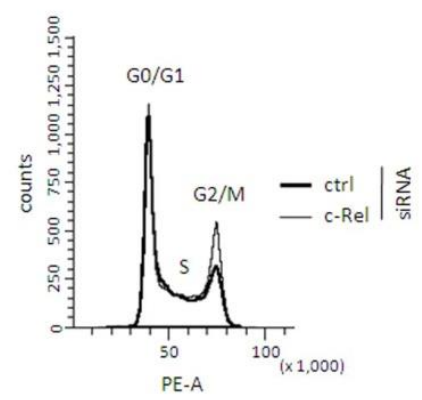

B

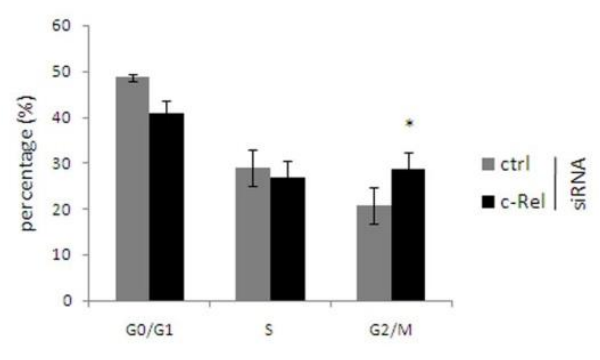

Figure 13: Induction of G2/M phase cell portion in c-Rel downregulated HaCaT cells.

(A) Overlay of one exemplary cell cycle phase histogram of vital control (ctrl, thicker line) and c-Rel (thinner line) siRNA cells $72 \mathrm{~h}$ after transfection. Each cell cycle phase is additionally marked. (B) Diagram of cell cycle phase distribution of vital control (ctrl, grey bar) and c-Rel siRNA transfected cells (black bar) $72 \mathrm{~h}$ after transfection. Data represents mean distribution values of four independent experiments, error bars are $\pm S D, *$ indicates $p \leq 0.05$.

Due to the determined shift in cell cycle phase distribution, we examined this effect more closely by investigating the expression level of cell cycle regulatory proteins, involved in both the G1/S phase- and the G2/M phase checkpoint. Furthermore, to investigate whether c-Rel knockdown-related growth inhibition may be associated with differentiation (a result of keratinocytes exiting G1 phase), we also included the early differentiation marker involucrin into our studies. 
By western blotting, no expression change of the early differentiation marker involucrin was observed for c-Rel downregulated cells suggesting no further effects on differentiation (Figure 14A). However, of all examined G1/S phase related proteins, a consistent, twofold upregulation of $\mathrm{p} 15^{\mathrm{INK} 4 \mathrm{~B}}$ could be detected (Figure 14B). Further consistent expression changes in cyclin D1 or D3, CDK4 or CDK6 or other CKIs did not occur. The INK4 protein family member $\mathrm{p} 15^{\mathrm{INK} 4 \mathrm{~B}}$ is usually activated by anti-mitogenic stimuli leading to cyclin dependent kinases (CDK) binding, thus preventing them from complexing with cyclin $D$ at the transition from $G 1$ to $S$ phase. Based on our findings, we hypothesized that $\mathrm{p} 15^{\mathrm{INK} 4 \mathrm{~B}}$ upregulation leads to a - yet undiscovered - G1 phase arrest. To study this issue, control and c-Rel siRNA cells were treated with $50 \mathrm{ng} / \mathrm{ml}$ nocodazole to arrest them in mitosis. $16 \mathrm{~h}$ after nocodazole addition and $72 \mathrm{~h}$ after transfection, both samples were harvested and subjected to flow cytometry cell cycle analysis (Figure 14C). However, analysis showed no additional G1 phase peak for c-Rel knockdown cells suggesting that $\mathrm{p} 15^{\mathrm{INK} 4 \mathrm{~B}}$ upregulation alone is not sufficient to induce $\mathrm{G} 1$ phase arrest. 


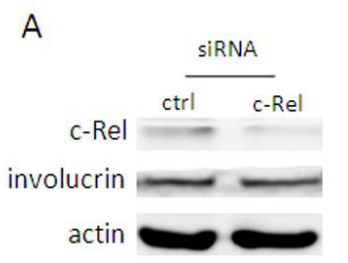

B

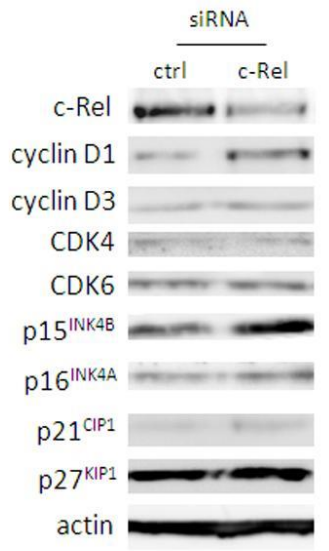

C

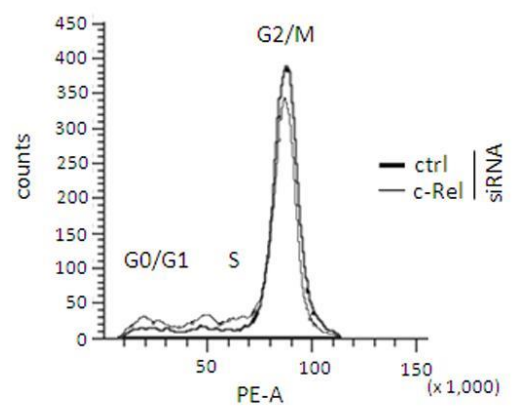

Figure 14: c-Rel downregulation induces $\mathrm{p} 15^{\mathrm{INK} 4 \mathrm{~B}}$ expression but no subsequent $\mathrm{G} 1$ phase arrest in HaCaT keratinocytes.

(A) Western blotting of $50 \mu \mathrm{g}$ whole cell lysate of control (ctrl) and c-Rel downregulated HaCaT cells $72 \mathrm{~h}$ after transfection examining early differentiation marker involucrin. Actin served as loading control and one of two representative experiments is shown here. (B) Western blotting of $50 \mu \mathrm{g}$ whole cell lysate of control (ctrl) and c-Rel downregulated HaCaT cells $72 \mathrm{~h}$ after transfection regarding $\mathrm{G} 1 / \mathrm{S}$ phase related protein expression. Actin served as loading control and one of three representative experiments is shown here. (C) Overlay of one cell cycle histogram of control (ctrl) and c-Rel siRNA cells with indicated cell cycle phases. Control and c-Rel siRNA transfected cells were treated with $50 \mathrm{ng} / \mathrm{ml}$ nocodazole for $16 \mathrm{~h}$ and were then, $72 \mathrm{~h}$ after transfection, subjected to cell cycle analysis.

In summary, c-Rel downregulation could be associated with upregulation of G1/S phase regulator $\mathrm{p} 15^{\mathrm{INK} 4 \mathrm{~B}}$ whereas no impact on cell cycle progression or on expression level of early differentiation marker involucrin could be shown.

Furthermore, G2/M cell cycle checkpoint related protein expression was analyzed by western blotting (Figure 15A). Downregulated c-Rel cells showed a distinct increase of phosphorylated histone $\mathrm{H} 3$ at $\operatorname{Ser} 10\left(\mathrm{p}-\mathrm{H} 3^{\operatorname{Ser} 10}\right)$ compared to control levels (Figure 15A). For quantitative evaluation, we subsequently determined the portion of $\mathrm{p}-\mathrm{H} 3^{\mathrm{Ser} 10}$ positive cells of control and c-Rel knockdown cells by immunofluorescence (Figure 15B and C). In these stainings, an about threefold increase in the percentage of $\mathrm{p}-\mathrm{H} 3^{\mathrm{Ser} 10}$ positive cells could be detected for c-Rel downregulated HaCaT cells (5.89\% vs. $1.89 \%, p<0.01$ ).

For cyclin A2, cyclin B1 and the active (phosphorylated) form of cdc2 or wee1, no consistent expression changes could be observed in several independent experiments. 
A

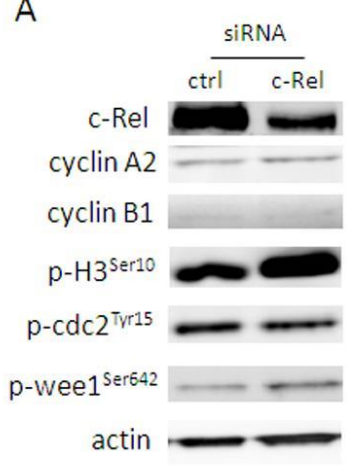

B

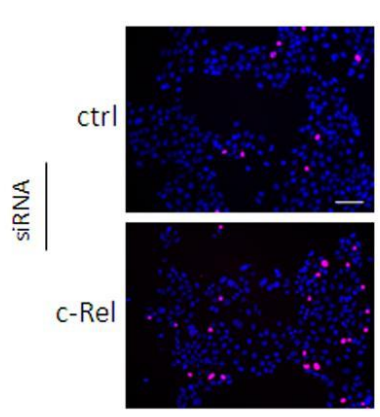

C

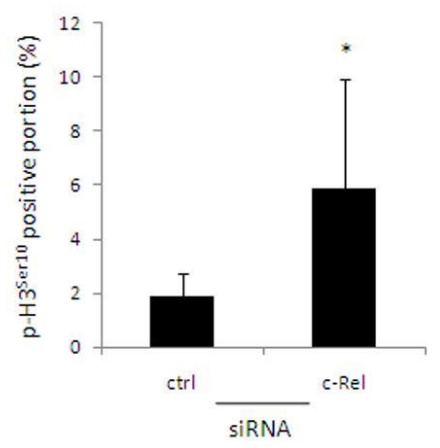

Figure 15: Induction of phospho-histone $\mathrm{H}^{\mathrm{Ser10}}$ in c-Rel downregulated HaCaT cells.

(A) Western blotting of $50 \mu \mathrm{g}$ whole cell lysate of control (ctrl) and c-Rel siRNA cells examining G2/M phase cell cycle related protein expression $72 \mathrm{~h}$ after transfection. Actin served as loading control and one of three similar independent experiments is shown here. (B) Exemplary photographs of $\mathrm{p}-\mathrm{H} 3^{\mathrm{Ser} 10}$ immunofluorescence staining of control (ctrl) and c-Rel siRNA cells are depicted $72 \mathrm{~h}$ after transfection, digitally enhanced with Axiovision software Rel 4.7. Secondary anti-rabbit antibody was labeled with Alexa Fluor 555 and nuclei were counterstained with DAPI (bar $=100 \mu \mathrm{m}$ ). (C) Quantitative evaluation of $\mathrm{p}-\mathrm{H} 3^{\text {Ser10 }}$ positive cell portions of at least ten microscopic fields of view $(x 100)$. One of two independent experiments is representatively shown here, error bars are $\pm S D, *$ indicates $p \leq 0.05$.

Condensed chromosomes show phosphorylated histone H3 at Ser10 starting in late G2 phase reaching its maximum during metaphase and disappearing in late anaphase or early telophase (Hendzel et al., 1997).

Since the chromosomal passenger complex (CPC) regulates this phosphorylation event, we hypothesized a dysregulated CPC complex by c-Rel downregulation. As one component of the CPC, we studied subcellular localization of survivin by immunofluorescence and its expression status. Immunofluorescence co-staining with c-Rel showed similar localization of survivin during later mitotic stages of c-Rel and control siRNA cells as highlighted in the enlarged boxes, however, pro- and metaphase signals were only hardly detectable (Figure 16A). Furthermore, neither western blot analysis (Figure 16B) nor semi-quantitative PCR revealed any expression changes (Figure 16C). Based on recent experiments, no indications for CPC dysregulation were given. 

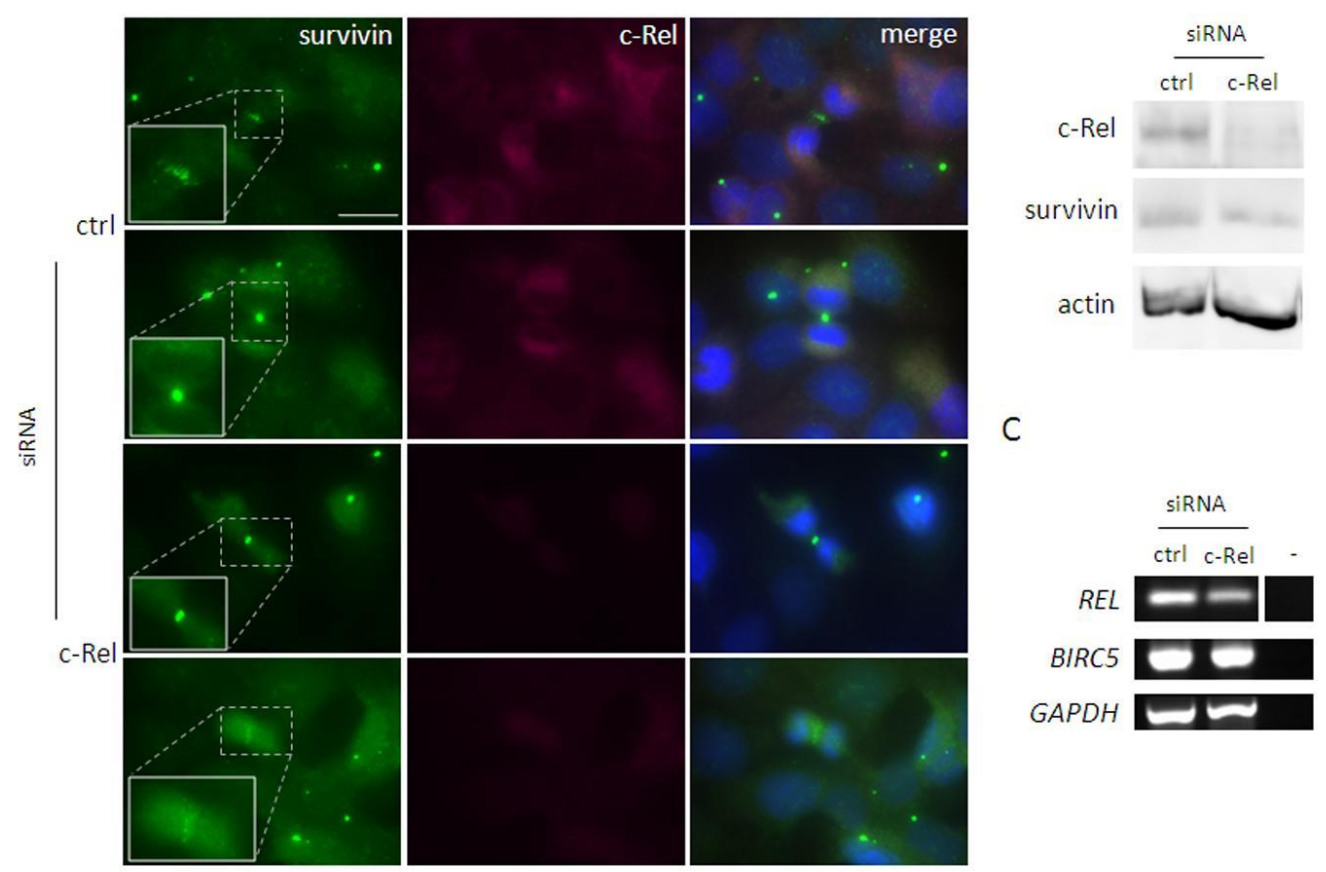

Figure 16: Stable survivin localization and expression in c-Rel downregulated HaCaT cells.

(A) Representative photographs of survivin and c-Rel immunofluorescence co-stainings of control (ctrl) and c-Rel siRNA cells $72 \mathrm{~h}$ after transfection in later mitotic stages. Secondary anti-mouse Alexa Fluor 488 antibody was used for detection of survivin and anti-rabbit Alexa Fluor 555 antibody for detection of c-Rel. Both, control and c-Rel siRNA samples were subjected to the same exposure time, nuclei were counterstained with DAPI (bar= $20 \mu \mathrm{m}$ ). (B) Western blotting of $50 \mu \mathrm{g}$ whole cell lysate of control (ctrl) and c-Rel siRNA cells $72 \mathrm{~h}$ after transfection. c-Rel served as positive control and actin as loading control. (C) Semi-quantitative PCR of BIRC5 (gene encoding for survivin) of control (ctrl) and c-Rel siRNA cells $72 \mathrm{~h}$ after transfection. REL PCR confirms successful downregulation, GAPDH served as positive control. All experiments were performed twice with similar results.

As aforementioned, phosphorylation of histone $\mathrm{H}^{\mathrm{Ser} 10}$ appears mostly during mitotic stages. To directly examine mitotic characteristics of c-Rel and control siRNA cells, ß-tubulin immunofluorescence stainings were performed to identify cells with mitotic spindles (Figure 17B). Subsequently, portion of cells in mitosis was determined via immunofluorescence and revealed a significant, almost twofold induction of c-Rel knockdown cells $(7.77 \%$ vs. $4.25 \%, p<0.05)$. 
Thus, c-Rel downregulation increased the percentage of cells in mitosis while concomitantly showing reduced cell viability. We therefore hypothesized that mitotic dysregulation may cause accumulation of mitotic cells. To further study this issue, mitotic spindle structures were examined with respect to potential formation defects since dysregulation of bipolar spindle assembly can abrogate proper mitotic proceeding.

Indeed in our studies, a distinctly higher portion of aberrantly structured mitotic spindles was obvious for c-Rel knockdown cells compared to control siRNA cells $(5.97 \%$ vs. $1.46 \%, p<0.001$, Figure 17B). Typical examples of how aberrant mitotic spindles were structured are depicted in Figure 17A. Generally, spindles appeared to be less organized: Many aberrant spindles remained monopolar and were located in the center of the mitotic cell with astral microtubules pointing outwards (arrows Figure 17A). When spindles were bipolar, they often seemed to be disproportionally arranged and lacked the typical geometry of metaphase spindles (arrowheads Figure 17A). To more precisely characterize this formational defect, we classified the spindles according to their appearance into mono-, bi- or multipolar spindles (Figure 17C).

According to this sub-classification, the most distinct feature was an about fourfold increased portion of monopolar spindles for c-Rel downregulated cells $(86.62 \%$ vs. $21.17 \%, p<0.01)$. Contrary, the bipolar spindle appearance was significantly reduced for c-Rel downregulated cells ( $8.81 \%$ vs. $67.17 \%, p<0.05)$ whereas the portion of multipolar spindles remained comparable to control siRNA cells. 
A

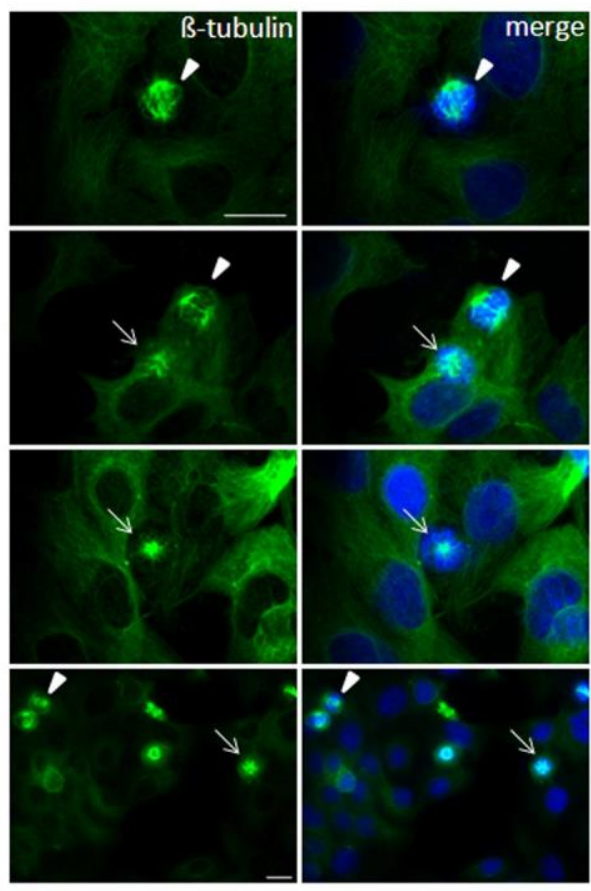

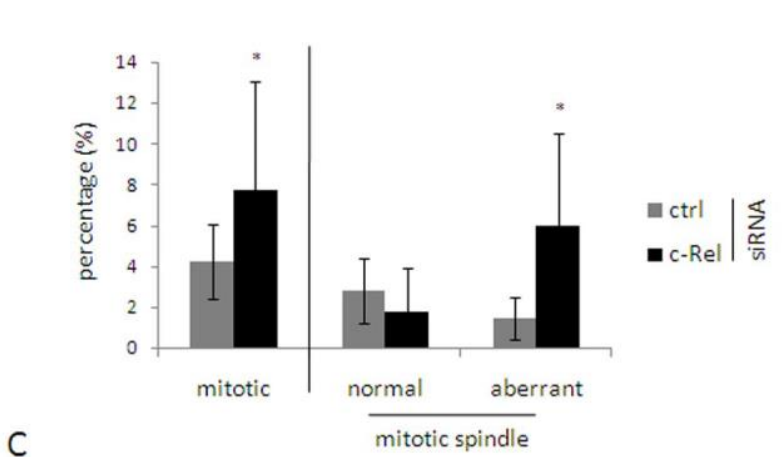

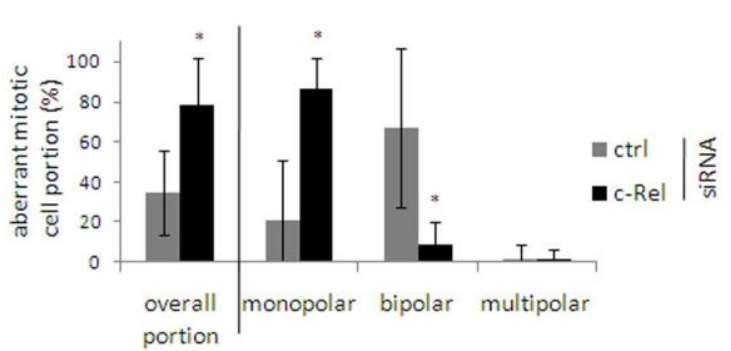

Figure 17: Increased mitotic cell portion and aberrant mitotic spindle formation in c-Rel downregulated HaCaT cells.

(A) Exemplary photographs of ß-tubulin immunofluorescence stainings of mitotic c-Rel siRNA cells $72 \mathrm{~h}$ after transfection with aberrant spindle formation digitally enhanced with Axiovision software Rel 4.7. Arrowheads point at aberrantly structured bipolar spindles whereas arrows show aberrant spindles classified as monopolar. Secondary anti-mouse Alexa Fluor 488 antibody was used for detection of B-tubulin and nuclei were counterstained with DAPI (bar $=20 \mu \mathrm{m})$. (B) Quantitative evaluation of control (ctrl) and c-Rel siRNA mitotic cell portion of at least 19 microscopic fields (x200) additionally subdivided into normal and aberrant mitotic spindles. Classification based on immunofluorescence findings. One of three experiments is representatively shown here, error bars are $\pm S D$, * indicates $p \leq 0.05$. (C) Quantitative evaluation of aberrantly structured spindles of control (ctrl) and c-Rel siRNA cells subdivided into mono-, bi- or multipolar spindle morphology. Classification based on immunofluorescence findings. One of three experiments is representatively shown here, error bars are $\pm S D, *$ indicates $p \leq 0.05$.

In conclusion, c-Rel downregulated cells accumulate in G2/M phase and show induction of $\mathrm{p}-\mathrm{H} 3^{\mathrm{Ser} 10}$. In contrast to $\mathrm{p} 15^{\mathrm{INK} 4 \mathrm{~B}}$ upregulation, which did not affect $\mathrm{G} 1 / \mathrm{S}$ phase transition, $\mathrm{p}-\mathrm{H} 3^{\mathrm{Ser} 10}$ induction could be associated with additional changes. We detected an almost twofold increased number of cells in mitosis for c-Rel downregulated cells. When examining mitotic spindle formation, c-Rel downregulated cells showed a fourfold increase of aberrantly structured mitotic spindles. These structural abnormalities likely cause cell accumulation in mitosis due to disturbed mitotic proceeding. 


\subsubsection{Expression of c-Rel in mitotic HaCaT cells}

Since previous experiments indicated a role for c-Rel during mitosis, c-Rel expression and abundance in untreated mitotic $\mathrm{HaCaT}$ cells was examined by immunofluorescence and showed increased signal intensity of c-Rel in mitotic cells compared to surrounding interphase cells (Figure 18A).

To quantify this impression, HaCaT cells were forced into mitosis, either by nocodazole treatment (Figure 18B) or by synchronization (Figure 18C). Nocodazole prevents assembly of a proper mitotic spindle apparatus by disturbing microtubule dynamics and leads to artificial accumulation of cells in mitosis. After nocodazole treatment for $16 \mathrm{~h}$, about $80 \%$ of vital HaCaT cells remained in G2/M phase. Subsequent western blotting revealed an about twofold induction of c-Rel in nocodazole treated HaCaT cells (Figure 18B). Since nocodazole interferes with microtubule dynamics, synchronization of cells was used as a second method to support previous data without artificial interference into cellular metabolism. $\mathrm{HaCaT}$ cells were synchronized by serum starvation for $72 \mathrm{~h}$ and then released by serum addition. $6 \mathrm{~h}$ after serum addition, major part of vital HaCaT cells (84.7\%) remained in G0/G1 phase whereas 24 after serum addition, $59.2 \%$ vital cells were in G2/M phase and $28.8 \%$ in S phase. Again, a twofold induction of c-Rel could be determined densitometrically (Figure 18C). 
A

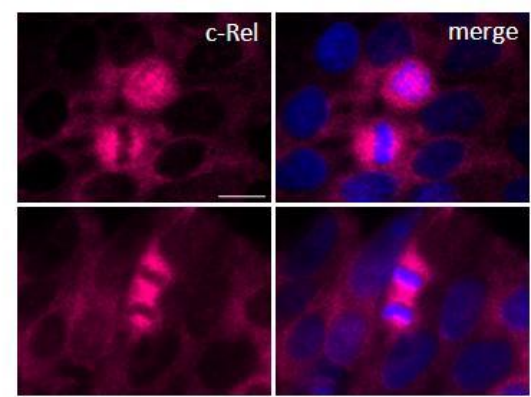

B

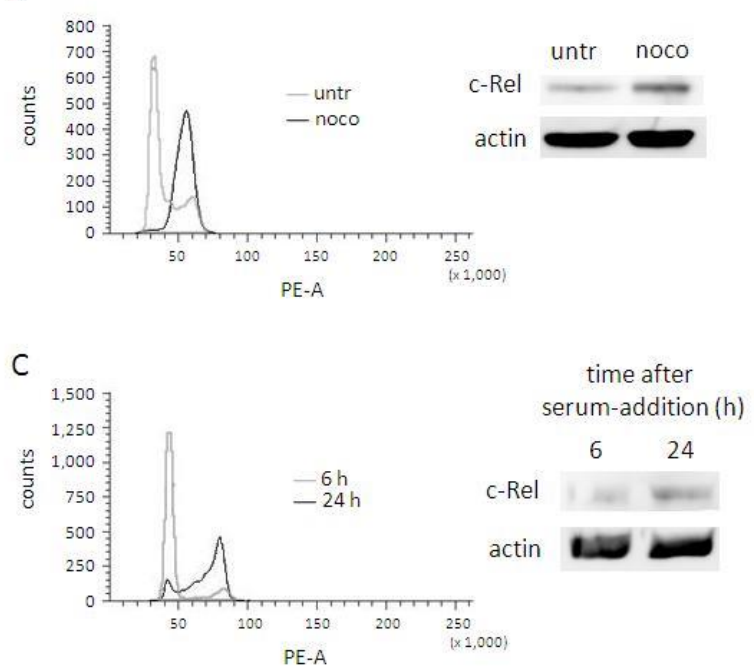

Figure 18: c-Rel expression is induced in mitotic HaCaT cells.

(A) Representative immunofluorescence photographs of mitotic HaCaT cells stained for c-Rel digitally enhanced with Axiovision software Rel 4.7. Secondary anti-rabbit Alexa Fluor 555 antibody was used for detection. Nuclei were counterstained with DAPI, bar $=20 \mu \mathrm{m}$. (B) On the left, flow cytometry cell cycle phase distribution of untreated (untr, grey line) HaCaT cells and cells treated with $30 \mathrm{ng} / \mathrm{ml}$ nocodazole for $16 \mathrm{~h}$ (noco, black line) is depicted. On the right, western blotting of $50 \mu \mathrm{g}$ whole cell lysate is shown examining c-Rel expression. Actin served as loading control and one of two similar experiments is shown. (C) On the left, flow cytometry cell cycle phase distribution of $48 \mathrm{~h}$ serum starved HaCaT cells $6 \mathrm{~h}$ after addition of serum ( $6 \mathrm{~h}$, grey line) and $24 \mathrm{~h}$ after serum addition ( $24 \mathrm{~h}$, black line) is depicted. On the right, western blotting of $50 \mu \mathrm{g}$ whole cell lysate of the same samples is shown examining c-Rel expression level. Actin served as loading control.

\subsubsection{Phenotypic changes of c-Rel downregulated HaCaT cells}

Another phenomenon induced by c-Rel downregulation was a phenotypic change of HaCaT cells (Figure 19). The cells had the tendency to lose their typical cobblestone-like morphology, they were elongated and more spindle-shaped on the single cell level (Figure 19A). Additionally, they grew more scattered compared to the keratinocyte-specific clustered growth of control siRNA cells (Figure 19B). 
A



B

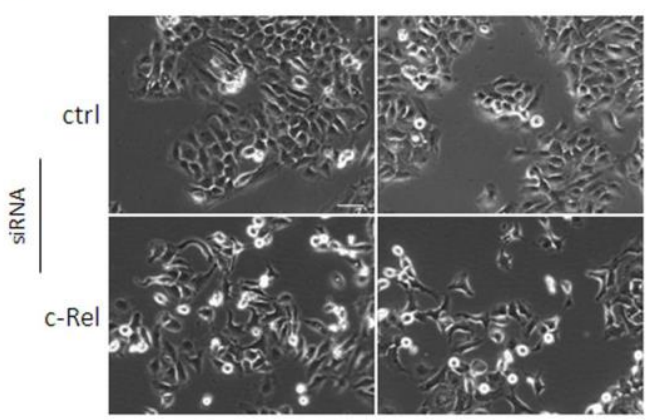

Figure 19: c-Rel downregulation alters HaCaT cell morphology to a more scattered, spindle shaped phenotype.

(A) Representative differential interference contrast (DIC) photographs of control (ctrl) and c-Rel knockdown cells $72 \mathrm{~h}$ after transfection (bar= $25 \mu \mathrm{m}$ ). (B) Representative phase contrast photographs of control (ctrl) and c-Rel knockdown cells $72 \mathrm{~h}$ after transfection (bar= $50 \mu \mathrm{m}$ ). These effects could be repeatedly observed $72 \mathrm{~h}$ after siRNA transfection.

Such morphological changes are characteristic for the process of epithelial mesenchymal transition (EMT) in which epithelial cells reduce their cell-to-cell contacts and gain mesenchymal characteristics such as a higher motility as well as a spindle-shaped phenotype. During recent years, EMT gained in importance due to its association with tumor progression (Gravdal et al., 2007; Hazan et al., 2004). EMT typically comprises differential expression of the calcium-dependent adhesion proteins cadherins involved in cell-to-cell contacts: the major cadherin form in epithelial cells, E-cadherin, switches towards expression of neural or N-cadherin (Boyer et al., 1989; Hay, 1995).

c-Rel downregulated HaCaT keratinocytes seemed to acquire EMT resembling qualities: loosening of cell-cell contacts as well as an elongated, singled phenotype. 
Therefore, expression of E-cadherin and N-cadherin were studied via immunofluorescence and western blot analysis (Figure 20A and B). However, no localization or expression changes could be observed in c-Rel downregulated HaCaT cells.

A

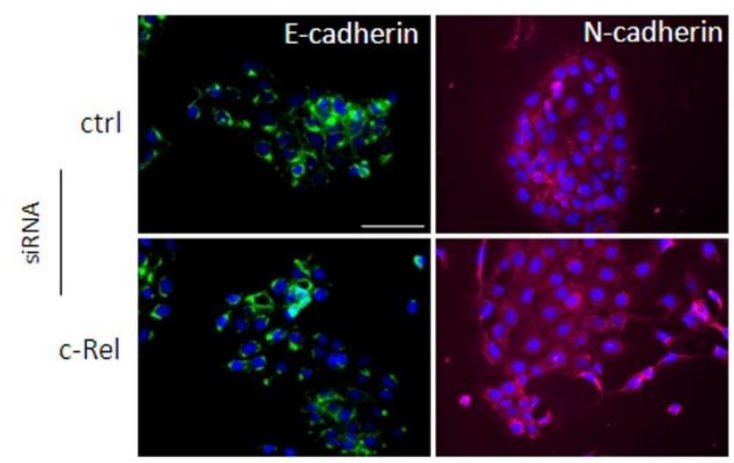

B

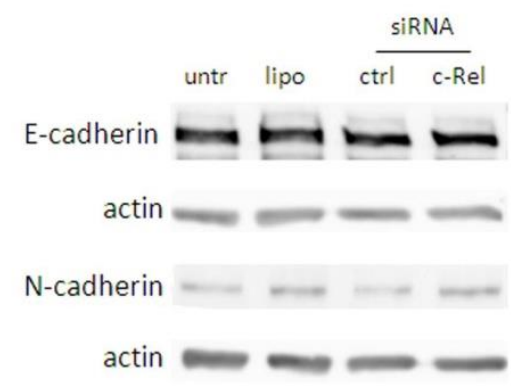

Figure 20: c-Rel downregulation reveals no changes of E-cadherin or $\mathbf{N}$-cadherin expression in HaCaT keratinocytes.

(A) Representative immunofluorescence photographs of control (ctrl) and c-Rel siRNA cells $72 \mathrm{~h}$ after transfection stained for $\mathrm{E}$ - and $\mathrm{N}$-cadherin. Secondary anti-mouse Alexa Fluor 488 antibody was used for detection of E-cadherin and anti-rabbit Alexa Fluor 555 antibody for detection of $\mathrm{N}$-cadherin. One of two representative experiments is shown here. Both ctrl and c-Rel siRNA samples were subjected to the same exposure time, nuclei were counterstained with DAPI, bar= $50 \mu \mathrm{m}$. (B) Western blotting of $40 \mu \mathrm{g}$ whole cell lysate of untreated (untr), lipofectamine treated (lipo), control siRNA (ctrl) and c-Rel siRNA (c-Rel) transfected cells after $72 \mathrm{~h}$ examining E-cadherin and $\mathrm{N}$-cadherin expression. Actin served in both cases as loading control and one of two experiments is depicted.

Another, more transitory process resulting in an EMT-resembling phenotype is wound healing or re-epithelialisation. 
After in vivo skin wounding, surrounding keratinocytes migrate to the wound bed, proliferate and finally differentiate. Likewise, migration during wound healing involves dissolution of cell-cell contacts, a change to a more flat and elongated phenotype as well as a different polarization (Sivamani, 2007, Kirfel and Herzog, 2004). Concomitant with this change, a different expression pattern of integrin surface receptors becomes apparent enabling the cells to gain a higher motility (Grinell, 1992). Typically, ß1 integrin upregulation can be observed during wound healing on the cellular surface, which we analyzed in further experiments along with one of its binding partners, $\alpha 2$ integrin (Figure 21). In a first approach using immunofluorescence studies, an increase of $\beta 1$ integrin was detectable for c-Rel knockdown cells compared to control siRNA cells (Figure 21A). Due to quantitative limitations of this method, surface expression was examined by flow cytometry analysis. Repeatedly, mean fluorescence intensity (MFI) of vital c-Rel downregulated cells resembled control cells (MFI of 11,937 vs. 12,828, Figure 21B). Therefore, even though immunofluorescence studies suggested differently, no upregulation of $ß 1$ integrin surface expression was verifiable. 
A

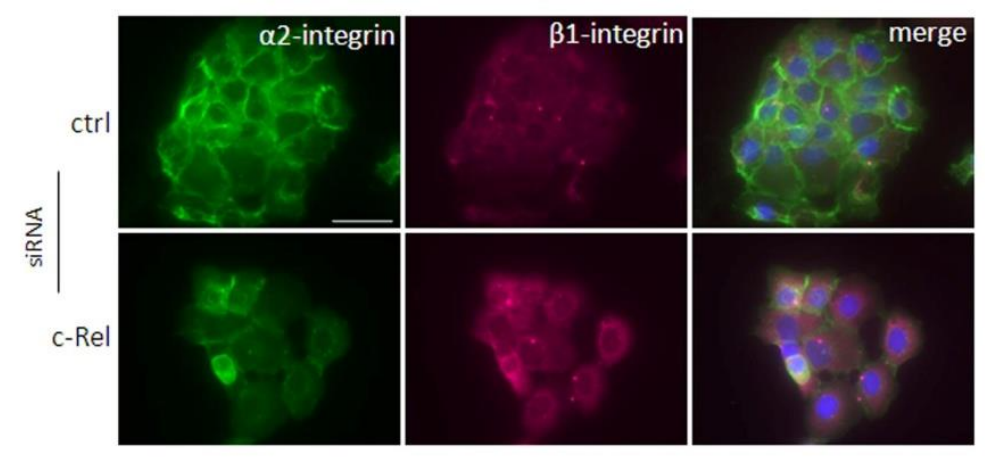

B

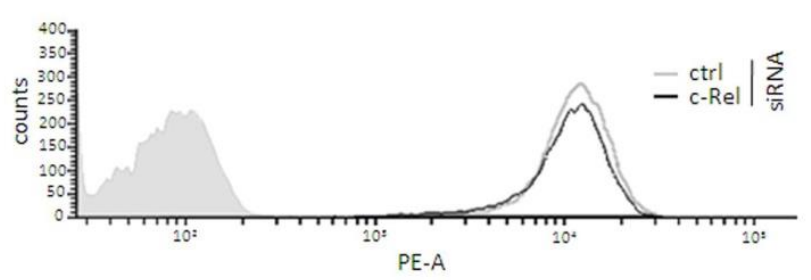

Figure 21: No changes in $\beta 1$ integrin surface expression on c-Rel downregulated HaCaT cells.

(A) Representative photographs of integrin $\alpha 2$ and B1 co-immunofluorescence staining of control (ctrl) and c-Rel siRNA cells $72 \mathrm{~h}$ after transfection. Secondary anti-mouse Alexa Fluor 488 antibody was used for detection of integrin $\alpha 2$ and anti-rabbit Alexa Fluor 555 antibody for detection of integrin B1. Both control and c-Rel siRNA samples were subjected to the same exposure time, nuclei were counterstained with DAPI (bar= $50 \mu \mathrm{m}$ ). (B) Flow cytometry analysis of surface B1 integrin for control (ctrl, grey line) and c-Rel siRNA cells (black line) $72 \mathrm{~h}$ after transfection. Negative control is depicted with a grey filling. One of three experiments yielded similar results.

To investigate in vitro wound healing/migration of c-Rel downregulated $\mathrm{HaCaT}$ cells further, wound healing assays were performed. Due to reduced growth of c-Rel siRNA cells, both samples were growth inhibited by exposing them to 55 Gray radiation $48 \mathrm{~h}$ after transfection. Hence, the resulting effect can be attributed exclusively to cell migration and not to cell growth. In the applied assay, cells were transfected and seeded onto a culture insert with two single wells separated by a $50 \mu \mathrm{m}$ thick dividing wall. $72 \mathrm{~h}$ after transfection, the culture insert was removed, leaving an equal gap between the cells of both wells. Subsequently, gap closure was documented for up to $48 \mathrm{~h}$ after insert removal (Figure 22). Surprisingly, the wound healing rate of c-Rel downregulated $\mathrm{HaCaT}$ cells was dramatically reduced as shown for $10 \mathrm{~h}$ and $24 \mathrm{~h}$ after insert removal (Figure 22A). Wound closure was already declined after $6 \mathrm{~h}(2.21 \%$ vs. $7.73 \%)$ becoming significant after $24 \mathrm{~h}(9.07 \%$ vs. $73.22 \%, \mathrm{p}<0.05)$ while being most pronounced and highly significant after 48 h ( $26.55 \%$ vs. $97.7 \%$ wound healing, $p<0.001$, Figure 22B). 
A

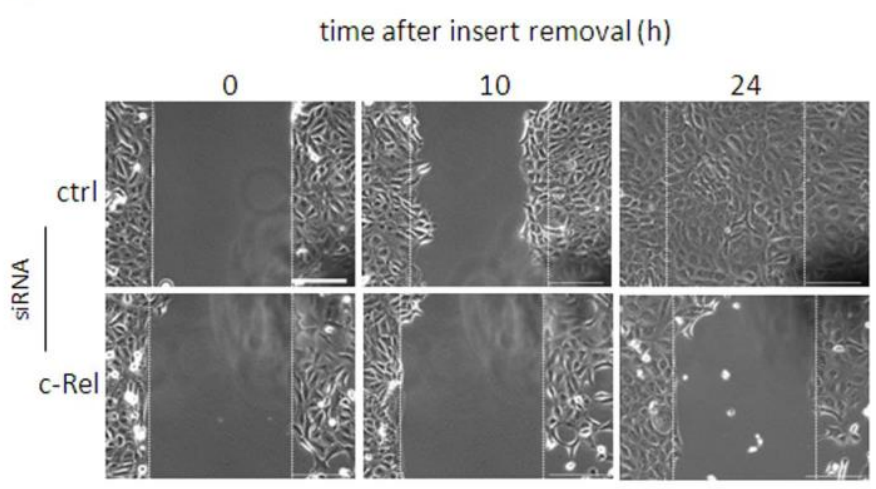

B

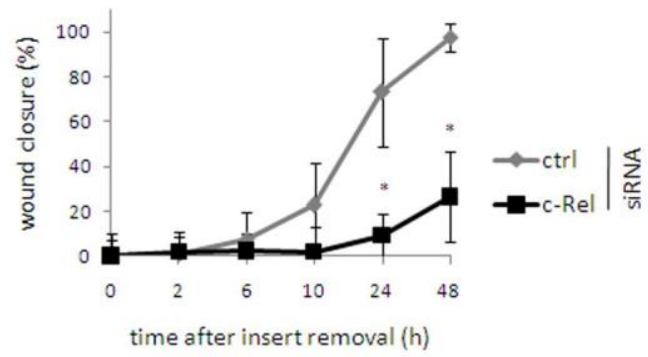

Figure 22: Migration of c-Rel downregulated HaCaT cells is considerably impaired.

(A) Photographs of wound healing assay $0 \mathrm{~h}, 10 \mathrm{~h}$ and $24 \mathrm{~h}$ after insert removal of growth inhibited c-Rel siRNA compared to control siRNA HaCaT cells $72 \mathrm{~h}$ after transfection (bar= $100 \mu \mathrm{m}$ ). (B) Quantitative evaluation of wound closure rate of control (ctrl) and c-Rel siRNA cells from insert removal $(0 \mathrm{~h})$ until $48 \mathrm{~h}$ after insert removal. One of two experiments is representatively shown here, error bars are $\pm S D, *$ indicates $p \leq 0.05$.

Furthermore, adhesion, a process closely related to migration, was examined. Initially, in a more general approach adhesion of cells onto tissue culture treated wells after reseeding of control and c-Rel knockdown cells was tested (Figure 23A). $3 \mathrm{~h}$ and $6 \mathrm{~h}$ after reseeding, a significant reduction of adhesion was determined for c-Rel knockdown cells $(27 \%$ reduction after $3 \mathrm{~h}(p<0.001)$ and even $37 \%$ reduction $(p<0.001)$ after $6 h)$. In the adhesion process, various compositions of heterodimeric integrin receptors are generally involved. However, binding of basal keratinocytes to various ECM proteins in the basement membrane is a process of higher specificity since different integrins bind to specific sequence motifs on ECM proteins. 
Subsequently, adhesion to different concentrations $(0.125 \mu \mathrm{g} / \mathrm{ml}-20 \mu \mathrm{g} / \mathrm{ml})$ of four ECM proteins was examined $2 \mathrm{~h}$ after reseeding; collagen $\mathrm{I}$, fibronectin, laminin as well as vitronectin. Adhesion onto all ECM proteins was generally reduced for c-Rel downregulated HaCaT cells but also showed concentration- and ECM protein dependent effects (Figure 23B). Adhesion to collagen I was about 20 - $35 \%$ impaired except at the lowest concentration of $0.125 \mu \mathrm{g} / \mathrm{ml}$ with about $70 \%$ decreased adhesion. Significant reduction could be detected at a concentration of $2.5 \mu \mathrm{g} / \mathrm{ml}$ and $5 \mu \mathrm{g} / \mathrm{ml}$ of collagen I $(p<0.05)$. Adhesion to fibronectin was not significantly reduced however, at lower concentrations impaired adhesion was more pronounced (about 30 - $50 \%$ ) than at higher concentrations (about $10-30 \%$ ). Similarly, adhesion to laminin was more impaired at lower concentrations (50-80\%) than at higher concentrations (about $40-45 \%$ ) with a significant difference of $45 \%$ at $20 \mu \mathrm{g} / \mathrm{ml}$ laminin $(p<0.01)$. On vitronectin however, adhesion was most clearly impaired constantly ranging between $40-60 \%$ with most pronounced effects at the two highest concentrations (about $60 \%$ ). Significant differences were obtained at a concentration of $1.25 \mu \mathrm{g} / \mathrm{ml}$ (59\% impairment, $\mathrm{p}<0.05$ ) and $10 \mu \mathrm{g} / \mathrm{ml}(60 \%$ impairment, $\mathrm{p}<0.05)$ vitronectin.

Since adhesion was most affected on vitronectin, we subsequently focused on the corresponding integrin receptors on the cellular surface. avß3 integrin and avß5 integrin have both been reported to bind to vitronectin whereas only avß5 integrin is expressed on keratinocytes (Kim et al., 1994). However, flow cytometry analyses revealed no clear changes in surface expression level of $\alpha v ß 5$ integrin comparing c-Rel downregulated and control siRNA cells (MFI 271 vs. 242, Figure 23C). Even though surface expression level of avß5 integrin is not affected by c-Rel downregulation, final conclusions about the functional state of the respective integrin may not be drawn from these experiments.

However, general adhesion is significantly impaired for c-Rel downregulated $\mathrm{HaCaT}$ cells on tissue culture treated surfaces and mostly also on various ECM proteins with vitronectin-binding being most affected. Yet, this could not be associated with a diminished surface expression level of the respective integrin receptor. 
A

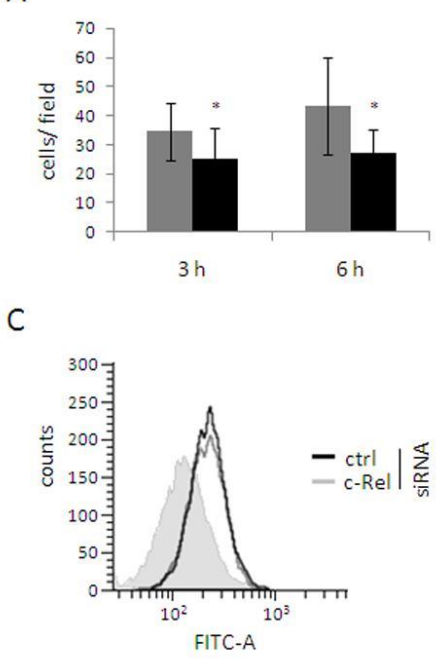

B
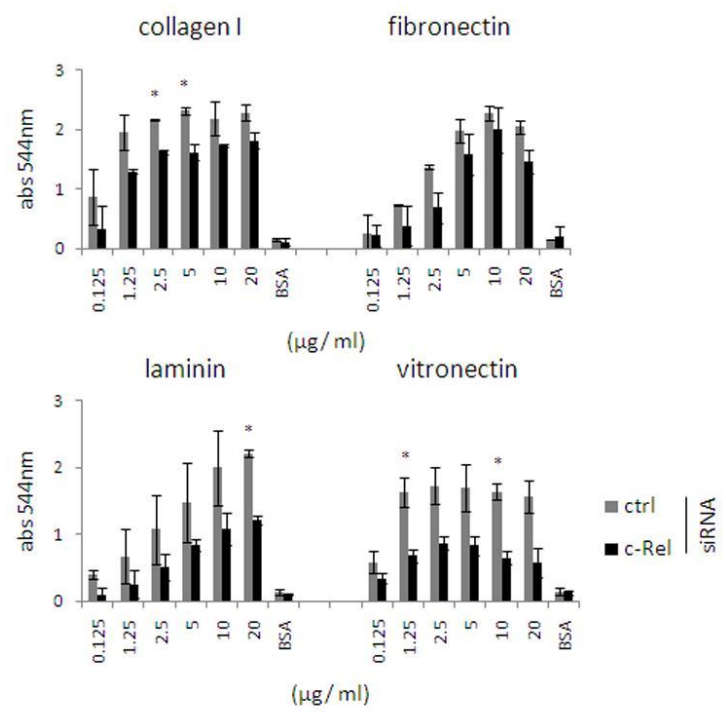

Figure 23: Reduced adhesion of c-Rel downregulated HaCaT keratinocytes.

(A) Adhesion assay of control (ctrl) and c-Rel downregulated cells onto tissue culture treated wells. $72 \mathrm{~h}$ after transfection, cells were detached, reseeded and allowed to re-attach again for $3 \mathrm{~h}$ and $6 \mathrm{~h}$, respectively. Quantitative evaluation occurred by evaluating the number of attached cells per microscopic field of at least 30 fields $(x 160)$ via ImageJ. One of two experiments is representatively shown here, error bars are $\pm S D, *$ indicates $p \leq 0.05$. (B) Adhesion assay of control (ctrl) and c-Rel downregulated cells onto wells coated with different ECM proteins and BSA, respectively. $72 \mathrm{~h}$ after transfection, cells were detached, reseeded and allowed to re-attach again for $2 \mathrm{~h}$ on wells with concentrations ranging from $0.125-20 \mu \mathrm{g} / \mathrm{ml}$. Wells were coated with collagen I, fibronectin, laminin, vitronectin and BSA as control. Shown are mean absorbance values of two independent experiments, error bars are $\pm S D, *$ indicates $p \leq 0.05$. (C) Flow cytometry analysis of integrin avß5 expression shows no clear changes between control (ctrl, black line) and c-Rel (grey line) downregulated cells. Isotype control is depicted with a bright grey filling. One representative of three independent analyses is shown here.

Although adhesion and migration are two distinct processes, both rely on similar molecular mechanisms such as adhesion receptor binding and assembly of multi-protein complexes on the inner side of the cell membrane.

Adhesomes consist of about 180 proteins with a complex interaction network generating small and highly transient nascent adhesions $(<0.25 \mu \mathrm{m})$. These can either disassemble or turn into more mature and larger focal complexes $(<1 \mu \mathrm{m})$. Most stable adhesion complexes focal adhesions are the tallest complexes $(1-5 \mu \mathrm{m})$ leading to increased adhesion strength (Ciobanasu et al., 2012; Parsons et al., 2010). 
To investigate whether adhesion complexes are deregulated in c-Rel siRNA cells, two very common adhesome proteins were studied by immunofluorescence: paxillin and vinculin (Figure 24A). Paxillin interacts with the intracellular integrin tail whereas vinculin binds directly to F-actin. We subsequently aimed to evaluate adhesions in number, distribution and size according to previously described classifications. However, this revealed to be not practicable due to rather faint paxillin signals on the one hand and on the other hand rather strong cytoplasmic vinculin signal potentially covering specific adhesion complexes. Additionally, keratinocyte clusters further complicated affiliation of the respective adhesion complex to specific cells. Possibly due to the aforementioned reasons, we could not detect any changes of vinculin and paxillin expression comparing control and c-Rel siRNA cells.

Actin polymerization to F-actin and generation of stress fibers at adhesomes is a prerequisite for traction generation and subsequent movement of the cell, and is required specifically during the migration process. Therefore, we focused on examining stress fiber appearance in c-Rel downregulated cells via immunofluorescence (Figure 24B). On the one hand, F-actin signal appeared fainter for c-Rel downregulated cells while on the other hand also less stress fibers were detectable for c-Rel downregulated cells especially at cell elongations, as highlighted in the enlarged boxes (Figure 24B). 
A

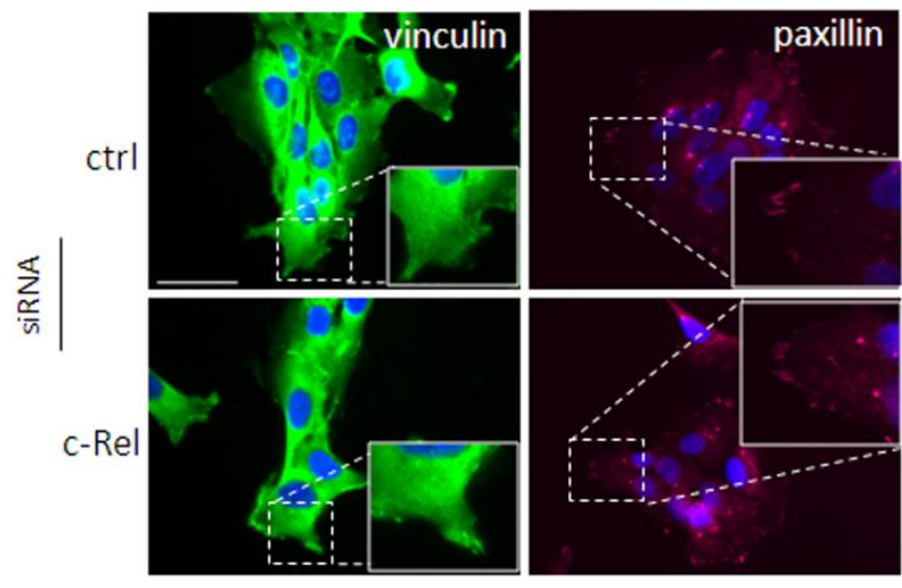

B

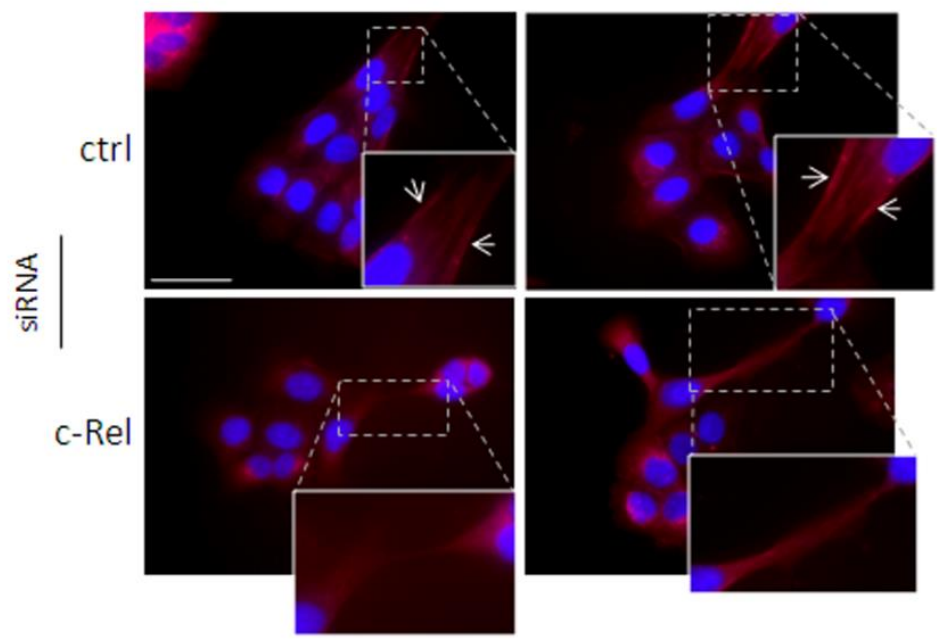

Figure 24: Reduced stress fiber appearance in c-Rel downregulated HaCaT cells.

(A) Immunofluorescence stainings of focal adhesion proteins vinculin and paxillin of control (ctrl) and c-Rel downregulated cells $72 \mathrm{~h}$ after transfection. Secondary anti-mouse Alexa Fluor 488 antibody was used for detection of vinculin and anti-rabbit Alexa Fluor 555 antibody for detection of paxillin. Enlarged boxes highlight adhesion rich regions, nuclei are counterstained with DAPI (bar $=50 \mu \mathrm{m}$ ). (B) Immunofluorescence staining of PromoFluor 555 labelled phalloidin of control (ctrl) and c-Rel siRNA cells $72 \mathrm{~h}$ after transfection. Enlarged boxes highlight stress fiber containing regions. Nuclei are counterstained with DAPI (bar= $50 \mu \mathrm{m}$ ). All experiments were performed at least twice with similar results.

In summary, a modified phenotype for c-Rel downregulated HaCaT cells was obvious with a reduced colony-growth formation and more elongated cell phenotype which could not be associated with EMT-determining protein expression. 
Even though surface expression of wound healing associated $ß 1$ integrin did not change, a clearly diminished migratory response could be observed in wound healing assay with downregulated c-Rel. Furthermore, impaired adhesion to tissue culture treated surfaces and to the ECM protein vitronectin was obvious whereas vitronectin associated adhesion receptor showed no significant expression changes. Thus, we hypothesize a more general mechanism initiating reduced migratory and adhesive characteristics. According to this, a clearly reduced amount of stress fibres became apparent in c-Rel downregulated $\mathrm{HaCaT}$ cells constituting a prerequisite for proper adhesion and migration.

\subsection{Characterization of NF-KB expression in primary keratinocytes}

Even though spontaneously immortalized HaCaT cells are one of the best model systems to study keratinocytes, they show some different characteristics compared to primary keratinocytes such as loss of both p53 alleles, hypermethylation of the promotor region of p16 as well as a greater susceptibility to apoptosis. Regarding NF-KB activity, HaCaT cells have higher constitutive levels of p50 and p65 (Chaturvedi et al., 1999).

To increase the impact of our studies, NF-KB expression and functional studies on c-Rel were subsequently investigated in the primary cell system with human epidermal keratinocytes derived from foreskin (Figure 25). Regarding transcription, these cells showed relatively lower levels of NFKB1 and REL in contrast to RELA, NFKB2 and RELB as determined by semi-quantitative PCR with varying cycle counts (Figure 25A). Again, western blotting revealed expression of all subunits (Figure 25B). Immunofluorescence studies revealed that all NF-KB subunits were predominantly localized within the cytoplasm. However, primary keratinocytes showed greater heterogeneity than $\mathrm{HaCaT}$ cells; within some clusters, several cells showed cytoplasmic staining, others even distribution while some cells revealed nuclear staining as well. Again, c-Rel and RelB but also p52 revealed additional punctate nuclear staining pattern. 
A

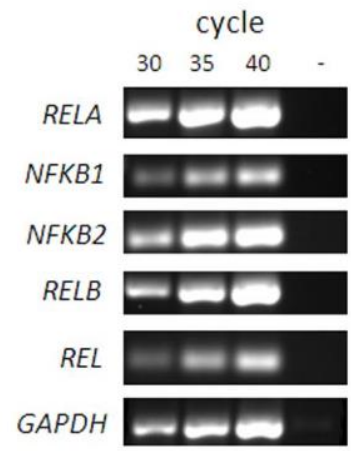

$\mathrm{C}$
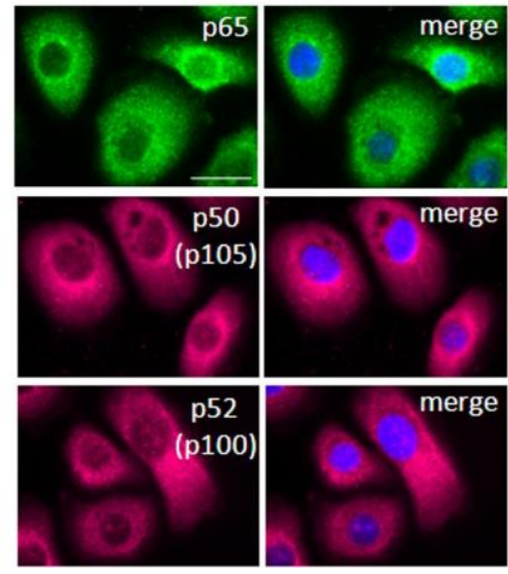

B
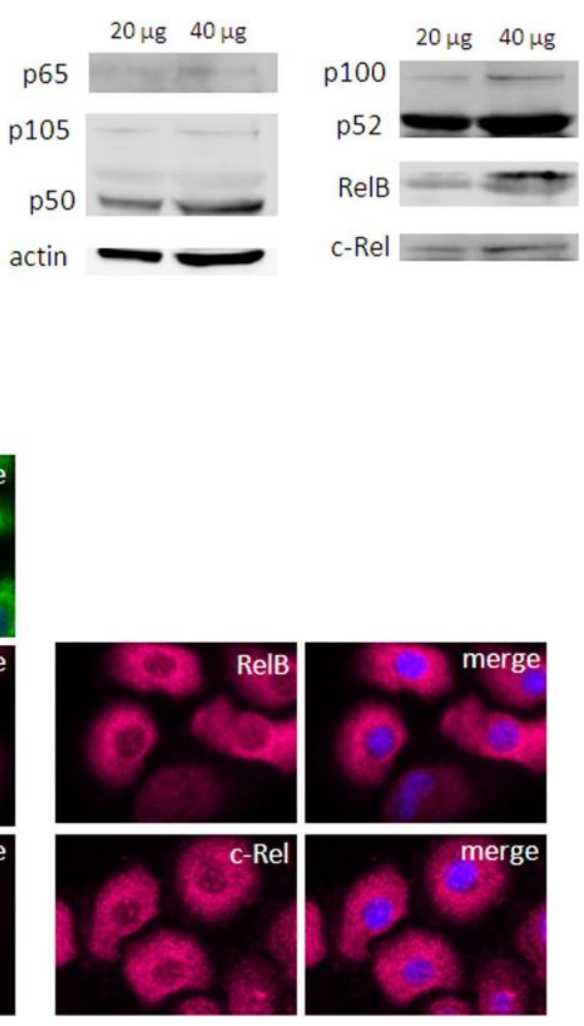

Figure 25: Expression of NF-KB proteins in primary epidermal keratinocytes.

(A) Semi-quantitative PCR of all NF-KB genes with different cycle counts (30 - 40). GAPDH served as positive control, (-) displays the sample without template. (B) Western blotting of $20 \mu \mathrm{g}$ and $40 \mu \mathrm{g}$ whole cell lysate using antibodies directed against each respective NF-KB protein. Actin served as loading control. (C) Exemplary photographs of immunofluorescence staining of all NF-kB subunits digitally enhanced with Axiovision software Rel 4.7. p65 stained sample was incubated with anti-mouse secondary antibody conjugated with AlexaFluor 488, whereas p50, p52, RelB and c-Rel stained samples were incubated with anti-rabbit secondary antibody conjugated with AlexaFluor 555. On the right side, photographs were merged with DAPI stained nuclei. Bar $=20$ $\mu \mathrm{m}$. One of two representative experiments is depicted.

Our studies identified expression differences of NF-KB proteins in HaCaT cells and primary epidermal keratinocytes as follows: Primary keratinocytes show lower relative transcription of NFKB1 and REL, whereas NFKB2, RELA and RELB are expressed more strongly while being reverse in $\mathrm{HaCaT}$ cells. Subcellular distribution revealed only minor differences since all NF-KB subunits are predominantly localized to the cytoplasm. However, NF-kB subunits were more heterogeneously distributed in primary keratinocyte clusters compared to HaCaT cells. 


\subsection{Impact of c-Rel downregulation on primary keratinocytes}

To clarify whether c-Rel downregulation yields similar results compared to $\mathrm{HaCaT}$ keratinocytes, analogous transfection experiments were conducted with primary keratinocytes. For these experiments, keratinocytes were used exclusively from passage 3 to 4 guaranteeing basal characteristics. Western blotting confirmed c-Rel downregulation $72 \mathrm{~h}$ after transfection with a $60 \%$ reduction as determined densitometrically confirming a highly efficient siRNA downregulation (Figure 26A).

Subsequently, keratinocyte growth was analyzed by quantification of cells per microscopic field every $24 \mathrm{~h}$ after transfection establishing a growth curve (Figure 26B). $48 \mathrm{~h}$ after transfection, c-Rel downregulated primary keratinocytes revealed an about $22 \%$ reduced growth compared to control cells $(p<0.01) .72 \mathrm{~h}$ after transfection, growth reduction was slightly more pronounced (about $25 \%, p<0.01$ ) whereas after $96 \mathrm{~h}$, growth reduction was most distinct with $44 \%$ compared to control $(p<0.001)$. However, $96 \mathrm{~h}$ after transfection, control cells reached confluency potentially inducing differentiation related growth arrest. To exclude this effect, for the following studies the time point of $72 \mathrm{~h}$ after transfection was chosen. 
A

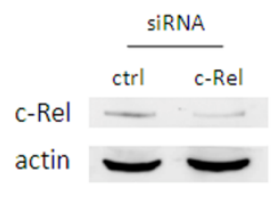

B

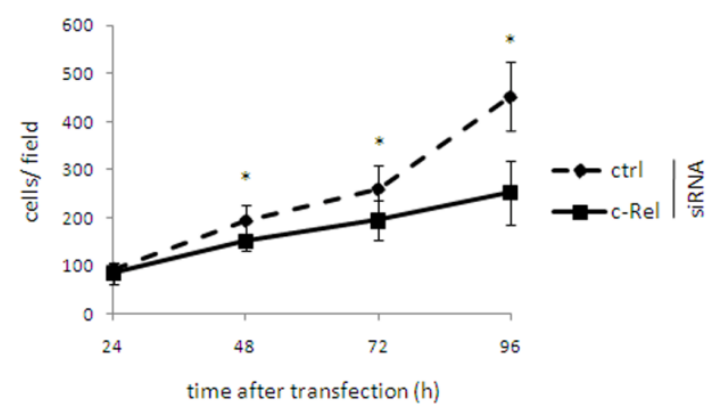

Figure 26: c-Rel downregulation leads to growth reduction in primary keratinocytes.

(A) Western blotting of $40 \mu \mathrm{g}$ whole cell lysate of control siRNA (ctrl) and c-Rel siRNA transfected primary epidermal keratinocytes $72 \mathrm{~h}$ after transfection. Actin served as loading control. (B) Growth curve of control (ctrl) and c-Rel siRNA transfected primary keratinocytes between $24 \mathrm{~h}$ and $96 \mathrm{~h}$ after transfection. Curve represents mean cell numbers of ten microscopic fields $(x 100)$ evaluated using ImageJ. One of two experiments with similar results is representatively shown, error bars are $\pm S D, *$ indicates $p \leq 0.05$.

Regarding functional studies, MTT viability assay revealed moderate, non-significant reduction for c-Rel downregulated keratinocytes, repeatedly around $10 \%$ (Figure 27A). In contrast to this, BrdU incorporation assays showed a significantly reduced proliferation rate for c-Rel siRNA treated cells of about $36 \%(p<0.01$, Figure 27B). Furthermore, apoptosis was increased, about $44 \%$ compared to control cells (Figure $27 \mathrm{C}$ ) revealing no significance. 
A

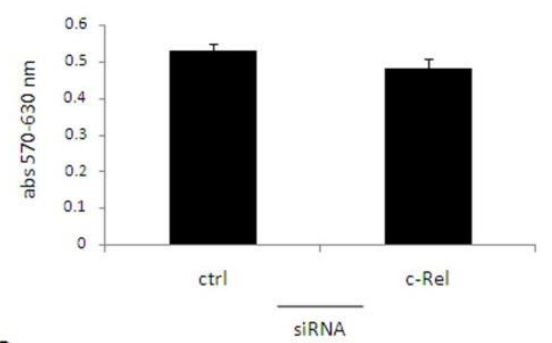

C

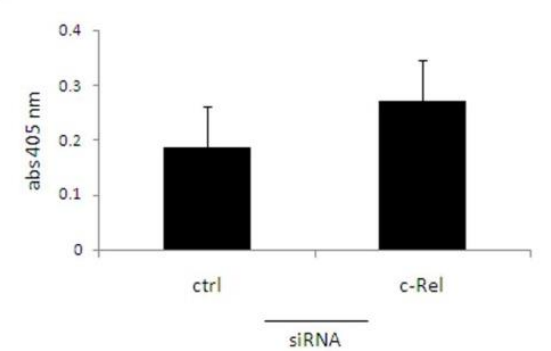

B

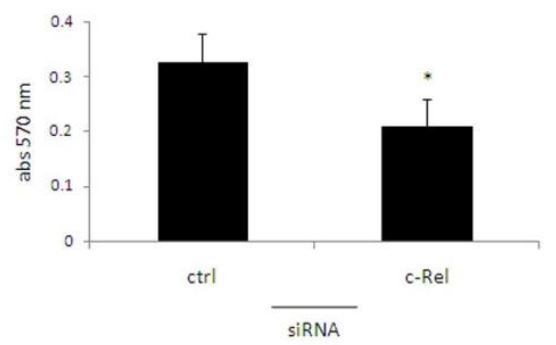

Figure 27: c-Rel downregulation reduces proliferation of primary keratinocytes.

(A) MTT viability assay of control (ctrl) siRNA and c-Rel siRNA transfected keratinocytes $72 \mathrm{~h}$ after transfection. One of three experiments with similar results is shown, every experiment was performed in triplicates, error bars are $\pm S D$. (B) BrdU incorporation assay of control (ctrl) siRNA and c-Rel siRNA transfected primary keratinocytes $72 \mathrm{~h}$ after transfection. Two experiments revealed similar results, one is representatively shown here, error bars are $\pm S D$, * indicates $p \leq 0.05$. (C) Apoptosis assay of control (ctrl) siRNA and c-Rel siRNA keratinocytes $72 \mathrm{~h}$ after transfection. Data represent mean absorbances of two independent experiments, every experiment was performed in triplicates, error bars are \pm SD.

In summary, our studies confirmed that c-Rel downregulation induces growth reduction in primary keratinocytes both impacting proliferation and apoptosis comparable to previous results for HaCaT keratinocytes.

When analyzing cell cycle phase distribution, c-Rel downregulated primary keratinocytes showed a significant $24 \%$ increase of cells in $\mathrm{G} 2 / \mathrm{M}$ phase compared to control $(43.2 \%$ vs. $34.9 \%, \mathrm{p}<0.05$, Figure $28 \mathrm{~A})$. Furthermore, $\mathrm{p}-\mathrm{H} 3^{\mathrm{Ser} 10}$ immunofluorescence staining revealed an increased positive cell portion; by trend, about $56 \%$ more primary keratinocytes were $\mathrm{p}-\mathrm{H} 3^{\mathrm{Ser} 10}$ positive compared to control (Figure $28 \mathrm{~B}$ and $\mathrm{C})$. To determine the mitotic cell portion, immunofluorescence stainings of $ß$-tubulin were evaluated and revealed $53 \%$ increase of c-Rel downregulated sample compared to control (Figure 28D). 
Generally, due to the lower mitotic cell number and quite considerable variations, no significant differences between control and c-Rel sample could be determined, however, the trend was detected repeatedly.

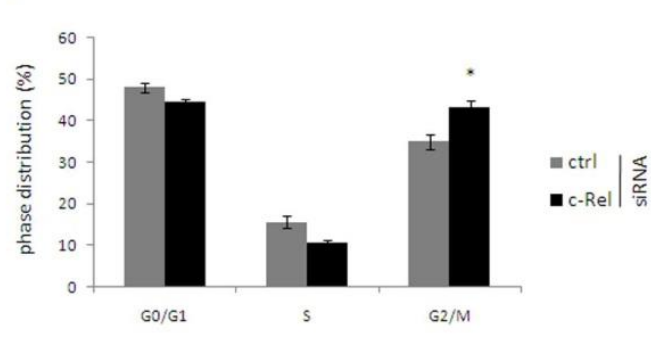

C

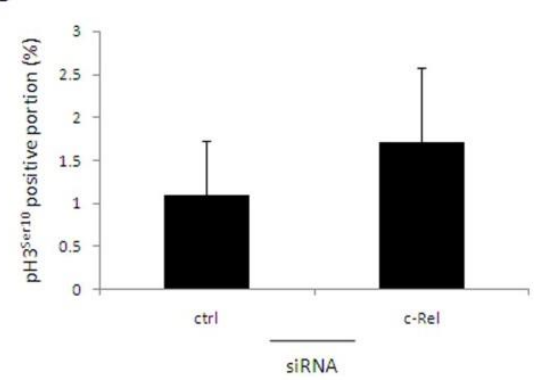

B

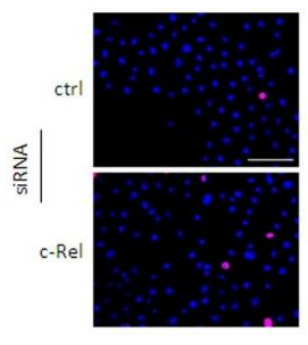

D

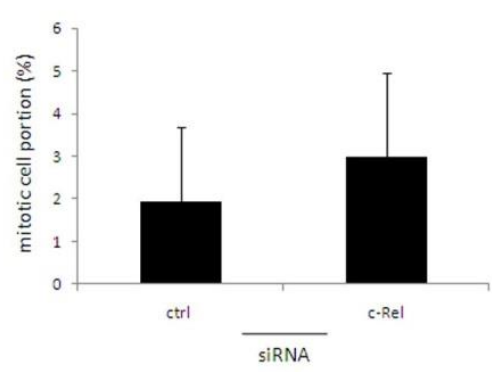

Figure 28: Increased G2/M phase cell portion of c-Rel downregulated primary keratinocytes. (A) Diagram of cell cycle phase distribution of vital control (ctrl, grey bar) and c-Rel siRNA transfected primary keratinocytes (black bar) $72 \mathrm{~h}$ after transfection. Shown are mean distribution values of two independent experiments, error bars are $\pm S D, *$ indicates $p \leq 0.05$. (B) Exemplary photographs of $\mathrm{p}-\mathrm{H} 3^{\mathrm{Ser} 10}$ immunofluorescence staining of control (ctrl) and c-Rel siRNA primary keratinocytes $72 \mathrm{~h}$ after transfection digitally enhanced with Axiovision software Rel 4.7. Secondary anti-rabbit antibody was labeled with Alexa Fluor 555 and nuclei were counterstained with DAPI (bar $=100 \mu \mathrm{m}$ ). (C) Quantitative evaluation of $\mathrm{p}-\mathrm{H} 3^{\text {Ser10 }}$ positive cell portions of control (ctrl) and c-Rel siRNA transfected primary keratinocytes of 20 microscopic fields of view (x200). One of two experiments is representatively shown here, error bars are \pm SD. (D) Quantitative evaluation of control (ctrl) and c-Rel siRNA transfected mitotic cell portions of at least 19 microscopic fields (x200) based on ß-tubulin immunofluorescence stainings. One of two experiments is representatively shown here, error bars are $\pm S D$.

Furthermore, the phenotype of primary keratinocytes with downregulated c-Rel was analyzed. However in contrast to HaCaT cells, no or only minor morphological changes could be observed $72 \mathrm{~h}$ after transfection for primary keratinocytes (Figure 29A). Furthermore, wound healing assay revealed only a mildly impaired migration of c-Rel downregulated primary keratinocytes (Figure 29B). 
A

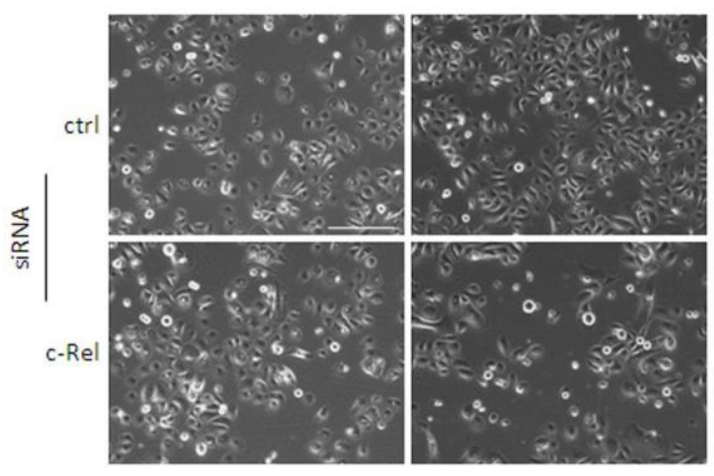

B

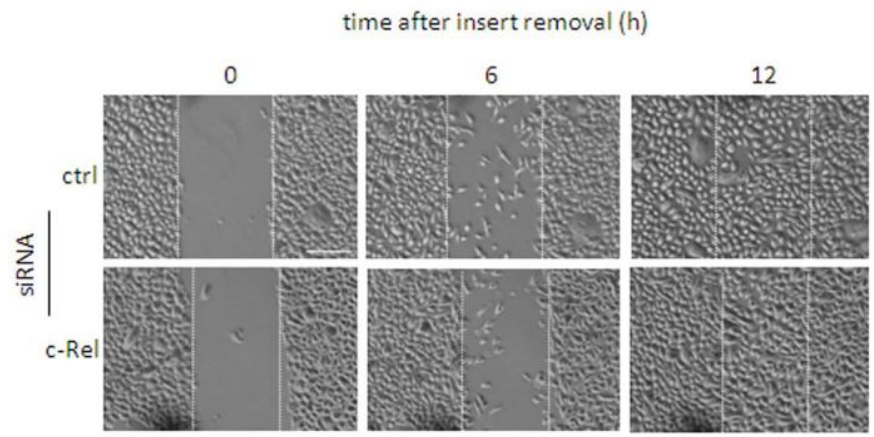

Figure 29: c-Rel downregulation shows minor effects on primary keratinocyte phenotype and migration.

(A) Representative phase contrast photographs of control (ctrl) and c-Rel knockdown primary keratinocytes $72 \mathrm{~h}$ after transfection (bar $=50 \mu \mathrm{m}$ ). (B) Representative photographs of wound healing assay $0 \mathrm{~h}, 6 \mathrm{~h}$ and $12 \mathrm{~h}$ after insert removal for control (ctrl) and c-Rel siRNA transfected primary keratinocytes $72 \mathrm{~h}$ after transfection (bar= $100 \mu \mathrm{m}$ ).

In summary, effects of c-Rel downregulation in primary keratinocytes are similar to those of $\mathrm{HaCaT}$ cells with respect to cell growth and cell cycle: impaired growth of primary keratinocytes, reduced proliferation and increased yet non-significant apoptosis. In contrast, cell cycle phase distribution is significantly shifted towards a greater cell fraction in $\mathrm{G} 2 / \mathrm{M}$ phase. Furthermore, $\mathrm{p}-\mathrm{H} 3^{\mathrm{Ser} 10}$ positive and mitotic cell portion is induced in c-Rel downregulated primary keratinocytes as well. Regarding phenotypic and associated changes, no or only minor effects were seen for c-Rel downregulated primary keratinocytes in contrast to HaCaT cells. 
Conclusively, taking into consideration system-specific difficulties like transfection efficiency and greater variability of primary cells, our data generated in primary keratinocytes support c-Rel downregulation specific effects especially regarding cell growth. 


\section{Discussion}

The ubiquitously expressed transcription factor NF-KB exerts a wide variety of crucial cellular functions by regulating typical tumor promoting characteristics such as proliferation, apoptosis, invasion as well as inflammation (Karin, 2006). In various cancer types, NF-KB is constitutively active being an intriguing target for cancer therapeutics (Van Waes, 2007). However, showing a higher complexity than originally anticipated, NF-KB exerts its specific effects in a cell type- and context-dependent manner (Perkins, 2004). In human skin, NF-KB activation influences epidermal homeostasis by showing a growth inhibitory effect on keratinocytes (Seitz et al., 1998; van Hogerlinden et al., 1999). Previously, NF-KB has been associated with development and progression of human SCC by demonstration of ambiguous expression- and activity patterns (Dajee et al., 2003; Loercher et al., 2004). The major aim of this thesis was to further elucidate the function of the five single NF-KB subunits with respect to basic keratinocyte characteristics involved in the regulation of epidermal homeostasis.

\subsection{Pro-proliferative, anti-apoptotic implications for c-Rel in HaCaT cells}

Functional studies on single NF-KB subunits using a siRNA based approach revealed significant effects in HaCaT cells for c-Rel but not for the NF-KB proteins p50, p52, RelB, or p65.

However, this finding does not necessarily point at a negligible function of the four latter proteins, more probably representing a consequence of functional redundancy between the subunits as could previously be shown in mouse fibroblasts (Hoffmann et al., 2003). 
Among the five different NF-KB proteins, c-Rel owns exclusive properties as it constitutes the only subunit associated with oncogenic features: An avian mutated homologue of c-Rel, v-Rel, has been reported to malignantly transform chicken hematopoietic cells in vitro (Chen et al., 1981). Furthermore, c-Rel was shown to be induced in the nuclei of solid and hematopoietic cancers (Rodig et al., 2005; Sovak et al., 1997). In addition, c-rel/- mice revealed mainly B-cell defects but also displayed smaller T-cell defects (Kontgen et al., 1995; Tumang et al., 1998). Interestingly, B-cells of c-rel-1mice showed reduced proliferation and increased apoptosis (Hsia et al., 2002), features that were also identified in the present work for $\mathrm{HaCaT}$ and primary keratinocytes.

Even though c-Rel is expressed in the epidermis and in hair follicles of fetal mice (Gugasyan et al., 2004), no overt skin phenotype has been detected in $c-r e I^{-/}$mice so far. However, recent studies uncovered previously unknown extralymphoid defects in c-rel-1mice such as cardiac hypertrophy (Gaspar-Pereira et al., 2012) as well as liver fibrosis and liver regeneration (Gieling et al., 2010). Therefore, these findings might reflect a broader range of defects in c-Rel knockout mice than previously suspected.

In our functional studies, we could show a negative impact of c-Rel downregulation on cell growth and proliferation in $\mathrm{HaCaT}$ cells. Therefore, our results suggest pro-proliferative, growth supportive functions of c-Rel. Since previous studies on the NF-KB subunits p50 and p65 revealed opposite effects in keratinocytes these findings were rather unexpected (Seitz et al., 1998; van Hogerlinden et al., 1999). It seems however that c-Rel acts differently than the NF-KB subunits p50 and p65 in this respect, more in accordance with the typical NF-KB related effects in most other cell types.

Beyond analysis of the impaired growth of c-Rel downregulated cells, we were able to identify underlying processes and molecular targets, thus contributing to a better understanding of the impact of c-Rel. Regarding cell cycle regulation, c-Rel knockdown led to $\mathrm{CKI}$ p $15^{\text {INK4B }}$ induction in HaCaT cells yet without any further effect on associated $\mathrm{G} 1 / \mathrm{S}$ cell cycle phase transition. 
However, c-Rel downregulation markedly increased HaCaT cell portion in G2/M phase. Subsequent studies examining G2/M phase associated protein expression revealed strong induction of histone H3 phosphorylated at serine 10 and a clearly increased portion of $\mathrm{p}-\mathrm{H} 3^{\mathrm{Ser} 10}$ positive cells. Whereas the exact function of histone $\mathrm{H} 3$ phosphorylation remains controversial so far (Cerutti and Casas-Mollano, 2009), phosphorylation was shown to be initiated in late G2 phase along with chromosome condensation, peaking in metaphase and disappearing in later mitotic phases (Hendzel et al., 1997). The chromosomal passenger complex (CPC) is known to regulate this phosphorylation event. Investigation of CPC localization and expression by studying one of the CPC components, survivin, revealed no alterations for c-Rel downregulated HaCaT cells. Since the CPC component aurora B kinase is responsible for phosphorylating histone H3 at serine 10 (Crosio et al., 2002; Murnion et al., 2001), experiments addressing its potentially dysregulated expression or activity status in c-Rel knockdown cells could further enlighten this issue. In this context, it may be of interest that overexpression of aurora B kinase has been reported in many cancer types, among others also a subtype of SCC, head and neck SCC (Qi et al., 2010).

Since $\mathrm{p}-\mathrm{H} 3^{\text {Ser10 }}$ induction is mainly associated with condensed chromatin during mitosis, our results suggested that there might be an aberrant mitotic proceeding of c-Rel downregulated cells. Therefore, further experiments were performed to determine the number of mitotic cells which indeed was clearly increased for c-Rel downregulated HaCaT cells. Subsequently, we focused on the appearance of the mitotic spindle apparatus and identified highly increased mitotic cell portion with aberrant mitotic spindle structures for c-Rel knockdown cells. When investigating and evaluating mitotic spindle morphology in more detail, a predominantly monopolar spindle morphology became obvious. 
Accurate bipolar mitotic spindle formation depends on several cellular events; centrosome duplication during S-phase, centrosome separation by molecular motor proteins in mitotic prophase pushing microtubules of opposite polarity apart, and finally formation of spindle microtubules emanating from each centrosome as microtubule organization center (MTOC) supported by a variety of proteins (Tillement et al., 2009). Monopolar spindle formation can be caused by inhibited centrosome duplication, functional defects of molecular motor proteins, decreased microtubule stability or by inhibition of specific dynein-related or kinesin-like proteins, such as the polo-like kinase 1 (Plk1) (Sumara et al., 2004; Tillement et al., 2009; van Vugt et al., 2004). Further experiments such as examination of centrosome number and -localization are needed to unravel the exact causes of monopolar spindle formation in c-Rel downregulated HaCaT cells.

As a consequence of disturbed bipolar mitotic spindle assembly, usually mitosis is delayed due to activation of the mitotic spindle assembly checkpoint (SAC). SAC activation is triggered by incorrect attachments of the mitotic spindle microtubules to the kinetochors of sister chromatids (Tillement et al., 2009). Since c-Rel downregulation induces disturbances in mitotic spindle assembly probably resulting in erroneous or no kinetochore attachment, we propose prolonged activation of SAC in c-Rel downregulated HaCaT cells.

As a general result of prolonged SAC activation, cells arrest in mitosis and sooner or later either proceed into apoptosis or slip through mitosis, i.e. escape from mitosis with improper chromosome separation (Huang et al., 2009). Indeed, functional studies showed an increased apoptosis rate of c-Rel downregulated HaCaT cells. Therefore, we suggest that induction of apoptosis may occur as a result of prolonged SAC activation. To prove whether mitotic slippage occurs as a result of c-Rel knockdown, future karyotype analysis should be performed. However, these would require longterm downregulation of c-Rel as could be achieved by stable shRNA insertion into HaCaT cells. 
Usually, SAC induction involves upregulation of cyclin B1 in various cell types (Castedo et al., 2004). However, this upregulation could not be detected in c-Rel downregulated $\mathrm{HaCaT}$ cells, possibly due to low cyclin B1 expression level. It will therefore be of great interest to examine other proteins associated with SAC activation such as the transcriptional activator p38 or kinetochore binding proteins such as the mentioned kinase BubR1 to confirm this hypothesis (Musacchio and Salmon, 2007; Takenaka et al., 1998).

Various anti-mitotic drugs such as paclitaxel or the Vinca alkaloid vinblastine are used as chemotherapeutic agents to treat a broad range of cancer types. These drugs generally act on microtubule dynamics interfering with proper mitotic spindle assembly resulting in mitotic arrest and following cell death (Hadfield et al., 2003; Pellegrini and Budman, 2005). Intriguingly, similar structured mitotic spindles as for c-Rel knockdown $\mathrm{HaCaT}$ cells could be observed when incubating HeLa cells with $6.4 \mathrm{nM}$ of vinblastine for 18 - 20 h. Spindle morphology was mainly monopolar with ball-shaped condensed chromatin and plenty star-like microtubule aggregates (Jordan et al., 1992). Vinblastine disrupts microtubule dynamics concentration-dependent by preventing addition of microtubule monomers to the microtubule end resulting in depolymerization and mitotic arrest of the respective cell (Matson and Stukenberg, 2011). Future studies need to unravel the exact mechanism of c-Rel downregulation on mitotic spindle formation and its potential similarity to vinblastine mechanism of action. One approach would involve live cell imaging of mitotic c-Rel downregulated HaCaT cells to obtain a more detailed insight into the origin of spindle formation disturbances over time.

Since most anti-mitotic agents have high neurotoxic effects, the search for alternatives is an ongoing field of research recently expanding to small molecule inhibitors for mitotic spindle proteins (Jackson et al., 2007).

In summary, c-Rel downregulation initiates mitotic spindle disturbances in $\mathrm{HaCaT}$ cells. Two examples will further highlight the relevance of our findings: 
First, Torchia and colleagues recently characterized conditional aurora $a^{-/-}$mice revealing a hypoproliferative epidermis and a strong increase of mitotic keratinocytes with disorganized mitotic spindles. Additionally, also apoptosis was induced in keratinocytes lacking aurora A kinase (Torchia et al., 2013). Aurora A is besides the previously mentioned aurora B a member of the aurora kinase family and is involved in proper mitotic proceeding. It is directly localized at the centrosomes and mitotic spindles regulating centrosome maturation, proper mitotic entry as well as bipolar spindle assembly (Marumoto et al., 2003; Vader and Lens, 2008). Intriguingly, aurora A has been reported to be overexpressed in SCCs of the skin suggesting a potential role during epidermal carcinogenesis (Clausen et al., 2006; Torchia et al., 2009). Based on the resemblance to c-Rel knockdown associated changes in HaCaT cells, one may hypothesize that c-Rel could directly affect mitotic spindle assembly suggesting a function for c-Rel apart from its role as transcriptional activator. However, no such indications for c-Rel functions have been reported yet. Furthermore, disturbances in mitotic spindle formation do not necessarily indicate a direct role in regulation of microtubule dynamics. Therefore, it seems more likely that c-Rel knockdown related spindle assembly disturbances might represent a secondary effect due to the lack of c-Rel at an earlier point of time.

The second example involves a similar experimental approach with in vitro downregulation of another transcription factor. Herein, shRNA depletion of the forkhead transcription factor FoxM1 in breast cancer cell lines led to mitotic cell accumulation and disturbed mitotic spindle formation. Generally, FoxM1 function is associated with accurate timely entry into mitosis and regulation of mitosis-associated target genes such as NIMA-related kinase 2 (Nek2), Kinesin-like protein 20A (KIF20A) or Centromere Protein A (CENP-A) (Wonsey and Follettie, 2005). Due to functional analogy of FoxM1 and c-Rel both owing transcription factor activity, we hypothesize c-Rel may similarly regulate target genes which are required for proper mitotic proceeding. Intriguingly, c-Rel and FoxM1 have also been reported to be interconnected: Wound healing responses of $\mathrm{c}-\mathrm{rel}^{-1-}$ mouse hepatocytes showed delayed induction of FoxM1 including reduction of cyclin B1 and cdc25c. As a response to injury, c-Rel binding to the promoter of FoxM1 was detected thus contributing to hepatocyte wound healing (Gieling et al., 2010). 
Since hepatocytes and keratinocytes share many functional similarities, future studies elucidating the expression and activation status of FoxM1 in c-Rel downregulated HaCaT cells could gain new insights into mitotic regulation.

In conclusion, we hypothesize a role for c-Rel in timely mitotic entry or mitotic proceeding by affecting the expression level of mitosis-associated regulatory genes. This is further supported by the fact that c-Rel is induced in mitotically arrested and serumsynchronized mitotic HaCaT cells compared to non-synchronized unstimulated cells. However, with our current data we cannot exactly determine the peak of c-Rel expression which might be prior to investigated time points. Future studies will have to focus on determination of c-Rel activity status prior to and during mitotic entry and proceeding compared to other cell cycle phases or non-synchronized HaCaT cells. In case of increased mitotic c-Rel activity, subsidiary ChIP analyses may give final hints on respective target genes of c-Rel during mitosis. Usually, the majority of transcription factors are silenced in mitotic cells but genomic DNA still remains accessible to certain transcription factor binding despite of the high condensation grade (Chen et al., 2005).

To summarize, current data point at a novel role for c-Rel in cell cycle progression, more precisely in proper mitotic entry or proceeding of $\mathrm{HaCaT}$ cells. Identification of c-Rel-associated specific target genes, its mitotic activity status as well as complementary studies focusing on overexpression effects of c-Rel in HaCaT cells will further contribute to a better understanding of c-Rel specific mode of action and its implications on epidermal homeostasis.

\subsection{Putative role for c-Rel in cytoskeleton dynamics of HaCaT cells}

Phenotypic modifications such as elongation and flattening of cells have been reported in early studies for overexpression of chicken c-Rel in HeLa cells but also in later studies overexpressing human c-Rel in primary keratinocytes (Bash et al., 1997; Bernard et al., 2004). The mechanistic causes of these morphological changes however have not been analyzed further. 
In our studies, we could show by transient c-Rel downregulation a conversion of the typical HaCaT keratinocyte phenotype to an elongated and more singled appearance. These phenotypic traits have been previously associated with EMT of keratinocytes, however, the hallmarks of EMT (upregulation of $\mathrm{N}$-cadherin and downregulation of E-cadherin) could not be detected. On contrary, when examining migration of $\mathrm{HaCaT}$ cells in a wound healing assay, the wound healing i.e. in vitro migration rate was dramatically diminished. Not quite as pronounced as the migration rate but also reduced was adhesion of c-Rel downregulated $\mathrm{HaCaT}$ cells. Even though examination of cellular adhesion to different ECM proteins revealed protein specific varieties, no impairment of specific integrin surface receptors could be associated with c-Rel downregulation.

Both of these processes, adhesion and migration are closely related with adhesion constituting a prerequisite for migration. Whereas adhesion includes more the simple attachments of a cell associated with increased integrin clustering, migration comprises rather diffuse integrin localization as well as the sequential adherence and disadherence from the substrate resulting in cellular movement (Kim et al., 1994).

In following experiments examining molecular components responsible for adhesion and migration, study of the two typical adhesome components, vinculin and paxillin, revealed no obvious differences. In contrast to this, stress fiber appearance was clearly diminished in c-Rel downregulated $\mathrm{HaCaT}$ cells. Since stress fibers are required for cellular motility by generation of traction forces, these findings can be directly associated with the abrogated migration rate in wound healing of c-Rel downregulated cells. Adhesion does not depend to the same extent on traction forces, resulting in a not quite as pronounced effect compared to migration.

Since actin dynamics also regulate the cellular shape, we suggest the modified phenotype of c-Rel downregulated HaCaT cells being caused by diminished stress fiber appearance. Therefore, the faulty impression of increased cellular motility might actually be due to cytoskeleton changes. 
Generally, stress fibers are generated by crosslinking of the actin filaments involving $\alpha$-actinin and tropomyosins while myosin serves as a molecular motor to generate traction forces (Ciobanasu et al., 2012). Thus, the question arises how c-Rel downregulation impacts stress fiber appearance and associated changes. We suggest that c-Rel could affect stress fiber generation or stabilization by targeting actin or actin-binding cellular components as those contributing to the adhesome formation.

Indeed, there is experimental evidence for a function of single NF-KB subunits beyond transcription factor regulation regarding cytoskeleton dynamics: In rat fibroblasts, association of p65 with F-actin and adhesomes could be shown (Are et al., 2000). However, interaction of c-Rel with cytoskeleton components has not been reported to our knowledge yet.

Besides its impact in adhesion and migration, actin acts in concert with microtubules and intermediate filaments in a wide variety of essential cellular processes as mitosis for instance. Mitosis not only involves mitotic spindle formation but also remodeling of the actin cytoskeleton presenting a tremendous reorganization process (Stewart et al., 2011). It comprises dissolution of adhesion complexes and stress fibers leading to retraction of the cell margin (Cramer and Mitchison, 1997), mitotic cell rounding anchoring the cell via actin-based retraction fibers and generation of the rigid acto-myosin based cell cortex (Maddox and Burridge, 2003). Intriguingly, the acto-myosin cortex generates tensile forces in retraction fibers suggested to support proper mitotic spindle alignment and also being required for accurate centrosome separation (Rosenblatt et al., 2004; Uzbekov et al., 2002). Furthermore, F-actin is located at the mitotic spindle suggesting a direct role for mitotic spindle dynamics (Woolner et al., 2008; Yasuda et al., 2005). Due to recent findings emphasizing the role of actin during mitosis, we propose a connection of disturbed actin dynamics in c-Rel downregulated keratinocytes and previously mentioned mitotic spindle aberrations. 
Even though our findings are related to stress fiber appearance in interphase cells which retract during mitosis, disturbed actin dynamics can affect mitotic cells on many levels, for instance in rigidity of the mitotic cell cortex that also depends on acto-myosin mediated forces and affects mitotic spindle position and stability.

An experimental approach to identify c-Rel influence on actin dynamics involves determination of the activation status of the Rho GTPase protein RhoA in c-Rel downregulated HaCaT cells. Rho GTPases are small proteins switching between an active GTP bound form and a GDP bound inactive form mainly mediating actin- but also microtubule assembly and organization incorporating many downstream signaling pathways (Bishop and Hall, 2000; Etienne-Manneville and Hall, 2002; Hall, 1998). Thereof, RhoA was reported to be upregulated in rounded mitotic cells supporting acto-myosin based contractility and retraction of the mitotic cell cortex (Maddox and Burridge, 2003). Therefore, investigating potential changes of RhoA activation status in c-Rel downregulated cells may be an interesting field for future studies potentially combining both, cell cycle regulation and actin dynamic changes.

\section{3 c-Rel downregulation in HaCaT and primary keratinocytes}

Although HaCaT cells are spontaneously immortalized, they show some differences compared to primary keratinocytes such as loss of both p53 alleles, hypermethylation of the promoter region of $\mathrm{p} 16^{\mathrm{INK} 4 \mathrm{~A}}$ as well as a greater susceptibility to apoptosis. Furthermore, HaCaT cells reveal higher constitutive expression levels of p50 and p65 (Chaturvedi et al., 1999).

Characterization of single NF-kB subunit expression in primary keratinocytes showed expression of all proteins similar to HaCaT cells. However, HaCaT cells and primary keratinocytes revealed differences in relative transcriptional expression patterns and subcellular localization with greater signal heterogeneity in primary cells. 
To confirm general validity of c-Rel downregulation related effects, key experiments were repeatedly performed with primary keratinocytes. Regarding functional parameters, cell growth and proliferation were reduced whereas apoptosis tended to increase. Furthermore, cell cycle phase distribution shifted towards a higher fraction of $G 2 / M$ phase cells. Also the portion of $\mathrm{p}-\mathrm{H} 3^{\mathrm{Ser} 10}$ positive and mitotic c-Rel downregulated primary keratinocytes was increased but due to higher variations in mitotic cell number no statistically significant differences could be shown.

Including system specificities such as heterogeneous expression level and greater transfection sensitivity, former data on c-Rel downregulation could be clearly verified in primary keratinocytes regarding cell cycle related effects.

Previous studies investigating c-Rel function in human primary keratinocytes were performed by the use of retroviral constitutive expression vectors. Ambiguously, these studies also showed growth inhibition responses (Bernard et al., 2004; Hinata et al., 2003). Whereas cell cycle phase distribution of c-Rel overexpressing keratinocytes had not been analyzed further, Bernard and colleagues associated growth inhibition with specific features of premature senescence involving exiting out of the cell cycle (Bernard et al., 2004).

Despite of these seemingly contradictory results, it can be concluded that balanced c-Rel expression is required for regulated keratinocyte cell growth in vitro. Our obtained data indicate a pro-proliferative and anti-apoptotic function of c-Rel in keratinocytes by regulation of target genes important for mitotic entry or proceeding. Studies examining c-Rel function in other cell types such as HeLa and B-cells suggested similar functions for c-Rel but proposed involvement in G1/S-phase transition (Bash et al., 1997; Hsia et al., 2002). Even though our data show similarities of c-Rel-associated functions, there might be differences in regulatory target genes of c-Rel in keratinocytes compared to other cell types, further supported by the previously shown unique role of NF-KB in keratinocytes. 
At this point, we can only speculate about the exact effect of c-Rel on cell cycle progression in keratinocytes. For clarification, further experiments are required such as expression analysis by microarray screenings of control and c-Rel downregulated keratinocytes possibly identifying dysregulated target genes.

In contrast to similar cell-cycle-associated changes, no or only minor phenotypic and wound healing response changes could be observed in primary keratinocytes in contrast to $\mathrm{HaCaT}$ cells after c-Rel downregulation. The exact causes for this difference remain speculative at this point. Possibly, loss of both alleles of the tumor suppressor p53 in $\mathrm{HaCaT}$ cells might contribute to this finding.

\subsection{Summary and conclusion}

The transcription factor NF-KB represents one of the major players in the regulation of epidermal homeostasis. To further enlighten its specific and unique impact in the skin, this thesis aimed at unraveling the functional contribution of each single NF-kB subunit in vitro. A novel role of the NF-KB subunit c-Rel could be indicated being involved in the regulation of keratinocyte cell fate decisions. Contrary to former studies associating NF-KB p50 and p65 activation with growth reduction, our c-Rel related data indicate a growth supportive function. In detail, we obtained hints for a regulatory function of c-Rel in mitotic entry and/or proceeding.

Altogether, our studies emphasize the individual role of every single NF-kB subunit as previously shown by the diversity of single knockout mice: whereas rela ${ }^{-/-}$mice die shortly after birth due to massive apoptosis induction in hepatocytes (Beg et al., 1995), relb $b^{-/-}$mice develop for instance a T-cell regulated inflammatory dermatitis (Barton et al., 2000). A unique role of c-Rel has been previously suggested by showing a broader range of target binding sequences compared to other NF-KB subunits generally indicating a greater range of target genes (Hoffmann, 2003). In accordance with these data, new c-Rel interaction partners are recently emerging such as an isoform of the p53 tumor suppressor homologue p63 ( $\triangle \mathrm{Np63})$ in keratinocytes. 
Intriguingly, $\triangle N$ N63 was furthermore shown to be up-regulated in a subtype of SCC (head and neck SCC) (King et al., 2008). As previously mentioned, C-Rel is the only NF-KB protein associated with proto-oncogenic functions (Chen et al., 1981) and has also been associated to be deregulated in various cancer types such as breast- and hematopoietic cancers (Curry et al., 2009; Sovak et al., 1997). However, a detailed study of c-Rel expression in SCC of the skin has not been performed to date, noteworthy our laboratory is currently trying to elucidate this aspect potentially furthermore unraveling an effect for c-Rel in epidermal carcinogenesis. 


\section{Literature}

Alberts, B., Johnson, A., Lewis, J., Raff, M., Robert, K., and Walter, P. (2002). Molecular Biology of the Cell. $4^{\text {th }}$ edn. New York: Garland Publishing.

Andl, T., Murchison, E.P., Liu, F., Zhang, Y., Yunta-Gonzalez, M., Tobias, J.W., Andl, C.D., Seykora, J.T., Hannon, G.J., and Millar, S.E. (2006). The miRNA-processing enzyme dicer is essential for the morphogenesis and maintenance of hair follicles. Curr Biol $16,1041-1049$.

Are, A.F., Galkin, V.E., Pospelova, T.V., and Pinaev, G.P. (2000). The p65/RelA subunit of NFkappaB interacts with actin-containing structures. Exp Cell Res 256, 533-544.

Barton, D., HogenEsch, H., and Weih, F. (2000). Mice lacking the transcription factor RelB develop $\mathrm{T}$ cell-dependent skin lesions similar to human atopic dermatitis. Eur J Immunol 30, 2323-2332.

Bash, J., Zong, W.X., and Gelinas, C. (1997). c-Rel arrests the proliferation of HeLa cells and affects critical regulators of the G1/S-phase transition. Mol Cell Biol 17, 6526-6536.

Beg, A.A., Sha, W.C., Bronson, R.T., Ghosh, S., and Baltimore, D. (1995). Embryonic lethality and liver degeneration in mice lacking the RelA component of NF-kappa B. Nature $376,167-170$.

Bernard, D., Gosselin, K., Monte, D., Vercamer, C., Bouali, F., Pourtier, A., Vandenbunder, B., and Abbadie, C. (2004). Involvement of Rel/nuclear factor-kappaB transcription factors in keratinocyte senescence. Cancer Res 64, 472-481.

Bishop, A.L., and Hall, A. (2000). Rho GTPases and their effector proteins. Biochem J 348 Pt 2, 241-255.

Blanpain, C., and Fuchs, E. (2009). Epidermal homeostasis: a balancing act of stem cells in the skin. Nat Rev Mol Cell Biol 10, 207-217.

Blanpain, C., Lowry, W.E., Pasolli, H.A., and Fuchs, E. (2006). Canonical notch signaling functions as a commitment switch in the epidermal lineage. Genes Dev 20, 30223035. 
Bonizzi, G., Bebien, M., Otero, D.C., Johnson-Vroom, K.E., Cao, Y., Vu, D., Jegga, A.G., Aronow, B.J., Ghosh, G., Rickert, R.C., et al. (2004). Activation of IKKalpha target genes depends on recognition of specific kappaB binding sites by RelB:p52 dimers. EMBO J 23, 4202-4210.

Boukamp, P., Petrussevska, R.T., Breitkreutz, D., Hornung, J., Markham, A., and Fusenig, N.E. (1988). Normal keratinization in a spontaneously immortalized aneuploid human keratinocyte cell line. J Cell Biol 106, 761-771.

Boyce, S.T., and Ham, R.G. (1983). Calcium-regulated differentiation of normal human epidermal keratinocytes in chemically defined clonal culture and serum-free serial culture. J Invest Dermatol 81, 33s-40s.

Boyer, B., Tucker, G.C., Valles, A.M., Gavrilovic, J., and Thiery, J.P. (1989). Reversible transition towards a fibroblastic phenotype in a rat carcinoma cell line. Int J Cancer Suppl 4, 69-75.

Brash, D.E., and Ponten, J. (1998). Skin precancer. Cancer Surv 32, 69-113.

Caamano, J.H., Rizzo, C.A., Durham, S.K., Barton, D.S., Raventos-Suarez, C., Snapper, C.M., and Bravo, R. (1998). Nuclear factor (NF)-kappa B2 (p100/p52) is required for normal splenic microarchitecture and B cell-mediated immune responses. J Exp Med 187, 185-196.

Castedo, M., Perfettini, J.L., Roumier, T., Andreau, K., Medema, R., and Kroemer, G. (2004). Cell death by mitotic catastrophe: a molecular definition. Oncogene 23, 2825-2837.

Cerutti, H., and Casas-Mollano, J.A. (2009). Histone H3 phosphorylation: universal code or lineage specific dialects? Epigenetics 4, 71-75.

Chaturvedi, V., Qin, J.Z., Denning, M.F., Choubey, D., Diaz, M.O., and Nickoloff, B.J. (1999). Apoptosis in proliferating, senescent, and immortalized keratinocytes. J Biol Chem 274, 23358-23367.

Chen, D., Dundr, M., Wang, C., Leung, A., Lamond, A., Misteli, T., and Huang, S. (2005). Condensed mitotic chromatin is accessible to transcription factors and chromatin structural proteins. J Cell Biol 168, 41-54.

Chen, I.S., Mak, T.W., O'Rear, J.J., and Temin, H.M. (1981). Characterization of reticuloendotheliosis virus strain T DNA and isolation of a novel variant of reticuloendotheliosis virus strain T by molecular cloning. J Virol 40, 800-811.

Chen, L.F., and Greene, W.C. (2004). Shaping the nuclear action of NF-kappaB. Nat Rev Mol Cell Biol 5, 392-401. 
Ciobanasu, C., Faivre, B., and Le Clainche, C. (2012). Actin dynamics associated with focal adhesions. Int J Cell Biol 2012, 941292.

Clausen, O.P., Aass, H.C., Beigi, M., Purdie, K.J., Proby, C.M., Brown, V.L., Mattingsdal, M., Micci, F., Kolvraa, S., Bolund, L., et al. (2006). Are keratoacanthomas variants of squamous cell carcinomas? A comparison of chromosomal aberrations by comparative genomic hybridization. J Invest Dermatol 126, 2308-2315.

Cramer, L.P., and Mitchison, T.J. (1997). Investigation of the mechanism of retraction of the cell margin and rearward flow of nodules during mitotic cell rounding. Mol Biol Cell 8, 109-119.

Crosio, C., Fimia, G.M., Loury, R., Kimura, M., Okano, Y., Zhou, H., Sen, S., Allis, C.D., and Sassone-Corsi, P. (2002). Mitotic phosphorylation of histone H3: spatio-temporal regulation by mammalian Aurora kinases. Mol Cell Biol 22, 874-885.

Curry, C.V., Ewton, A.A., Olsen, R.J., Logan, B.R., Preti, H.A., Liu, Y.C., Perkins, S.L., and Chang, C.C. (2009). Prognostic impact of C-REL expression in diffuse large B-cell lymphoma. J Hematop 2, 20-26.

Dajee, M., Lazarov, M., Zhang, J.Y., Cai, T., Green, C.L., Russell, A.J., Marinkovich, M.P., Tao, S., Lin, Q., Kubo, Y., et al. (2003). NF-kappaB blockade and oncogenic Ras trigger invasive human epidermal neoplasia. Nature 421, 639-643.

Etienne-Manneville, S., and Hall, A. (2002). Rho GTPases in cell biology. Nature 420, 629635.

Fuchs, E., and Green, H. (1980). Changes in keratin gene expression during terminal differentiation of the keratinocyte. Cell 19, 1033-1042.

Gaspar-Pereira, S., Fullard, N., Townsend, P.A., Banks, P.S., Ellis, E.L., Fox, C., Maxwell, A.G., Murphy, L.B., Kirk, A., Bauer, R., et al. (2012). The NF-kappaB subunit c-Rel stimulates cardiac hypertrophy and fibrosis. Am J Pathol 180, 929-939.

Gieling, R.G., Elsharkawy, A.M., Caamano, J.H., Cowie, D.E., Wright, M.C., Ebrahimkhani, M.R., Burt, A.D., Mann, J., Raychaudhuri, P., Liou, H.C., et al. (2010). The c-Rel subunit of nuclear factor-kappaB regulates murine liver inflammation, woundhealing, and hepatocyte proliferation. Hepatology 51, 922-931.

Gravdal, K., Halvorsen, O.J., Haukaas, S.A., and Akslen, L.A. (2007). A switch from Ecadherin to $\mathrm{N}$-cadherin expression indicates epithelial to mesenchymal transition and is of strong and independent importance for the progress of prostate cancer. Clin Cancer Res 13, 7003-7011. 
Gugasyan, R., Voss, A., Varigos, G., Thomas, T., Grumont, R.J., Kaur, P., Grigoriadis, G., and Gerondakis, S. (2004). The transcription factors c-rel and RelA control epidermal development and homeostasis in embryonic and adult skin via distinct mechanisms. Mol Cell Biol 24, 5733-5745.

Hadfield, J.A., Ducki, S., Hirst, N., and McGown, A.T. (2003). Tubulin and microtubules as targets for anticancer drugs. Prog Cell Cycle Res 5, 309-325.

Hall, A. (1998). Rho GTPases and the actin cytoskeleton. Science 279, 509-514.

Hay, E.D. (1995). An overview of epithelio-mesenchymal transformation. Acta Anat (Basel) 154, 8-20.

Hazan, R.B., Qiao, R., Keren, R., Badano, I., and Suyama, K. (2004). Cadherin switch in tumor progression. Ann N Y Acad Sci 1014, 155-163.

Hendzel, M.J., Wei, Y., Mancini, M.A., Van Hooser, A., Ranalli, T., Brinkley, B.R., BazettJones, D.P., and Allis, C.D. (1997). Mitosis-specific phosphorylation of histone H3 initiates primarily within pericentromeric heterochromatin during $G 2$ and spreads in an ordered fashion coincident with mitotic chromosome condensation. Chromosoma 106, 348-360.

Hinata, K., Gervin, A.M., Jennifer Zhang, Y., and Khavari, P.A. (2003). Divergent gene regulation and growth effects by NF-kappa B in epithelial and mesenchymal cells of human skin. Oncogene 22, 1955-1964.

Hoffmann, A., Leung, T.H., and Baltimore, D. (2003). Genetic analysis of NF-kappaB/Rel transcription factors defines functional specificities. EMBO J 22, 5530-5539.

Hsia, C.Y., Cheng, S., Owyang, A.M., Dowdy, S.F., and Liou, H.C. (2002). c-Rel regulation of the cell cycle in primary mouse B lymphocytes. Int Immunol 14, 905-916.

Huang, H.C., Shi, J., Orth, J.D., and Mitchison, T.J. (2009). Evidence that mitotic exit is a better cancer therapeutic target than spindle assembly. Cancer Cell 16, 347-358.

Jackson, J.R., Patrick, D.R., Dar, M.M., and Huang, P.S. (2007). Targeted anti-mitotic therapies: can we improve on tubulin agents? Nat Rev Cancer 7, 107-117.

Jordan, M.A., Thrower, D., and Wilson, L. (1992). Effects of vinblastine, podophyllotoxin and nocodazole on mitotic spindles. Implications for the role of microtubule dynamics in mitosis. J Cell Sci 102 ( Pt 3), 401-416.

Karin, M. (2006). Nuclear factor-kappaB in cancer development and progression. Nature $441,431-436$. 
Kim, J.P., Zhang, K., Chen, J.D., Kramer, R.H., and Woodley, D.T. (1994). Vitronectin-driven human keratinocyte locomotion is mediated by the alpha $v$ beta 5 integrin receptor. J Biol Chem 269, 26926-26932.

King, K.E., Ponnamperuma, R.M., Allen, C., Lu, H., Duggal, P., Chen, Z., Van Waes, C., and Weinberg, W.C. (2008). The p53 homologue DeltaNp63alpha interacts with the nuclear factor-kappaB pathway to modulate epithelial cell growth. Cancer Res 68, 5122-5131.

Kontgen, F., Grumont, R.J., Strasser, A., Metcalf, D., Li, R., Tarlinton, D., and Gerondakis, S. (1995). Mice lacking the c-rel proto-oncogene exhibit defects in lymphocyte proliferation, humoral immunity, and interleukin-2 expression. Genes Dev 9, 19651977.

Koster, M.I., Kim, S., Mills, A.A., DeMayo, F.J., and Roop, D.R. (2004). p63 is the molecular switch for initiation of an epithelial stratification program. Genes Dev 18, 126-131.

Koster, M.I., and Roop, D.R. (2007). Mechanisms regulating epithelial stratification. Annu Rev Cell Dev Biol 23, 93-113.

Kouzarides, T. (2007). Chromatin modifications and their function. Cell 128, 693-705.

Loercher, A., Lee, T.L., Ricker, J.L., Howard, A., Geoghegen, J., Chen, Z., Sunwoo, J.B., Sitcheran, R., Chuang, E.Y., Mitchell, J.B., et al. (2004). Nuclear factor-kappaB is an important modulator of the altered gene expression profile and malignant phenotype in squamous cell carcinoma. Cancer Res 64, 6511-6523.

Maciag, T., Nemore, R.E., Weinstein, R., and Gilchrest, B.A. (1981). An endocrine approach to the control of epidermal growth: serum-free cultivation of human keratinocytes. Science 211, 1452-1454.

Maddox, A.S., and Burridge, K. (2003). RhoA is required for cortical retraction and rigidity during mitotic cell rounding. J Cell Biol 160, 255-265.

Marks, R. (1990). Methods for the assessment of the effects of topical retinoic acid in photo-ageing and actinic keratoses. J Int Med Res 18 Supp/ 3, 29C-34C.

Marumoto, T., Honda, S., Hara, T., Nitta, M., Hirota, T., Kohmura, E., and Saya, H. (2003). Aurora-A kinase maintains the fidelity of early and late mitotic events in HeLa cells. J Biol Chem 278, 51786-51795.

Matson, D.R., and Stukenberg, P.T. (2011). Spindle poisons and cell fate: a tale of two pathways. Mol Interv 11, 141-150. 
Mills, A.A., Zheng, B., Wang, X.J., Vogel, H., Roop, D.R., and Bradley, A. (1999). p63 is a p53 homologue required for limb and epidermal morphogenesis. Nature 398, 708-713.

Momoi, H., Watanabe, K., Matsui, Y., Nara, N., Ito, S., and Kudo, H. (1979). [Analysis of the cell cycle using a cell sorter (FACS-II) and its theoretical background]. Nihon Rinsho Suppl, 1565-1571.

Murnion, M.E., Adams, R.R., Callister, D.M., Allis, C.D., Earnshaw, W.C., and Swedlow, J.R. (2001). Chromatin-associated protein phosphatase 1 regulates aurora-B and histone H3 phosphorylation. J Biol Chem 276, 26656-26665.

Musacchio, A. (2011). Spindle assembly checkpoint: the third decade. Philos Trans R Soc Lond B Biol Sci 366, 3595-3604.

Musacchio, A., and Salmon, E.D. (2007). The spindle-assembly checkpoint in space and time. Nat Rev Mol Cell Biol 8, 379-393.

Neill, U.S. (2012). Skin care in the aging female: myths and truths. J Clin Invest 122, 473 477.

Nelson, M.A., Einspahr, J.G., Alberts, D.S., Balfour, C.A., Wymer, J.A., Welch, K.L., Salasche, S.J., Bangert, J.L., Grogan, T.M., and Bozzo, P.O. (1994). Analysis of the p53 gene in human precancerous actinic keratosis lesions and squamous cell cancers. Cancer Lett 85, 23-29.

Parsons, J.T., Horwitz, A.R., and Schwartz, M.A. (2010). Cell adhesion: integrating cytoskeletal dynamics and cellular tension. Nat Rev Mol Cell Biol 11,633-643.

Pellegrini, F., and Budman, D.R. (2005). Review: tubulin function, action of antitubulin drugs, and new drug development. Cancer Invest 23, 264-273.

Perkins, N.D. (2004). NF-kappaB: tumor promoter or suppressor? Trends Cell Biol 14, 6469.

Peters, D. (2002). Deregulation von Zellzyklus und Apoptose als molekulare Grundlage der Therapieresistenz von Tumoren. (Doctoral Dissertation, Medical Faculty Charité, Berlin).

Pollard, T.D. (2007). Regulation of actin filament assembly by Arp2/3 complex and formins. Annu Rev Biophys Biomol Struct 36, 451-477.

Prose, P.H., Friedman-Kien, A.E., and Neistein, S. (1967). Ultrastructural studies of organ cultures of adult human skin. In vitro growth and keratinization of epidermal cells. Lab Invest 17, 693-716. 
Qi, G., Kudo, Y., Ando, T., Tsunematsu, T., Shimizu, N., Siriwardena, S.B., Yoshida, M., Keikhaee, M.R., Ogawa, I., and Takata, T. (2010). Nuclear Survivin expression is correlated with malignant behaviors of head and neck cancer together with AuroraB. Oral Oncol 46, 263-270.

Rangarajan, A., Talora, C., Okuyama, R., Nicolas, M., Mammucari, C., Oh, H., Aster, J.C., Krishna, S., Metzger, D., Chambon, P., et al. (2001). Notch signaling is a direct determinant of keratinocyte growth arrest and entry into differentiation. EMBO J 20, 3427-3436.

Ratushny, V., Gober, M.D., Hick, R., Ridky, T.W., and Seykora, J.T. (2012). From keratinocyte to cancer: the pathogenesis and modeling of cutaneous squamous cell carcinoma. J Clin Invest 122, 464-472.

Rheinwald, J.G., and Green, H. (1975). Formation of a keratinizing epithelium in culture by a cloned cell line derived from a teratoma. Cell 6, 317-330.

Rice, R.H., and Green, H. (1979). Presence in human epidermal cells of a soluble protein precursor of the cross-linked envelope: activation of the cross-linking by calcium ions. Cell 18, 681-694.

Rieder, C.L., Schultz, A., Cole, R., and Sluder, G. (1994). Anaphase onset in vertebrate somatic cells is controlled by a checkpoint that monitors sister kinetochore attachment to the spindle. J Cell Biol 127, 1301-1310.

Robert Koch-Institut (Hrsg.) und die Gesellschaft der epidemiologischen Krebsregister in Deutschland e.V. (Hrsg.) (2012) Krebs in Deutschland 2007/2008. $8^{\text {th }}$ edn. Berlin

Rodig, S.J., Savage, K.J., Nguyen, V., Pinkus, G.S., Shipp, M.A., Aster, J.C., and Kutok, J.L. (2005). TRAF1 expression and c-Rel activation are useful adjuncts in distinguishing classical Hodgkin lymphoma from a subset of morphologically or immunophenotypically similar lymphomas. Am J Surg Pathol 29, 196-203.

Rosenblatt, J., Cramer, L.P., Baum, B., and McGee, K.M. (2004). Myosin II-dependent cortical movement is required for centrosome separation and positioning during mitotic spindle assembly. Cell 117, 361-372.

Ruchaud, S., Carmena, M., and Earnshaw, W.C. (2007). Chromosomal passengers: conducting cell division. Nat Rev Mol Cell Biol 8, 798-812.

Scian, M.J., Stagliano, K.E., Anderson, M.A., Hassan, S., Bowman, M., Miles, M.F., Deb, S.P., and Deb, S. (2005). Tumor-derived p53 mutants induce NF-kappaB2 gene expression. Mol Cell Biol 25, 10097-10110. 
Seitz, C.S., Deng, H., Hinata, K., Lin, Q., and Khavari, P.A. (2000a). Nuclear factor kappaB subunits induce epithelial cell growth arrest. Cancer Res 60, 4085-4092.

Seitz, C.S., Freiberg, R.A., Hinata, K., and Khavari, P.A. (2000b). NF-kappaB determines localization and features of cell death in epidermis. J Clin Invest 105, 253-260.

Seitz, C.S., Lin, Q., Deng, H., and Khavari, P.A. (1998). Alterations in NF-kappaB function in transgenic epithelial tissue demonstrate a growth inhibitory role for NF-kappaB. Proc Natl Acad Sci U S A 95, 2307-2312.

Senftleben, U., Cao, Y., Xiao, G., Greten, F.R., Krahn, G., Bonizzi, G., Chen, Y., Hu, Y., Fong, A., Sun, S.C., et al. (2001). Activation by IKKalpha of a second, evolutionary conserved, NF-kappa B signaling pathway. Science 293, 1495-1499.

Senoo, M., Pinto, F., Crum, C.P., and McKeon, F. (2007). p63 Is essential for the proliferative potential of stem cells in stratified epithelia. Cell 129, 523-536.

Sha, W.C., Liou, H.C., Tuomanen, E.I., and Baltimore, D. (1995). Targeted disruption of the p50 subunit of NF-kappa B leads to multifocal defects in immune responses. Cell 80, 321-330.

Singh, H., Sen, R., Baltimore, D., and Sharp, P.A. (1986). A nuclear factor that binds to a conserved sequence motif in transcriptional control elements of immunoglobulin genes. Nature 319, 154-158.

Smale, S.T. (2012). Dimer-specific regulatory mechanisms within the NF-kappaB family of transcription factors. Immunol Rev 246, 193-204.

Sovak, M.A., Bellas, R.E., Kim, D.W., Zanieski, G.J., Rogers, A.E., Traish, A.M., and Sonenshein, G.E. (1997). Aberrant nuclear factor-kappaB/Rel expression and the pathogenesis of breast cancer. J Clin Invest 100, 2952-2960.

Stewart, M.P., Helenius, J., Toyoda, Y., Ramanathan, S.P., Muller, D.J., and Hyman, A.A. (2011). Hydrostatic pressure and the actomyosin cortex drive mitotic cell rounding. Nature 469, 226-230.

Sumara, I., Gimenez-Abian, J.F., Gerlich, D., Hirota, T., Kraft, C., de la Torre, C., Ellenberg, J., and Peters, J.M. (2004). Roles of polo-like kinase 1 in the assembly of functional mitotic spindles. Curr Biol 14, 1712-1722.

Sur, I., Ulvmar, M., and Toftgard, R. (2008). The two-faced NF-kappaB in the skin. Int Rev Immunol 27, 205-223. 
Takao, J., Yudate, T., Das, A., Shikano, S., Bonkobara, M., Ariizumi, K., and Cruz, P.D. (2003). Expression of NF-kappaB in epidermis and the relationship between NF-kappaB activation and inhibition of keratinocyte growth. Br J Dermatol 148, 680-688.

Takenaka, K., Moriguchi, T., and Nishida, E. (1998). Activation of the protein kinase p38 in the spindle assembly checkpoint and mitotic arrest. Science 280, 599-602.

Tillement, V., Remy, M.H., Raynaud-Messina, B., Mazzolini, L., Haren, L., and Merdes, A. (2009). Spindle assembly defects leading to the formation of a monopolar mitotic apparatus. Biol Cell 101, 1-11.

Torchia, E.C., Chen, Y., Sheng, H., Katayama, H., Fitzpatrick, J., Brinkley, W.R., Caulin, C., Sen, S., and Roop, D.R. (2009). A genetic variant of Aurora kinase A promotes genomic instability leading to highly malignant skin tumors. Cancer Res 69, 72077215.

Torchia, E.C., Zhang, L., Huebner, A.J., Sen, S., and Roop, D.R. (2013). Aurora Kinase-A Deficiency during Skin Development Impairs Cell Division and Stratification. J Invest Dermatol 133, 78-86.

Truong, A.B., Kretz, M., Ridky, T.W., Kimmel, R., and Khavari, P.A. (2006). p63 regulates proliferation and differentiation of developmentally mature keratinocytes. Genes Dev 20, 3185-3197.

Tumang, J.R., Owyang, A., Andjelic, S., Jin, Z., Hardy, R.R., Liou, M.L., and Liou, H.C. (1998). $\mathrm{C}-\mathrm{Rel}$ is essential for B lymphocyte survival and cell cycle progression. Eur J Immunol $28,4299-4312$.

Uzbekov, R., Kireyev, I., and Prigent, C. (2002). Centrosome separation: respective role of microtubules and actin filaments. Biol Cell 94, 275-288.

Vader, G., and Lens, S.M. (2008). The Aurora kinase family in cell division and cancer. Biochim Biophys Acta 1786, 60-72.

Vader, G., Medema, R.H., and Lens, S.M. (2006). The chromosomal passenger complex: guiding Aurora-B through mitosis. J Cell Biol 173, 833-837.

van Hogerlinden, M., Auer, G., and Toftgard, R. (2002). Inhibition of Rel/Nuclear FactorkappaB signaling in skin results in defective DNA damage-induced cell cycle arrest and Ha-ras- and p53-independent tumor development. Oncogene 21, 4969-4977.

van Hogerlinden, M., Rozell, B.L., Ahrlund-Richter, L., and Toftgard, R. (1999). Squamous cell carcinomas and increased apoptosis in skin with inhibited Rel/nuclear factorkappaB signaling. Cancer Res 59, 3299-3303. 
van Vugt, M.A., van de Weerdt, B.C., Vader, G., Janssen, H., Calafat, J., Klompmaker, R., Wolthuis, R.M., and Medema, R.H. (2004). Polo-like kinase-1 is required for bipolar spindle formation but is dispensable for anaphase promoting complex/Cdc20 activation and initiation of cytokinesis. J Biol Chem 279, 36841-36854.

Van Waes, C. (2007). Nuclear factor-kappaB in development, prevention, and therapy of cancer. Clin Cancer Res 13, 1076-1082.

Vermeulen, K., Van Bockstaele, D.R., and Berneman, Z.N. (2003). The cell cycle: a review of regulation, deregulation and therapeutic targets in cancer. Cell Prolif 36, 131-149.

Vicente-Manzanares, M., and Horwitz, A.R. (2011). Cell migration: an overview. Methods Mol Biol 769, 1-24.

Watt, F.M., Estrach, S., and Ambler, C.A. (2008). Epidermal Notch signalling: differentiation, cancer and adhesion. Curr Opin Cell Biol 20, 171-179.

Wille, J.J., Jr., Pittelkow, M.R., Shipley, G.D., and Scott, R.E. (1984). Integrated control of growth and differentiation of normal human prokeratinocytes cultured in serumfree medium: clonal analyses, growth kinetics, and cell cycle studies. J Cell Physiol $121,31-44$.

Wonsey, D.R., and Follettie, M.T. (2005). Loss of the forkhead transcription factor FoxM1 causes centrosome amplification and mitotic catastrophe. Cancer Res 65, 51815189.

Woolner, S., O'Brien, L.L., Wiese, C., and Bement, W.M. (2008). Myosin-10 and actin filaments are essential for mitotic spindle function. J Cell Biol 182, 77-88.

Yang, A., Schweitzer, R., Sun, D., Kaghad, M., Walker, N., Bronson, R.T., Tabin, C., Sharpe, A., Caput, D., Crum, C., et al. (1999). p63 is essential for regenerative proliferation in limb, craniofacial and epithelial development. Nature 398, 714-718.

Yasuda, H., Kanda, K., Koiwa, H., Suenaga, K., Kidou, S., and Ejiri, S. (2005). Localization of actin filaments on mitotic apparatus in tobacco BY-2 cells. Planta 222, 118-129.

Yi, R., Poy, M.N., Stoffel, M., and Fuchs, E. (2008). A skin microRNA promotes differentiation by repressing 'stemness'. Nature 452, 225-229.

Zhang, J.Y., Green, C.L., Tao, S., and Khavari, P.A. (2004). NF-kappaB RelA opposes epidermal proliferation driven by TNFR1 and JNK. Genes Dev 18, 17-22. 


\section{Curriculum Vitae}

Verena Lorenz

born $17^{\text {th }}$ May 1983 in Bremen, Germany

verena.lorenz@med.uni-goettingen.de

\section{Education:}

Doctoral thesis, Molecular Medicine Study Program, Georg-August University Göttingen, Lower Saxony, Germany, 2009-2013

"NF-KB mediated signaling mechanisms in epidermal homeostasis and carcinogenesis"

Supervisors: PD Dr. Cornelia S. Seitz, Prof. Dr. Michael P. Schön

\section{Publications:}

Streckfuss-Bömecke, K., F. Wolf, A. Azizian, M. Stauske, M. Tiburcy, S. Wagner, D. Hübscher, R. Dressel, S. Chen, J. Jende, G. Wulf, V. Lorenz, M.P. Schön, L.S. Maier, W.H. Zimmermann, G. Hasenfuss and K. Guan (2012). "Comparative study of human-induced pluripotent stem cells derived from bone marrow cells, hair keratinocytes, and skin fibroblasts." European Heart Journal, in press (doi: 10.1093/eurheartj/ehs203)

Lorenz, V., M.P. Schön and C.S. Seitz (2013). "c-Rel is a regulator of key functions in human keratinocytes." Current status: submitted

\section{Congresses:}

$33^{\text {th }}$ Annual Meeting of the German Society for Cell Biology 2010

$35^{\text {th }}$ Annual Meeting of the German Society for Cell Biology 2012

$42^{\text {nd }}$ Annual ESDR (European Society for Dermatological Research) Meeting 2012 International Meeting of the German Society for Cell Biology (DGZ) on Actin Dynamics, 2012 
Diploma thesis, University of Bremen, Bremen, Germany, 2008-2009

“Molekulare Charakterisierung von Kandidatengenen bei der Tumorgenese von

Schilddrüsen"

Supervisors: Dr. Volkhard Rippe, Prof. Dr. Jörn Bullerdiek

Publication:

Rippe, V., L. Dittberner, V. Lorenz, N. Drieschner, R. Nimzyk, W. Sendt, K. Junker, Belge, G. and J. Bullerdiek (2010). "The two stem cell microRNA gene cluster C19MC and miR-371-3 are activated by specific chromosomal rearrangements in a subgroup of thyroid adenomas" PLoS One, 5(3): e9485. doi:10.1371/journal.pone.0009485

Master Degree Project in Molecular Biology, Study year abroad, University of Gothenburg, Gothenburg, Sweden, 2006-2007

Diploma, Biology, University of Bremen, Bremen, Germany, 2002-2009

High school, Kippenberg Gymnasium, Bremen, Germany, 1995-2002 


\section{Danksagung}

Zuerst möchte ich Herrn Prof. Dr. Michael P. Schön für die Möglichkeit danken, in seiner Arbeitsgruppe mit diesem Projekt promovieren zu können. Durch seine langjährige Erfahrung, sein Forschungsinteresse und seine Begeisterungsfähigkeit hat er die Arbeit maßgeblich begleitet, unterstützt und gefördert.

Weiterer großer Dank gilt Frau PD Dr. Cornelia S. Seitz, die dieses Projekt direkt betreut und mich mit ihrer Forschungserfahrung unterstützt hat, mir den richtigen Weg gewiesen hat und mit Rat und Tat bei Seite stand.

Vielen Dank an die Mitglieder meines Komitees, Prof. Dr. Matthias Dobbelstein und Prof. Dr. Heidi Hahn für ihr Interesse an diesem Projekt, für viele sehr wertvolle Tipps und die Zeit, die sie sich hierfür genommen haben. Herzlichen Dank auch an Prof. Dr. Holger Bastians für seine Zeit und nützliche Hinweise.

Weiterhin gilt ein großer Dank den Mitarbeitern des Forschungslabors und die tolle Atmosphäre, in der ich arbeiten durfte. Ein großer Dank gebührt Bianca Messerschmidt für ihre Hilfe, ihre stets ansteckende gute Laune und ihre geopferten Haare. Genauso herzlich möchte ich mich bei Anette Bennemann und Karolin Zachmann bedanken, die das Labor zusammen und am Laufen halten. Ein Dankeschön außerdem an unsere Laborleiterinnen, Prof. Dr. hum. biol. Margarete Schön, Dr. rer. nat. Andrea Braun und Dr. rer. nat. Katrin Wallbrecht.

Vielen Dank an die Mit-Doktorand(inn)en, allen voran Dr. Nadin Pletz - für viele gemeinsam verbrachte Stunden im Labor und Büro, für wissenschaftliche und außerwissenschaftliche Diskussionen, deine positive Energie und dafür, auch mal über sich selbst Lachen zu können. Bea Richter, danke für den Sonnenschein im Laboralltag, deine große Hilfsbereitschaft und viele schöne Unternehmungen. Ein Dankeschön auch an Dr. Philine Schneider, Dr. Nora Drick, Steffi Piegholdt und Sinan Sag sowie Kristina Kotzerke, Anike Lockmann, Anna-Carina Hund, Dr. Katharina Amschler und Susann Forkel.

Vielen Dank auch an die AG Emmert, besonders Annika Schäfer, Steffen Schubert, Antje Apel und Petra Laspe, die stets sehr hilfsbereit waren.

Ein riesiges Dankeschön an meine großartigen, teilweise verstreuten Bremer Freunde, ihr seid die Besten! Steph, danke für dein immer offenes Ohr. Lena, danke für legendäre Exkursionen und deine Unterstützung. Ein großes Dankeschön auch an Tine, André, Aytac und Jan. Mit am meisten Dank gebührt meinen Eltern für ihre große Unterstützung, die mir viel Halt gegeben hat und für ihr Vertrauen in mich. 